\title{
RELATIVE FREQUENCY AS A DETERMINANT OF PHONETIC CHANGE
}

\author{
By George Kingsley ZipF
}

\section{INTRODUCTION}

B EFORE presenting in detail this investigation, $I$ think that it may not be amiss to give a brief account of its origin and development. Some time ago it occurred to me that a great deal of light might be thrown on the history of the languages of the past by an extensive examination of modern, spoken tongues from a new point of view. It has, of course, ever been emphasized that sound-changes similar to those of remoter times are constantly taking place in the present, and thus affording not only the advantage of more direct observation, but also data otherwise obtainable or suggested only by subjective analysis. As time passed, however, and collateral facts began to accumulate rapidly, the firm outlines of a powerful law of language became ever more manifest, until, after having presented my data to others better qualified in physics, psychology, and biology, I was encouraged to take up the whole question of mutation in language itself. With my a priori theory in mind, I accordingly proceeded to collect evidence, pursuing the following course. I argued that, if my theory were valid, it should be demonstrable in modern speech. Upon research in ten modern languages I began to be convinced, to my own amazement and that of my scientific friends, of the validity of my theory. Emboldened by this discovery, I proceeded to consider phonetic and accentual changes in the so-called "dead" languages, Greek, Latin, Sanskrit, and Gothic.

Obviously, the scope of such a thesis will not admit, within the limits of a single article, a discussion of every ramification of the subject. Hence, I have been content to give analyses only of the most salient sound-changes and shifts in accent, for the sole purpose of putting my theory in a clear, definite light before scholars, whose criticism I invite as an aid for future study. None the less, the arrangement of the presentation is such that I believe any reader, at home in Indo-European 
philology, can test for himself the validity of the theory in those corollary problems, the full treatment of which in this discussion $I$ have for the sake of brevity been forced to forego.

I should mention at the outset that the cumulative evidence in confirmation of my theory was at times of such embarrassing exactitude that I felt compelled to substitute, wherever relevant and attainable, the results of other investigators, made for quite different purposes. Since the results thus incorporated may not be known in every case to the reader, I consistently give necessary references, and, in cases of delayed publication, add the address of library or author.

Needless to say, in approaching any such problem as that of mutation in language, one is at once beset by Streitfragen in the very field of Comparative Philology itself. Since it is my desire to establish the theory as far as possible on incontestable grounds, that it may in turn throw light on unsettled issues, I have studiously avoided treating any extraneous problem the solution of which is itself still quite obscure. Moreover, the new Gestalt psychology, which promises to be a boon to philology, I have been obliged, both from its present stage of infancy and from my own ignorance, to disregard almost entirely. But I add here that criticism from no point of view will be more welcome to me than from that of the Koehler-Wertheimer Gestalt psychologists.

The presentation of my thesis is intended to begin with the simpler and less complicated sound-changes, proceeding by degrees to the subtler and more delicate. ${ }^{1}$

1 I need not say that the entire investigation, submitted in partial fulfilment of the requirements for the degree of $\mathrm{Ph}$. D. in Comparative Philology at Harvard University, would have been impossible without the friendly aid of others. First of all, I express my greatest thanks to Professor George H. Chase, Dean of the Graduate School of Harvard University, for his continued and strong encouragement, which alone sustained me through many hours of baffling theoretical work preliminary to the investigation of specific, linguistic changes. In gathering the great mass of statistical evidence I was helped considerably by the kindness of Professor Fuchs of the Sächsisches Stenographisches Landesamt, Dresden; Dr. Christian Johnen of Düsseldorf; Mr. George A. S. Oliver of Nottingham, England; Mr. Alexander Iurkovskii, Moscow; Professor Prokop Novák of Prague; Dr. Th. Goluboff, Sophia; the Royal Hungarian Ministerialrat Dr. Rónay Károly of Budapest; S. H. Herr Ludwig von Jakab, Budapest; Signor Cav. Uff. Professore Dott. Giuseppe Aliprandi of Padua; Colonel Olof Melin of Arild, Sweden; and Mr. J. B. Estoup, Paris. I take this occasion to acknowledge my great in- 


\section{THE THESIS}

Scholars long ago observed that whenever a word, hitherto uncommon, suddenly comes to be frequently used, it is likely to undergo a weakening of form to make it more easily pronounceable. Obvious examples of such weakening are "gas" for "gasolene," "auto" for "automobile," "movies" for "moving-pictures," "how d' ye do" for "how do you do," "good-bye" for "God be with you." A good example in English is the word Mister beside the stronger form master. These words or expressions not only are weakened in form, but admittedly are in frequent use. It might be argued to the contrary that the word master became weakened to mister because, in the peculiar use of the latter, the accent was always on the following proper name, thus,

\section{Mister Brówen, Mister Smith,}

and that this accent in turn caused a reduction not dissimilar to that of the Latin:

\section{${ }^{*}$ Cónfacio $>{ }^{*}$ cónficio $>$ confício;}

whereas the $a$ in master was always accented in such phrases as "He's my máster." Very true. Yet here, as in all cases of ablaut, the question at once arises, why did the accent leave master, to settle on Brown? If we can find an explanation for this simple case, we may see light on a possible explanation of the accentual shift in the Latin *confacio; for there is no graver problem in all philology than the question why a word, for generations conveniently pronounceable, should for no apparent cause shift its accent.

The case of Mister Brown is simple. Mister is, as it were, the common denominator of all masculine names; the distinguishing part of the phrase is what follows. The only possible confusion with Mister is

debtedness to them. To Professor Joshua Whatmough, of Harvard University I am indebted more than I can say for his patient readiness to discuss my investigation with me, his suggestions of related problems, his valuable criticisms of the rough and finished drafts, and his assistance at every turn of the thesis toward publication. I should express my thanks also to Professors Walter E. Clark and Taylor Starck, also of Harvard University, for their valued comments; and to Mr. Alan N. Holden of the Bell Telephone Laboratories in New York, for his readiness to discuss the phonetic and psychological aspects of the theory. 
Miss or Mrs., and it therefore needs no powerful accent of its own. But there are hundreds of possibilities for confusion of the proper name. Hence, if one part should be made more conspicuous by accent, it must logically be this, the proper name. We may say that, as soon as master became a frequently used title of address, it was so normal in discourse that it lost its strong accent, so as to cause a weakening in form.

But I should point out here, by way of preface to many examples, that the weaker form is invariably the more frequent form. For example, let us simply take the special case of mister and master. According to Godfrey Dewey's ${ }^{1}$ analysis of 100,000 modern English words, mister occurs 148 times, master but I3. In other words the weaker form is more than eleven times more frequent than the stronger. Indeed, in hundreds of cases similar to that of master beside mister, one finds that some weakening of form is ever concomitant with a decided increase in frequency of use.

Moreover, a word both "phonetically" and "acoustically" unfamiliar (that is, from both the speaker's and the hearer's point of view) is seldom if ever abbreviated. On the contrary, it is always distinctly pronounced and often overemphasized. Should one say "gater," few New Englanders would at once think of an alligator; but in the land of alligators such a verbal foreshortening would undoubtedly be at once understood. Indeed, this principle has always been recognized as fundamental in the origin of dialects: different environments produce different cultures, which in turn bring about a different use of words.

The foregoing theory of the inter-dependence of form and frequency of usage I shall now try to demonstrate $a$ posteriori with the thesis:

Principle of Frequency. The accent, or degree of conspicuousness, of any word, syllable, or sound, is inversely proportionate to the relative frequency of that word, syllable, or sound, among its fellow words, syllables, or sounds, in the stream of spoken language. As usage becomes more frequent, form becomes less accented, or more easily pronounceable, and vice versa.

1 Godfrey Dewey, Relativ Frequency of English Speech Sounds (Harvard University Press, I923), p. I4 and p. 36, column 4. 


\section{PART I. SYLLABIC ACCENT ${ }^{1}$}

(I) All spoken syllables have some degree of accent, which in the stream of sound may be comparatively strong or weak. This accent may lie in the intonation of the voice, in the volume or sharpness of the breath, or in both. In either case it is more conspicuous to the hearer than a weaker accent, and more difficult for the speaker to pronounce. To say that a word, syllable, or sound is unaccented is, strictly speaking, to say that the word, syllable, or sound is not spoken at all; for the weakest utterance must have some breath and intonation. Hence, the problem of accent is but a question of degree from strong to weak.

In listening to spoken language, we notice that, among other things, the speaker invariably emphasizes these two: first, what is new or unexpected to the hearer; second, what the hearer desires to make especially clear. In other words, the speaker under normal conditions does not emphasize what he believes the hearer will be well acquainted with; when the hearer does not understand the casually uttered remark, the speaker repeats, giving his remark added emphasis of distinct articulation, loudness of voice, or definitive explanation. But that which is unexpected, unusual, or unfamiliar to the hearer is, by definition, the seldom. Hence, if any part of the discourse is more emphatically stressed, the words unusual, unfamiliar, or unexpected to the hearer or the speaker will tend to receive this added accent; so too with the everyday familiar words which are frequent in conversation - there is no reason for emphasizing them. Even in written language we avoid unnecessary repetition, believing that it weakens the force or emphasis of the concept. A relationship, then, between accent and frequency is clear.

(2) The parent Indo-European language is said to have possessed a "free" accent, by which is meant that the position of the accent of a word, though fixed, was not - as, for example, in Classical Latin determined by the quantities of its last three syllables. Nor is it overbold to assume that at a much earlier stage, either before certain suf-

1 I have examined for this purpose the Riksamhita, Herodotus, Horace, and modern German. 
fixes and endings ceased to be individual words, or, after the amalgamation of these suffixes and endings, while they were still richly imbued with their original meanings, the proto-Indo-European felt free to accent that part of the word - the root, stem, or ending - which he chose for the nonce to make more conspicuous to his hearers.

Though this theory is tacitly assumed as commonplace by philologists, for clearness let us give an example from modern English. In the phrase "I've sung," which in Indo-European times might have been expressed by one word, the modern speaker may at his option give greater accent to $I$, or 've (in which case it takes the full form have), or sung. Nor can anyone deny that the position of the accent in the phrase, which, I repeat, might have been expressed by one inflected word in pro-ethnic Indo-European, depends solely upon what element of the phrase the speaker selects for the occasion to make most conspicuous to his hearer.

But in proto-Indo-European times, as in modern, though the option as to the position of the accent remained, one particular order of accent, in a given case, was in fact more frequent in occurrence than any other. In time this more usual or more frequent manner of accenting the elements of an inflected word became the customary way of accenting that word, until finally, through frequent usage, it petrified into the regular and obligatory accent. These various positions of accent we still find to a large extent preserved in the earliest Sanskrit; whereas the resulting vowel-change - what we call ablaut - is everywhere to be observed in the early Indo-European tongues. In other words, tautologous as it sounds, we must see in the Indo-European prefixes, suffixes, and endings, elements of language, although joined in speech, yet individualized enough in sense to draw upon themselves the chief accent of the word whenever the speaker chose to make that phase of the word more conspicuous; and, through habitually bearing this accent, to retain it generation after generation as part of the normal state of affairs.

But what now caused the early Indo-European to show preference for one element in a word and not for another? To be specific, why did he accent the ending in ${ }^{*} r a \bar{j} n a ́ s,{ }^{1}$ the Sanskrit genitive singular

1 The accent of historical Sanskrit often differs from the accent of parent Indo. European, especially in the nouns. 
"king's," and not the ending in the nominative plural rấjānas, "kings"? If our thesis be correct, he neglected to accent the allocative endings which he frequently used, emphasizing only those that occurred less commonly in the stream of speech. ${ }^{1}$ But if this be true, namely, that the accented endings were less frequent in occurrence than the unaccented endings, we should find some such difference by examining arithmetically any piece of early Sanskrit literature, so as to see that, if indeed the nominative plural occurred so much more frequently than the genitive singular, the accent, according to our principle of frequency, passed in the latter case, for the purpose of conspicuousness, to the ending.

(3) As has been stated, such a difference in accent between stem and ending is found, for example, in the masculine consonantal declension in Sanskrit. The stem was accented in the nominative, accusative, vocative singular and dual, and in the nominative and vocative plural; but in all other cases the accent was on the ending. Before turning to an arithmetical analysis of their respective frequencies, we can simplify the matter by excluding from consideration all the vocatives and the entire dual. Since the vocative singular, as such, never possessed an inflectional ending, the accent could not but be on the stem. Moreover, in the dual and plural the nominatives were used as vocatives, the two cases coinciding exactly in form and accent. Therefore, we need not consider the vocative as a special case. As for the nominative dual, which was likewise used as the accusative, since the nominative singular and the nominative plural were both accented on the stem, and since the instrumental, dative, ablative, genitive, and locative cases, in the singular and plural, were accented on the endings, we may regard the accent of the entire dual as the result of analogy, which is especially plausible as an explanation of its accent, inasmuch as the dual was rapidly dying out. For this

1 Similarly, we emphasize behind more than to in the phrases: "Give it to the boy," and "It is behind the boy." On consulting Godfrey Dewey's tables, we find the word to occurring in 100,000 words 2,924 times, whereas the word behind occurs only 24 . That is to say, nearly 3 per cent of the words we use in the stream of speech are to, while behind occurs less than one one-hundredth as often. It is clear then that the speaker does not feel urged to keep accenting to whenever it appears, to make himself understood. This is undoubtedly the cause of its extreme weakening in "I wanna go," for "I want to go." 
reason, without any fear of distorting the facts, we may disregard it entirely.

Thus simplifying our problem, let us turn to the singular and plural. The names of the cases printed below in capitals were accented on the stem, and for convenience I shall call them the strong cases; the others, which are accented on the endings, I shall call weak:

\begin{tabular}{ll}
\multicolumn{1}{c}{ Singular } & \multicolumn{1}{c}{ Plural } \\
NOMINATIVE & NOMINATIVE \\
ACCUSATIVE & accusative \\
instrumental & instrumental \\
dative & dative \\
ablative & ablative \\
genitive & genitive \\
locative & locative
\end{tabular}

Or, taking the present participle of the verb to be, which follows the consonantal declension and shows ablaut which arose from the difference in accent, we have in pro-ethnic Sanskrit (masculine):

Singular
NOM. *ánts
Acc. sántam
ins. satáa
dat. saté
abl.
gen. satás
loc. satí

\section{Plural}

NOM. sántas

acc. satás

ins. ${ }^{*}$ sadbhis ${ }^{1}$

dat. )

abl. $\}^{*}$ sadbhyás

gen. satâm

loc. satsú

To be sure, in later times, after the accent had become petrified, the case of a noun was designated, not only by the individual case-endings, but to a considerable extent by the shift in accent itself and the resultant vowel-weakening. But this difference in stem was fortuitous, entirely secondary, and not even necessary, as is shown by the fact that the strong and weak stems were later levelled out in many languages. Indeed, the position which the accent chose in Sanskrit, already a

1 In the instrumental and dative-ablative plural the forms printed above are restored forms only in respect to accentuation. 
highly developed language, almost proves that its position was in no way a case-sign. If one assumes that stem-accent was a sign of the nominative because it occurs in the three nominatives, we nevertheless find it also in the accusative singular. And if one adds that it was also a sign of the accusative, why, then, was the accusative plural accented on the ending? This is indeed the touchstone. If we can show that the accusative plural, accented on the ending, was used as seldom as any other oblique case, and that the strong, or stem-accented, cases were distinctly more frequently used, we have the first definite proof of our thesis. Let us turn to a numerical analysis.

The oldest Vedic hymns, those of the Rikșamhita, were analyzed by Professor Charles Rockwell Lanman in his "Noun Inflections in the Veda." "His results, summarizing the frequency of all case-endings, are found in Table r, page 583 . I shall use this table. The neuters, not differing in form in the nominative and accusative, have 8,44I nominative-accusative singular forms, and 3,629 nominative-accusative plurals. Without implying an exactly equal proportion in fact, I have allotted in each number one half to the nominative, and one half to the accusative. The entire sum is so small that, if it were given completely to one case or the other, it would not seriously alter the relationship. A more exact allotment would be even more greatly in favor of my theory. Lanman's figures are (all three genders combined):

\begin{tabular}{lrrr}
\multicolumn{2}{c}{ Singular } & \multicolumn{2}{c}{ Plural } \\
NOM. 24,286 & \multicolumn{2}{c}{ NOM. } & I0,98I \\
ACC. & $\mathbf{1 7}, 55 \mathrm{I}$ & acc. & 5,353 \\
ins. & 4,234 & ins. & 3,360 \\
dat. & 4,092 & dat. & 363 \\
abl. & 923 & abl. & I24 \\
gen. & 5,274 & gen. & $\mathrm{I}, 595$ \\
loc. & 3,789 & loc. & $\mathrm{I}, 546$
\end{tabular}

That which we postulated $a$ priori we find to be a fact in Lanman's figures. It is indeed strange that the nominative and accusative singular and the nominative plural are, each, more than twice as frequently used as the most frequently used of the weak cases; that there is a

${ }_{1}$ Journal of the American Oriental Society, $\mathrm{X}$ (1872-80), $325 \mathrm{ff}$. 
decided chasm between the strong and weak cases; that the accusative plural ranks numerically among the weak cases to which it accentually belongs. ${ }^{1}$

It may, of course, be argued that all inflectional endings are so frequent that it is strange that the accent did not leave every one. In the course of time, in certain languages the accent did; even in Rigvedic times it had already shifted in many instances, and in Germanic the last surviving accented suffixal-endings are recorded by Verner's Law.

(4) But there is in Sanskrit another startling difference in accent well worthy of consideration which, because of the frequent parallels to it in other languages, leads one to conclude that it was to a large extent, if not entirely, inherited from the Indo-European parent tongue.

In the athematic conjugations (the Sanskrit classes nos. 2, 3, 5, 7, 8, 9 , commonly called the strong verbs), the accent in the present system was on the stem in the present and imperfect singular active (parasmaipadam), in the third singular imperative active, and in all three first persons imperative, active, and middle (ätmanepadam) - in all, thirteen forms. The remaining forms in the present, imperfect, imperative, and the entire optative were all accented on the endings. Further, the perfect system in Sanskrit, as in Germanic, shows stemaccent in the singular, but, for the most part, on the endings in the dual and plural. It was clearly a difference between the singular on the one hand, and the dual and plural on the other. That the imperative did not coincide entirely with this distribution may easily be explained by its contamination with other moods, as is to be expected in the language of a race developing in culture and politeness. An example of similar corruption is the English "Will you please go!" for the older imperative, "Go!"

But there still remains in the major indicative tenses this difference in accent between the singular active with its stem-accent, and the dual and plural active and the entire middle with the accent on the endings. According to our thesis it is, then, to be expected that the

1 That the neuter accusative plural is accented on the stem and not on the ending is naturally due to its having originally been a collective feminine singular, whose accent it maintains. 
singular number active was far more frequently used than either the singular middle or the duals and plurals. Because of this preponderance of frequency there was no need of accent on the ever-recurring singular active endings.

For the sake of clarity, let us do as with the nouns. The names of the numbers printed in capitals indicate stem-accented forms, the others have the accent on the endings.

\section{Indicative}

Active

(Parasmaipadam)

\section{Middle}

(Âtmanepadam)

$\begin{array}{llllll}\text { SINGULAR } & \text { dual } & \text { plural } & \text { singular } & \text { dual } & \text { plural } \\ \text { FIRST } & \text { first } & \text { first } & \text { first } & \text { first } & \text { first } \\ \text { SECOND } & \text { second } & \text { second } & \text { second } & \text { second } & \text { second } \\ \text { THIRD } & \text { third } & \text { third } & \text { third } & \text { third } & \text { third }\end{array}$

Or, if we take the root dvis, "hate," of the second class, which has an Indo-European $e i$ : $i$ ablaut showing the shift in accent, the full grade $e i$ appearing as Sanskrit $\bar{e}$ in the accented root, and the reduced grade $i$ appearing where the accent was on the endings, we thus have:

\section{Present Indicative}

\section{Active}

\begin{tabular}{|c|c|c|}
\hline SINGULAR & dual & plural \\
\hline I. dvessmi & dvişvâs & dvismás \\
\hline 2. dvékși & dviṣthấs & dvișthá \\
\hline 3. dvéști & dviștás & dvişanti \\
\hline \multicolumn{3}{|c|}{ Middle } \\
\hline SINGULAR & dual & plural \\
\hline I. dvișe & dvișvâhe & dvișmáhe \\
\hline 2. dvikṣé & dvişâthe & dvidḍ̂é \\
\hline 3. dviștẹe & dviṣấte & dvișáte \\
\hline
\end{tabular}

So, too, the imperfect and perfect indicative show a similar relationship of accent, though differing in augment, reduplication, or endings. Now if we can show numerically, from some early Sanskrit text, that 
the singular active was more frequently used throughout the language than the other five numeri, we have found the reason why the accent was not compelled to wander from the stem to the endings in the singular active. That would be a second confirmation of our theory.

(5) Professor John Avery, in his "Contributions to the History of Verb-inflection in Sanskrit," ${ }^{1}$ examined among other things the numerical frequency of verb-forms in the Rikşamhita. His results in the tables on pages 3 II $\mathrm{ff}$. I have added together and give below. My additions represent the first, second, and third persons, singular, dual, and plural, active and middle, and include all moods and tenses of all classes of verbs considered in Avery's study. My purpose in so doing was to get a precise idea of the relative use of the three numeri both in the active and middle, thus approaching the Indo-European ratios as nearly as possible. The summarized results are:

Active

Singular

I. $6 \mathrm{I} 2$

2. 4,378

3. 5,467 I0,457

I. 428

2. $9 \mathrm{I} 4$

3. 2,257 3,599

\section{Dual}

$\begin{array}{r}\mathrm{I} 7 \\ \mathrm{I}, \mathrm{I} 43 \\ 265 \\ \hline \mathrm{I}, 425\end{array}$

Middle

\section{Plural}

932

963

$\frac{2,692}{4,587}$

$5 \mathrm{I} 2$

I 66

$\frac{1,589}{2,267}$

Or, the active and middle together:
Singular
Dual
Plural
I. I,040
28
I,444
2. 5,292
$\mathrm{I}, 263$
I, I 29
3. 7,724
357
$\frac{4,28 \mathrm{I}}{6,854}$

1 Journal of the American Oriental Society, X (1872-80), $220 \mathrm{ff}$. 
As we postulated $a$ priori, so we find $a$ posteriori in fact that the singular active is far more frequently used than the other parts. Indeed, all the singulars are more than twice as frequent as all the duals and plurals together; the singular active is more frequent than the entire middle. It is, then, not strange that the endings of the singular active, occurring so frequently, had no need of special accent; whereas the other endings, comparatively much less frequent, demanded stress. ${ }^{1}$

(6) There was a third great difference of accent in pro-ethnic IndoEuropean, namely, between the present system and the strong or root aorist. A well-known example in Greek is:

\section{Present $\lambda \epsilon i \pi \epsilon \iota \nu$}

Aorist $\lambda \iota \pi \epsilon \hat{\imath} \nu$

which has the base ${ }^{*} l^{e} /{ }_{0}^{i} q^{n e} / o^{-}$. The accent, which we find on the first syllable of the base in the present, must have been on some other syllable in the aorist, to account for the reduced grade of the stem-vowel. Endless examples of this variety of ablaut in the various bases may be found by consulting the handbooks. The strong, or root, aorist was unquestionably a distinct category.

The whole question of the aorist is unfortunately one of the great philological Streitfragen hinted at in the Introduction, and for this reason the application of our thesis here will be most difficult. For we are in no way clear as to just what elements originally constituted the strong, or root, aorist, nor as to their function and meaning. All we can definitely say is that the root-vowel in the strong aorist was reduced, and that this reduction ensued from a shift in accent.

Now the question arises: Why this shift in accent? Was the differing accent the sole distinguishing characteristic of the aorist? But first let this question be asked: Does accent move from one part of a

1 For the aid of other possible investigators in this field, I should like to call attention to slight arithmetical errors which have crept into Professor Avery's tabulation: Page $3 \mathrm{II}$, in the column of totals in the Subdivision A, for the SimpleAorist I, Subjunctive, read 335 instead of 338 . Accordingly, on page 310 , in the General Summary, Column A for the Simple-Aorist I, Subjunctive, of the Simple Verb, read 607 for 610 . Hence, for the total of the Simple-Aorist, read $1 \$_{5} 0$ for 1853: for the total of the Simple Verb in column A, read 20,278 instead of $20,28 \mathbf{r}$. Further, for the total of column A under the Denominative Verbs, read 285 for 15. Hence, for the Grand Total A at the bottom of page 319 , read 22,55 instead of 22,461 . 
word to another of its own free will and arbitrarily, for the sole purpose of forming a new category, or is it drawn to that different part of the word which takes on accent? In other words, did the pro-ethnic Indo-Europeans accent the aorist away from the base because they wanted to distinguish a new aspect of which they were in need, or did they have no control over the matter? To say that they deliberately shifted the accent means that one fine morning the pro-ethnic IndoEuropeans arose from their mats and by tacit agreement shifted the accent. For this follows naturally on the assumption that the aorist was so accented simply to differentiate it from the present system, the $i m$ perfectiva.

But from our analyses of the strong and weak cases of nouns, and the strong and weak numbers of verbs, we saw clearly that the accent shifted from the root to the ending. This shift, further, was not for the purpose of causing a differentiating ablaut, but for the purpose of making more distinct, emphatic, or conspicuous, an allocative ending which through its comparatively rare occurrence would otherwise, if it were not especially accented, be confused with the more frequently used endings; while these latter, through their frequency, and therefore their likelihood of appearing in the stream of language, were in need of no special emphasis. To be sure, after the accent had shifted and Stammabstufung, because of purely physical laws, had taken place, the weak stem became a sign of the weak ending, the strong of the strong. But let us not forget that Stammabstufung followed the shift of accent automatically, was not originally intended, and, to judge by the numerous levellings which took place in all the languages subsequently, was not in the least necessary.

In the nominative singular, for example, a strong case, the accent did not leave the ending for the stem where we find it, but had (presumably) hitherto been on the stem; and the case-ending, when it ceased to be an enclitic and became permanently suffixed, in no way robbed the stem of its accent. This principle holds true for suffixes from any other source, such as extraction. If the ending in this case had previously possessed accent, it now lost part of it. The vowel in the stem remained in what is called the "Normal Grade." But in a weak case, let us say the ablative, when the enclitic became suffixed to the stem, the accent, as pointed out above, passed on to the ending, 
to make it more conspicuous. For this reason we call the resulting stem-vowel reduced (the "Reduced Grade"). In fine, it was not a question of the passing of the accent from the ending to the stem in the strong cases, but of the shifting of the accent from the stem to the endings in the weak. This shift, as already indicated, sprang from the desire to make more distinguishable the less frequently occurring endings.

So, too, with the strong, or root, aorist. There must have been something independent of the base or termination which distinguished the aorist aspect from the imperfective, just as the personal or case-ending distinguished the cases, persons, or numbers from each other elsewhere. The fact that we cannot definitely lay our finger on this aoristic element in the strong, or root, aorist, as we can in the $s$-aorist, does not permit us to argue that there was originally no such element there. For to argue that there was no such element there, is to argue that the pro-ethnic Indo-Europeans by tacit agreement suddenly shifted the accent for the sake of having a new aspect. Accent does not move arbitrarily; it is attracted or repelled by some element in a word which, as the case may be, needs or does not need to be made more conspicuous so as to avoid misunderstanding. Since we cannot point out what this aoristic element was, we must simply postulate its existence, and either suppose that subsequently it disappeared, or else admit that we fail as yet to recognize it. In so postulating, the present author in no way departs from approved scientific procedure. As the unknown rays were called the $\mathrm{X}$-rays, so now let us call this unknown element the $\mathrm{X}$ of the aorist, leaving it to morphology to discover what the $\mathrm{X}$ of the aorist really was. ${ }^{1}$

Now, the accent moved from the first syllable of a dissyllabic base elsewhere, that it might rest upon the $\mathrm{X}$ of the aorist, and make it thereby more conspicuous, differentiating it more distinctly from the imperfectiva. If our theory be true, the reason that it so shifted was because the aorist as an aspect appeared less frequently in the stream of spoken language, and therefore needed to have its distinguishing

${ }^{1} \mathrm{I}$ am, of course, aware of the theory that the so-called thematic vowel ${ }^{e} \%$ is the element which may be regarded as distinguishing the strong aorist from an (originally) non-thematic present. But this theory can by no means yet be taken as proved. 
element, the $\mathrm{X}$ of the aorist, made more conspicuous by greater accent, to avoid possible confusion with the imperfectiva. The concomitant reduction of the vowel of the first syllable of the base was, if not gratuitous, at least not essential.

But if this be true, we should find then by an analysis of a piece of language where the aorist is still a vividly felt aspect that the $\mathrm{im}$ perfectiva (that is, the entire present system) are more frequent than the entire aoristic system. The question at once arises whether one should include also other varieties of aorist, for example, the $s$-aorist, which did not share in this change of accent, or only the strong, or root, aorist where the shift of accent occurred. To avoid dispute I shall include the $s$-aorist and give its percentage of the whole.

Using Table I of L. Schlachter's "Statistische Untersuchungen über den Gebrauch der Tempora und Modi bei einzelnen griechischen Schriftstellern," ${ }^{1}$ we find on pages r6 6 ff., "Sämtliche in Herodots Geschichtswerk (ed. Kallenberg, I899-I90I) mit Weglassung der zu

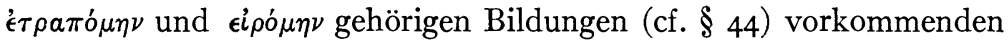
Verbalformen verteilen sich auf Tempora und Modi in folgender Weise." The total number of verb-forms counted was 36,386 , of which I shall give figures for only the aorist active, middle, and passive, and of the present system, the present and imperfect:

AORIST Active and Middle Passive
IMPERFECTIVA

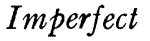

Present

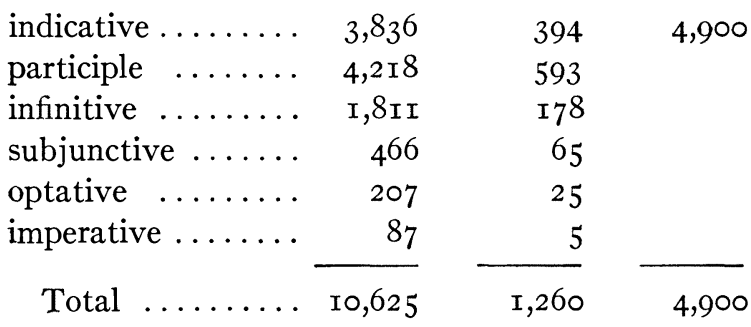

Entire aorist $\ldots \ldots \ldots \ldots \ldots \ldots \ldots \ldots \ldots \ldots \ldots \ldots \ldots \ldots \ldots \ldots$

All imperfectiva ................. 20,886

1 Indogermanische Forschungen, XXIII (1908), I6 6 ff., a continuation of XXII (I909), $202 \mathrm{ff}$., and continued in XXIV (I909), I89 ff. 
Or, in percentages, according to Table I B, page I69:

Aorist active and middle $\ldots \ldots \ldots \ldots \ldots \ldots$ 29.I

Aorist passive $\ldots \ldots \ldots \ldots \ldots \ldots \ldots \ldots \ldots .3 .48$

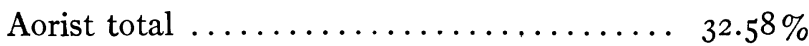

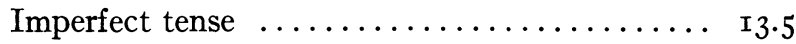

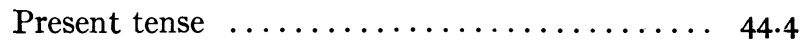

Imperfectiva total $\ldots \ldots \ldots \ldots \ldots \ldots \ldots, 57.9 \%$

In short, the present system is almost twice as frequent as the entire aorist, including the $s$-aorist. But let us see what it would be without the $s$-aorist, which, not sharing in the shift of accent, need not be considered here. By consulting the last column (marked "Herodot," on page I8I) and adding all the sigmatic aorists on the one hand and all the asigmatic aorists on the other, we find:

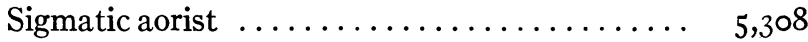

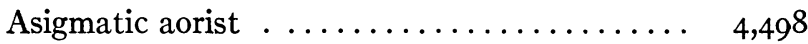

Athematic aorist $\ldots \ldots \ldots \ldots \ldots \ldots \ldots \ldots . \quad 8$ 19

Total aorist, active and middle $\ldots \ldots \ldots \ldots$ เo,625

Passive aorist................... I, 260

Total aorist $\ldots \ldots \ldots \ldots \ldots \ldots \ldots \ldots \ldots \ldots \ldots \ldots \ldots$ II 885

Reducing the same to percentages, we see that the strong, or root, aorist, including passives, is 55.44 per cent of all the aorists, including passives. Now 55.44 per cent of $32.5^{8}$ per cent - the percentage of all aorists in Herodotus to all verb-forms - is 18 per cent, the percentage of strong, or root, aorists, including the aorist passive, in the whole number of verbal forms - 36,386 in all. In other words, the imperfectiva are more than three times as frequent as the strong, or root, aorists.

The ratios for Thucydides ${ }^{1}$ are roughly the same. I chose Herodotus because his style is less polished and elaborate than that of the later historian. But, even so, it is hardly likely that his use of the aorist and imperfective in historical narrative corresponds exactly to popular spoken usage. But by examining the figures for Homer's Iliad and

1 Indogermanische Forschungen, XXIV (I909), I89. 
Odyssey, ${ }^{1}$ we find the aorist, though still less frequent than the imperfectiva, yet more frequently used than by Herodotus or Thucydides.

That we are justified, however, in trusting the Herodotean percentages is clear from the comparative rareness of the aorist in the Rikșamhita. I refer to the general summary on page 3 I9 of Avery's "Verb Inflection in Sanskrit." As pointed out above, ${ }^{2}$ the total verb forms of the Rikșamhita are 22,558 , instead of $22,46 \mathrm{I}$ as given by Avery.

\section{Present System}

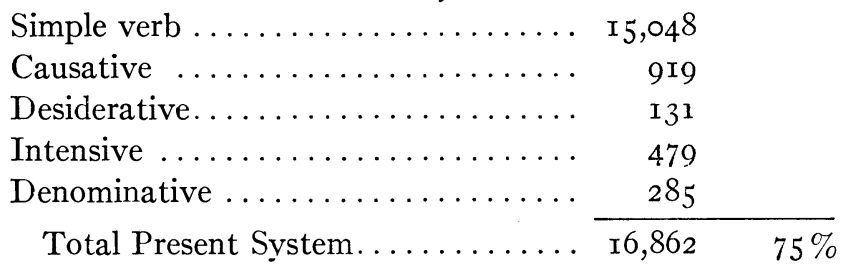

Simple Aorist

Simple verb ............... $\mathrm{x}, 853$

Causative verb $\ldots \ldots \ldots \ldots \ldots \ldots . \quad 423$

Total ................. $2,276 \quad$ 10.1

S-aorist

Simple verb ............................ $75^{6}$

Intensive verb $\ldots \ldots \ldots \ldots \ldots \ldots \ldots \ldots$

Total $\ldots \ldots \ldots \ldots \ldots \ldots \ldots \ldots \ldots \ldots+759 \quad 3.1 \%$

Total Aorists $\ldots \ldots \ldots \ldots \ldots \ldots \ldots, 3,035 \quad \mathrm{I} 3.2 \%$

In other words, the present system in Sanskrit is more than five times as frequent as the total aorist system; or more than seven and one-half times as frequent as the strong, or root, aorist alone. Hence, we must say here as we have said before, that, because of the rareness of the strong, or root, aorist in comparison with the present system, from which it differed only by the $\mathrm{X}$ of the aorist, the accent, according to our principle of frequency, moved elsewhere from the first syllable of the base, bringing about the reduction of the root-vowel.

1 Indogermanische Forschungen, XXII (1907), $210 \mathrm{ff}$.

${ }^{2}$ See p. I3, n. I. 
(7) Let us now turn to still another difference in Indo-European accent, which was to a considerable extent still maintained in early Sanskrit, and the exact position of which is clearly attested by numerous traces of ablaut both there and in other languages. I refer to the varying accent of the present stem of the verb-classes, which in the strong numbers (that is, Ist, 2nd, and 3 rd, singular active, present and imperfect), accented with decided regularity either the first syllable, the infix, or the formant, though to some extent this original condition of things has been obliterated even by Rigvedic times.

Of course, where the present stem was a monosyllabic base, as in the root es (the verb substantive), *és-mi, Sanskrit âsmi, the accent was perforce on the stem in the singular active, and on the endings elsewhere, for reasons pointed out earlier. But there were many bases which were either dissyllabic by nature, such as $* l^{e} /{ }_{o}^{i} q^{u e} / \sigma^{-}$, or else became dissyllabic by the addition of some stem-building suffix or infix. Invariably in the latter case, the accent shifted from the root to the said infix or formative suffix of the present stem in the strong number. As already indicated, not only is this shift in accent clearly apparent from the concomitant reduction of the root-vowel, but in many instances the accented affix still bore the stress in Rigvedic times.

Since the stem-formant or infix distinguished the various Aktionsarten of the present classes from one another, we must assume that the cause of this shift of accent was the desire of the speaker to make more conspicuous that particular part of the stem which was peculiar to it, and the cause of this desire was the rareness of these stems as compared with others. If this be the case, we should find that the stems which accent the stem-building element occur much more rarely than the others. But before proceeding, let us arrange the present classes from this point of view.

In Sanskrit the verbs of Class I were accented on the first syllable of the stem. The third singular present of the root $b h \bar{u}$, "to be, become," was bhâvati.

Class II, which was made up of many monosyllabic bases such as es, nevertheless had in the case of dissyllabic bases the accent in the singular active indicative on the first syllable, as is clearly shown by the vowel-weakening of the second syllable of brâiti, "he says," of the 
root $b r \bar{u}$ "to speak." 1 Furthermore, this is the root-class, in which the endings are suffixed to the root without any stem-building element.

The verbs of Class III have reduplication in the present, such as $h u$, present juhoti, "he sacrifices." These we must leave out of consideration entirely because of their intimate connection with the perfect system.

Class IV contains the $y a$-stems, in which the accent is generally on the root in the reduced grade, as div, third singular divyati, "he plays." But here we must be exceedingly careful, for, though the root has accent, yet the reduced grade of the root-vowel almost proves that the original accent was elsewhere. There is, moreover, some evidence in the Rigveda that the accent might rest on the $-y a .^{2}$ If we consider such roots as *bhrainš, bhrášyati; *drinh, drhyati; *vyadh, vidhyati; ${ }^{*}$ rañj, rajyyati, and the like, it is to my mind unthinkable that the accent had always been on the reduced grade of the vowel. But if one assumes that the accent was originally on the $y a$ of the stem, it is not difficult to perceive an excellent dissimilatory cause for its recession, when one remembers that the passive, even in Rigvedic times, was precisely similar to the $y a$-stems in the middle inflection, differing only in point of accent, which with the passives was consistently on the $y a$ of the stem. Perhaps, then, there is some historical connection between these two categories.

Class V builds its present stem by means of the suffix $n \bar{o}: n u$, with accent on the suffix $n \hat{o}$ in the strong persons (see p. II), on the endings, with the $n u$-suffix, in the weak. The root-vowel is reduced throughout: for example, su, sunóti, "he presses out," sunumás, "we press out."

Class VI has its accent on the stem-vowel, thereby reducing the first syllable of the root. The accent remains on the theme-vowel throughout the present system. An example is the root $t u d$, third

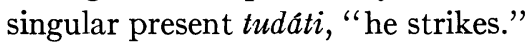

Class VII has a nasal infix in the present stem, the accented $n a$ being infixed before the last consonant of the root in the strong persons, the consonant $n$ being infixed in the same position in the persons having

1 Hermann Hirt, Der Indogermanische Vokalismus (Carl Winter, Heidelberg I92I), p. 2 I2.

2 William Dwight Whitney, Sanskrit Grammar (Harvard University Press, Cambridge, Massachusetts, I923), pp. 273 ff., $\$ \S 76 \mathrm{I} b, 765,767$. 
accent on the endings. The root-vowel is reduced throughout: for example, bhid, bhinádmi, "I split," bhindmás, "we split."

Class VIII forms its present stem with an $\bar{o}: u$ suffix, the accented $\bar{o}$ in the strong form, but $u$ (with accent on the endings) in the weak: for example, tan, tanómi, "I stretch out," tanumás, "we stretch out."

Class IX forms its present with the accented suffix $n a$ in the strong forms, and the suffix $n \bar{\imath}$ or $n$ (with accent on the endings) in the weak. The root $k r \bar{\imath}$ is an example of this; krinaâti, "he buys," krinnimás, "we buy." The root-vowel is reduced throughout.

Now, disregarding the third or reduplicating class entirely, and assuming that the fourth or $y a$-class was originally accented on the stembuilding element before a possible dissimilation from the passives took place, we find that Classes I and II have accent on the first syllable, which contains generally the normal grade of the vowel, either throughout, as in Class I, or in the strong forms, as in Class II. The remaining Classes, IV, V, VI, VII, VIII, and IX, have the accent in the strong forms, wherever the strong-weak distinction is made, on the stembuilding element, whether infix or formant. Where the strong-weak distinction is not made, the accent is consistently on the suffix. In consideration of these facts, we should accordingly expect to find Classes I and II much more frequently used than any one of the remaining classes.

Professor John Avery presented at the meeting of the American Oriental Society in Boston, May, I877, a paper "On the Formation of Present-Stems of the Sanskrit Verb." ${ }^{1}$ On page cxlii he arranges the foregoing classes differently, thus:

The Indian Classification

I

II

III

IV

$\mathrm{V}$

VI

VII

VIII

IX

\section{Avery's Classification}

IV $a$

I

II

IV $c$

III $a$

IV $b$

III $c$

III $a$

III $b$

1 American Oriental Society Journal, X (1872-80), cxli ff. 
To these Professor Avery properly adds two more classes which he considers as irregular verbs. Avery's Class $\mathrm{V} a$ includes those stems having $i$ or $i$ before the endings, such as bráviti, "he says"; and $\mathrm{V} b$, those forming stems in cha.

His Class V $a$, I shall include with Class I (the Sanskrit Class II) because they are largely dissyllabic bases of the root-class with accent on the first syllable in the strong forms. His Class $\mathrm{Vb}$ is the IndoEuropean $s k o$-verbs, having accent on the suffix sko throughout the entire present system. An example is the root gam, "go," gacchati, "he goes," from the Indo-European form ${ }^{*} g_{n}^{u} m s k^{e} /{ }_{o} t i$. The original position of the accent is likewise here deducible only from the reduced grade of the root vowel. Some of the $s k o$-verbs followed the analogy of verbs like bhavati, and with recessive accent joined Class I; others, like is, "wish," stem $i$-ccha, preserved the accent on the suffix and passed into the sixth class: icchati, "he wishes." Since these $s k o$-verbs originally formed a separate category, I shall follow Avery in treating them separately.

In the light of this, we should expect to find Avery's Class IV $a$, and Class I plus $\mathrm{V} a$ together, each much more frequent than the other eight classes, including Class $\mathrm{V} b$ ( $s k o$-verbs).

On page cxlii, in Table II, Avery gives the relative frequency of stems, estimated by occurrences, (A) for the Rigveda, (B) for the Aitareya-Brahmana, and (C) for the Nala and the Bhagavad-Gitta, as follows:

I II IIIa IIIb IIIc IVa IVb IVc $\mathrm{Va} \quad \mathrm{Vb}$

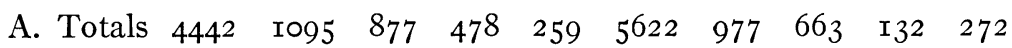
$\begin{array}{lllllllllll}\text { Percentages } & 30 & 7.4 & 5.9 & 3.2 & \text { 1.6 } & 38 & 6.5 & 4.5 & .9 & \text { 1.9 }\end{array}$ $\begin{array}{lllllllllll}\text { B. Totals } & 926 & 346 & 460 & \text { I80 } & 66 & \text { I975 } & \text { I92 } & 380 & 88 & \text { I84 }\end{array}$ $\begin{array}{lllllllllll}\text { Percentages I9.3 } & 7.2 & 9.6 & 3.7 & \text { I.4 } & 4 \mathrm{I} .2 & 4 & 7.9 & \text { I.8 } & 3.8\end{array}$ $\begin{array}{lllllllllll}\text { C. Totals } & 320 & 2 \text { I } & 89 & 57 & \text { II } & 475 & 56 & \text { I3 } 8 & 77 & 98\end{array}$ $\begin{array}{llllllllll}\text { Percentages } 23.8 & \text { I.6 } & 6.6 & 4.3 & .8 & 35.4 & 4.2 & \text { I0.2 } & 5.7 & 7.3\end{array}$

Or, restricting ourselves to the Rigveda, which is chronologically nearest to Indo-European times, we find, adding I and $\mathrm{V} a$, which gives 30.9 per cent for the Root or Sanskrit Class II, and arranging in the order of descending frequency: 


\begin{tabular}{rrrrrrrrr} 
IVa & I \& Va & II & IVb & IIIa & IVc & IIIb & Vb & IIIc \\
5622 & 4442 & I095 & 977 & 877 & 663 & 478 & 272 & 259 \\
& I32 & & & & & & & \\
\hline 5622 & 4574 & I095 & 977 & 877 & 663 & 478 & 272 & 259 \\
38 & 30.9 & 7.4 & 6.5 & 5.9 & 4.5 & 3.2 & 1.9 & I.6
\end{tabular}

In other words, that which we assumed $a$ priori we again find in fact: those stems accented on the root or first syllable of the stem are not merely more frequent of occurrence in the stream of spoken language than those present stems accented in part on the stem-building element, but are enormously more frequent. Indeed, the smaller category of first-syllable accented stems occurs more than four times more frequently than the most frequent class with accent on the formant. This is the fourth confirmation of our theory.

(8) The four analyses given above, which constitute four different, and, as I think, distinct proofs of the power of relative frequency, cover most of the obvious differences in accent in the parent IndoEuropean language. Corollary to this is the suffix-accent of the present active participle in ant, the present middle participle in $\bar{a} n a, m \bar{a} n a-$, the perfect active participle in vas, the perfect middle participle in $\bar{a} n a$, the past participle in $t a$, the stems in mant, vant, $t i, t u$, and so forth, all of which reflect the original Indo-European conditions, as ablaut in other languages indicates. And here, as above, we must assume that the cause of the shift of accent to the formant was the comparative rareness of the latter in the stream of speech. For some cases this is actually demonstrable by recourse to Lanman's valuable "Noun Inflections in the Veda," or to Avery's excellent study. Indeed, the most cursory examination of a few hymns of the Rigveda will so clearly convince the reader of the rareness of these suffixes compared with others that the present writer feels that he may safely assume that, if their rareness is not in itself sufficient to substantiate his theory, which is undoubtedly not the case, their frequency, on the other hand, is not so pronounced as to vitiate it.

Aside from the varying accent in the case-endings of nouns, the personal verb-endings, the formants of the present stem, and the aoristimperfective aspects, all of which have been demonstrated; and from the varying accent of the nominal-adjectival stem-building suffixes, 
the relative frequency of which has in the foregoing paragraph been with but little temerity assumed, there are two other differences of accent whose treatment here is precluded, not from lack of data as to their frequency, but from the total lack of necessary morphological information. By this I mean such differences of accent as occur in the Indo-European $o$-declension, in which, throughout the entire paradigm, save for the vocative singular, the accent remains rigidly on either the root or stem syllable; kâmas $(-m)$, "love," has accent throughout on the first syllable; devás $(-m)$, "god," - save for the vocative singular déva - maintains its accent throughout on the second.

According to our thesis, such nouns with accent on the first syllable should be much more frequent than those with accent on the second. $\mathrm{Or}$, in the words of the theory, there must have been something in the second syllable which placed it in a distinct category; and this something, which has either subsequently disappeared, or, though remaining, succeeds in eluding observation, during Indo-European times drew the accent upon itself as a result of its infrequency. To ascertain which class of $o$-stems is more frequent in the Rigveda would be a comparatively simple matter. But after having done so, and even after having found that the present hypothesis is correct, we could in no way use it as an argument for the support of the theory. For, though in the matter of the strong, or root, aorist we might postulate some element which distinguished that category from the imperfectiva, we cannot do the same with the accent-difference in the $o$-stems. For to no examination does a difference of accent betray any categorical difference of meaning. Unless new linguistic evidence comes to light, morphology will not be able to help. Considering the unlikelihood of such new evidence, we must rely rather upon the principle of frequency to throw light on morphology, than upon morphology to throw light on the present theory.

Another difference in accent occurs in the composita. This subject I hope to deal with separately at another time.

(9) Having treated a great majority of the salient differences in accent in the parent Indo-European language, we shall now turn to a consideration of shifts of accent in particular languages of like descent. As suggested in the introduction, it is unfortunately impossible to 
enter here into a meticulous historical delineation of every shift of accent in every Indo-European language. If for no other reason, the vastness of the field alone prevents any one man from doing so. This, however, is not so serious as it first sounds, since a number of the various accent-shifts are similar, and by treating one, one ipso facto treats many.

(Io) Few languages show a more interesting change of accent than Latin. In pre-historic times the entire accent shifted to the first syllable of every word, bringing about a weakening of certain vowels under determinable conditions in the unaccented syllable. But by historical times it had begun to recede in some cases from the first syllable ${ }^{1}$ until it finally rested firmly on the penult if it was long, or on the antepenult if the penult was short. In this position we find the accent in Classical Latin, thus:

$$
\begin{aligned}
& * \text { cónfacio }>*^{*} \text { cónficio }>\text { confício } \\
& \text { *cónfactus }>^{*} \text { cónfectus }>\text { conféctus } .
\end{aligned}
$$

The weakening of $a$ to $i$ in the open syllable of conficio, and that of $a$ to $e$ in the closed syllable confectus, give tangible proof of the earlier condition of things.

Now what caused the accent to wander to the first syllable, although generations of speakers had been capable of speaking clearly with the accent in its original position? And after the accent had shifted to the first syllable and the language had digested this change, why did it recede again? Many theories have been advanced to account for such mutation, though none, I believe, enjoys universal and complete assent. The present theory maintains that a change in language lies largely in language itself; and that a change in accent is due to some change of frequency of use.

Let us suppose, what is clearly attested by tmesis in early Sanskrit and Greek, that the early Latin or late Indo-European prefixes were, like some of the modern German, separable. Let us then assume that at a later period they became firmly fixed as non-separable prefixes, in which condition we find them in early written Latin. Now, the purpose of a compound is to express a shade of meaning not expressible

${ }^{1}$ See C. Exon, Hermathena, XIV (1906), i1 7 . 
by the simples. ${ }^{1}$ Indeed, we can constantly observe in daily speech that such differentiation is the very purpose of compounding. Hence, at a very early time, *confacio, dismitto, invenio, *prodouco, and the like, differed noticeably from facio, mitto, venio, douco, and the like, in meaning. Accordingly, there existed by the side of facio a dozen different compounds of facio. At the beginning of compounding (which must have originally been sparse and only as necessity demanded), since the stem of facio was to be found not merely in the simplex, but likewise in every one of its compounds, the stem facio was therefore, ipso facto, not only more frequent than any individual compound, but more frequent than all the compounds of facio reckoned together. Therefore, when the prehistoric speaker of Latin, using both the simples and compounds together in his daily speech, wished to differentiate, he tended to accent that in *confacio which distinguished it not only from facio, but from *adfacio, *infacio, *obfacio, and so forth, namely, the prefix.

Moreover, we can see clearly, in the light of our theory, why accent in time should leave the ever frequently recurring endings of a word. That shift would in turn throw the accent toward the stem, and thus easily account for the first syllable becoming accented in most, if not all, of the simples. Hence, we have a clear reason why the accent might well be further drawn from the stem of compounds to the first syllable, the prefix. Since this is very likely the cause not only of Latin, but of most other shifts of accent to the first syllable, it is not inopportune to ask why the accent, once so successfully tied to the first syllable, ever receded again to the penult or antepenult as the case might be.

As the process of compounding continued, and the prefixed verbs and nouns became almost as frequent as the simplices, the compounded word began to be felt less and less as a compound, and more as an individual Gestalt. This development is attested by the frequent assimilation of final sounds of the prefix to initial sounds of the stem (conligo $>$ colligo), which would not have taken place and remained permanent if the force of the compound had constantly been in the mind of the speaker; and it is also attested by the fact that in late

1 Professor Starck reminds me of pertinent examples in German, e.g., steinreich as contrasted with steinreich, blútarm but blutârm. 
and vulgar Latin the force of the compound was gradually lost. As the increasingly frequent use of compounds continued, it was no longer a question of distinguishing, for example, conficio from facio, which the different vowel easily accomplished, but of differentiating between conficio, conicio, conduco, confero, and the like, and similarly between the pro- compounds, the in-, the ex-, the ad-, the per-compounds, and so forth. Consequently, the accent gradually left the first syllable for parts of the word where we find it in Classical Latin. ${ }^{1}$

But if this be true, we should by an examination of a piece of Latin find the compounds almost as frequent as the simples. Using Lane Cooper's $A$ Concordance to the Works of Horace, ${ }^{2}$ I have added the occurrences of ten simple verbs in all their tense forms, participles, infinitives, gerunds, gerundives; and for each verb the similar occurrences of all its verbal compounds which appear in Horace, namely:

dare:

circumdare, ${ }^{3}$ abdere, addere, condere, abscondere, recondere, credere, concredere, dedere, didere, edere, obdere, perdere, prodere, reddere, tradere, uendere.

agere:

abigere, ambigere, cogere, degere, exigere, perigere, redigere, subigere.

uidere:

inuidere, peruidere, praeuidere, prouidere, diuidere. ire:

abire, adire, ambire, anteire, coire, exire, inire, interire, obire, perire, deperire, disperire, praeterire, prodire, redire, subire, transire.

1 The accent of compound verbs in the Rigveda is similar, the accent passing from the verbal prefix in subordinate clauses to the verb.

${ }^{2}$ Carnegie Institution of Washington, I916.

3 Obviously the crystallizing of a few of these words into conventionally recognizable compounds (for instance, circumdare) first took place after the period of vowel-weakening under accentual conditions; yet it is impossible to deny the previous existence, if not of the compound, at least of the collocation circum with dare. In abdere, condere and several others of these compounds, the speaker of Latin certainly saw compounds of dare; etymologically they contain ${ }^{*} d h \bar{e}-$, not ${ }^{*} d \bar{o}-$ except so far as these two had become confused, whether in I.-Eu. or in Italic. 
ferre:

afferre, adferre, anteferre, auferre, conferre, deferre, differre, efferre, inferre, offerre, perferre, proferre, referre, sufferre, transferre.

facere:

afficere, conficere, deficere, efficere, inficere, officere, perficere, proficisci, reficere, proficere.

legere:

colligere, eligere, religere, seligere, subligere, diligere, intellegere, neglegere.

ducere:

adducere, conducere, deducere, diducere, educere, inducere, perducere, producere, reducere, subducere, traducere.

capere:

accipere, concipere, decipere, excipere, incipere, percipere, praecipere, recipere, occupare.

dicere:

addicere, edicere, indicere, interdicere.

It is observable that only the most frequent simplices have been taken, without any regard for their number of compounds. I hope the absence of esse above will be pardoned, because of its extensive use in periphrastic constructions. The results are:

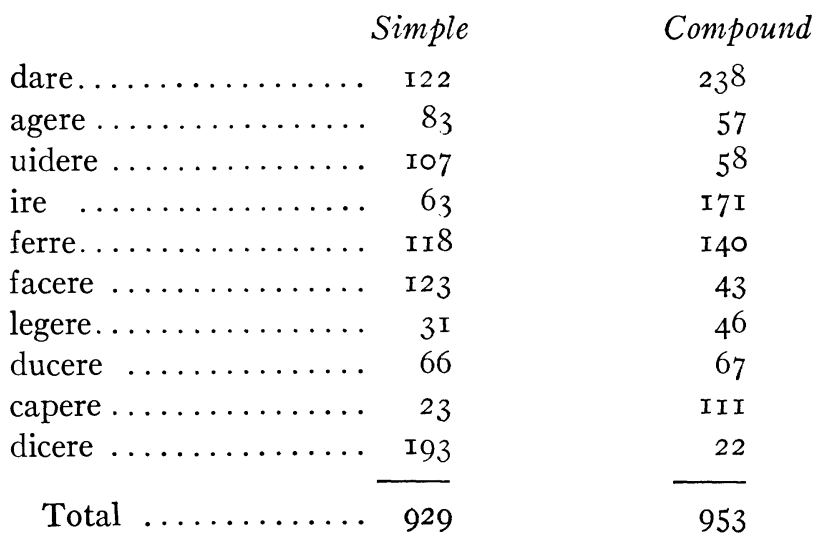


In short, what we assumed $a$ priori we find in fact: the compounds are roughly as frequently used as the simples. But let this be understood: we could include by the score additional verb-stems which admit compounding, but the number of prefixes so usable remains fixed to a few dozen. In this we have a condition somewhat similar to master-mister (see Introduction). The prefixes, both by their frequent occurrence and their limited variety, serve, so to speak, as a common denominator; the distinctive part of the word is what follows. Indeed, we may look upon the whole problem of accent in this light. As long as facio, for example, because of the rareness of its prefixed forms, was a common denominator to its compounds, the accent tended to pass from the common denominator to the distinguishing part, the prefix. As prefixing, however, increased, until the prefixes became, as it were, common denominators to the roots, the accent in turn began to recede from them. To be brief, accent on a frequently used prefix or suffix in the stream of language must be, by the very nature of things, ephemeral. For again, that which is less needy of emphasis, is accordingly less emphasized; and nothing so obviates the necessity of accent as a relatively high frequency of use.

Why the accent finally rested on the penult or antepenult is hard to say with certainty. Perhaps it was, as some maintain, the consequence of secondary accentuation. Perhaps it was due to analogy. The accent left the prefixes, and, after syncope had taken place in certain cases, found itself naturally in so many cases either on a long penult, or on the antepenult preceding a short penult, that through the preponderance of frequency the others took on this mode of accent. The accent, leaving the prefix in conficio, conficere, confeci, confectus, would, in falling on the succeeding syllable in many forms, obey the penultimate law, whereas the first-syllable accent, maintained in facio, facere, feci, factus, would fulfil the same conditions. Let us not forget that such forms, when we consider in addition all the nouns, pronouns, and other parts of speech, either by maintaining first-syllable accent in simples, or by shifting it to the following syllable in prefixed compounds, very frequently observed the penultimate law. The frequency of such a penultima-antepenultima accent could easily by analogy extend throughout all other forms where the receding accent had left a confusion. 
To show that this is not a matter of mere hypothesis, I have examined the first and third books of Caesar's Gallic War, ${ }^{1}$ arranging the words in six categories according to the actual position of the accent as it appeared in the various inflected forms occurring in Caesar: (I) accent on the prefix of prefixed compounds; (2) accent immediately after the prefix in prefixed compounds; (3) accent elsewhere in prefixed compounds; (4) accent on first syllable of simples; (5) accent elsewhere in simples; (6) accent on monosyllables. If analogy did indeed operate here, we should expect to find the sum of groups 2,4 , and $6-$ in which the accent in leaving the prefixes of compounded words, while remaining on the first syllable of simples, obeyed the three-syllable law - so much more frequent than the sum of classes I, 3 , and 5 , that the accent of the superior number spread by analogy throughout. The fact that the secondary accent undoubtedly assisted in this, does not in any way vitiate the presumption that the original impulse was first frequency and then analogy. Let us turn to the analysis:

Natural Forms

(2)

(4)

(6)

$69 \mathrm{I}$

3009

$\mathrm{I} 692=5392$

\section{Analogous Forms}

(3)

(5)

2I4

5I4

$\mathrm{I} 4 \mathrm{I} 3=2 \mathrm{I} 4 \mathrm{I}$

Totals........... $\overline{7533}$

Natural Forms ..... 7 I.57 per cent

Analogous Forms .... 28.43

In other words, in the confusion of accent resulting from its recession from the prefixes, the accent of almost three quarters of the words accidentally obeyed the three-syllable law, and, through sheer preponderance of frequency, brought the remaining one quarter into line. In this, the position of the secondary accent decidedly assisted. Moreover, the conditions of the accent in Early Latin smack of the battle-

${ }^{1}$ Edition of H. Meusel (Berlin: W. Weber, r894). 
field of analogy, where fácilius, séquimini, cécidero, múlierem, ${ }^{1}$ deliberately keep the accent on the first syllable of the simple, despite the three-syllable law, at least as late as the time of Plautus.

One may rejoin that the ratio of three to one is not sufficient for analogy. But any ratio of analogy depends, of course, upon the individual language concerned. Unfortunately, in spite of the frequent use of the concept of analogy in modern philology, philologists have not felt called upon to establish ratios of frequency in a given language, at which analogy not merely may operate, but must operate. Indeed, one occasionally feels that the ideas of analogy, Sprachmischung, borrowing, substrata of speech, and the rest, concepts perfectly sound in themselves, have often at the last minute been used as scapegoats, because nothing else seemed to work.

To determine whether or not three to one is a sufficient ratio for analogy in Latin, we can examine a different and unrelated case of Latin analogy, observing under what conditions levelling did or did not take place. Let us take the nominal $s$-stems: for example, tempus, corpus, labor, and honor, from earlier labos and honos. That these stems all originally ended in $s$, is a well-known fact. But in the cases having an ending, the $s$, being intervocalic, became voiced and eventually changed to $r$. Genitive *temposes and *honoses became temporis and honoris respectively. In the masculines and feminines, the $r$ of the oblique cases spread further, by analogy, to the nominative; yet in the neuter the nominative-accusative singular $s$ remained. Honos became colloquially honor (though honos continued as an archaism in literature), but tempus always remained tempus. Why? Since analogy depends admittedly upon frequency, and since the neuters differed from the masculines and feminines, in respect to the presence or absence of endings, only in the accusative singular, the accusative singular of tempus being tempus, of honor, honorem, the added frequency of the neuter accusative singular, which ended in $s$, must have prevented the $r$ of the oblique cases from levelling away the $s$ of the nominative and accusative singular. This fortunately is not a matter of mere opinion. By consulting Cooper's Concordance to Horace, and adding the number of times neuter stems occur in $-s$ or $-\boldsymbol{r}$-, and the number of times the nominative singular of the mascu-

${ }^{1}$ Cf. Lindsay, Philologus, LI (1893), $364 \mathrm{ff}$. 
lines and feminines occurs as opposed to all other cases, we can get a good working hypothesis toward an actual ratio of analogy.

Taking as examples of neuter s-stems, decus, dedecus, facinus, faenus, frigus, litus, nemus, pecus, pectus, penus, pignus, stercus, tempus, foedus, funus, genus, glomus, latus, munus, onus, opus, pondus, scelus, sidus, ulcus, uellus, uulnus; and taking as -s-stem masculines and feminines those words in which $s$ is attested by the grammarians: ${ }^{1}$ arbor, labor, uapor, clamor, color, amor, pauor, timor, honor, odor, olor, lepor; we gain the following results:

Neuters

Nom.-Acc. Sing. ending in $-s \quad \ldots \ldots$ r93

All other cases, ending in $-r-\ldots \ldots . \quad$ I97

Total ................. $\frac{197}{390}$

Masculines and Feminines

Nom. Sing., ending in $-s,-r \ldots \ldots \ldots \quad 59$

All other cases, ending in $-r-\ldots \ldots$ I 57

Total ................ $\overline{2 \mathrm{I} 6}$
Percentage

$49 \cdot 5$

$\frac{50.5}{100.0}$

$27 \cdot 3$

72.7

I00.0

The ratio of 27.3 to 72.7 per cent is astonishingly similar to the ratio of the words with analogous accent under the three-syllable law to those whose accent is, according to our theory, inevitable and natural.

Tempus and its like retained the $s$ in the nominative singular, because it was roughly as frequently used as the forms in $-r$. Labos, however, became labor, because the forms in $-r$ - were nearly three times as frequent, and levelled the $r$ throughout accordingly. Therefore, there is nothing to prevent our saying that, since three quarters of all the words in the stream of Latin speech had, as it happened, their accent on the penult or antepenult, and in the case of monosyllables, on the monosyllable, the preponderance of this order, after some battling, levelled itself through the remaining quarter. This was further aided in many cases by the position of the secondary accent (condítiò, conditiónibus).

A similar phenomenon may be observed in English, which on the one hand inherited to a large extent first-syllable accent, and on the

1 A list of sufficient length for our present purpose. 
other adopted Norman words with varying accent. In such words as parliament, promise, fiction, and the like, generally old and muchused borrowings, the first syllable has become accented.

(II) There is another interesting difference in accent, this time in a modern language. I refer to the separable and inseparable prefixes in German - some with accent, some without, many, under certain conditions, varying in accent. An especially interesting feature is that the prefixes which may never be separated, or used adverbially, have generally lost the heavy first-syllable accent. Dr. F. W. Kaeding and his colleagues examined for stenographic purposes word-frequency, syllable-frequency, and the frequency of printed letters in the German language. ${ }^{1}$ On page 464 they give the comparative frequencies of all prefixes among 10,910,777 words. From their extensive list, arranged in the order of frequency, I here quote the first twelve:

$\begin{array}{lr}\text { ge- } & 443,639 \\ \text { be- } & 226,827 \\ \text { ver- } & 195,412 \\ \text { er- } & 122,662 \\ \text { an- } & 85,473 \\ \text { zu- } & 75,218 \\ \text { vor- } & 59,132 \\ \text { aus- } & 52,778 \\ \text { un- } & 49,83 \mathrm{I} \\ \text { ent- } & 48,456 \\ \text { da- } & 48,252 \\ \text { ein- } & 45,645\end{array}$

It is, indeed, strange that the first four prefixes which lead the list with tremendously greater relative frequencies are never accented. Yet we must not forget that the prefixes $z e r$-, ent-, and $e m p$ - are likewise always unaccented, although they appear farther down in the list. Their relative positions of course testify against the principle of frequency. But it must not be forgotten either, as many German critics of Dr. Kaeding's excellent work have already pointed out, that Dr. Kaeding examined such quantities of such vastly different literature -

${ }^{1}$ Häufigkeitswörterbuch der deutschen Sprache (Steglitz bei Berlin, 1897). 
legal, medical, military, classical, poetical, epistolary, parliamentary, scientific, commercial, translations, and so on - that it is extremely doubtful whether his ratios at all approach those of vernacular speech. Being thoroughly satisfied myself with his results, I mention the criticism, as I shall later of other works, to warn other possible investigators, desirous of working in the same field. That zer-, ent-, and empare now relatively infrequent, does not prove that they were so at the time of the fixing of the accent-position.

(12) Conclusion of Part One. The foregoing data, if they do not convince the reader as quickly as the frequency of consonants (see below) may, do show a startling confirmation. It cannot be by chance that a difference in accent is regularly attended by a difference in relative frequency. Moreover, theoretically it is certainly to be expected in the language of man, as in human expression in general, that his tendency toward laziness (Trägheitsgesetz) will prevent his accenting any element in language which his hearer will understand without accent. Nor is the hearer so likely to understand any element of language unaccented so readily as an element of language which occurs frequently.

\section{PART II. SOUNDS}

\section{$A$. Consonants ${ }^{1}$}

(I3) Every language must have so great a variety of vowels and consonants that their permutations may, together with the resources of accent and syntax, adequately express its wealth of concepts. Whether the Urwörter or Urausdrücke were imitative or exclamatory or of some other origin, I do not here presume to judge. For it is patent that, with the continuous development of language, various sounds and sound-groups, once full of meaning in themselves, slowly became abstract symbols, which the speaker of later time, had he reflected on the subject at all, would have considered from any point of view quite arbitrarily selected. It is this later period of development, after language had become largely abstract and had lost whatever its original devices, onomatopoeia and the rest, may have been, that I here intend to examine. I shall call it post-primitive.

1 I have examined for this purpose: Sanskrit, Greek, Latin, Old English, Old High German, Modern Bulgarian, English, French, German, Hungarian, Italian, Russian, Spanish, Swedish, Czech. 
(14) Examining the history of any language, we find over a long period of time a constant tendency toward change, not only in accent and meaning of words, but even in the nature of its sounds. On closer analysis, we are startled to find that a given sound, let us say $t$, when it shifts at all in one word, let us say to a $b$, shifts throughout the entire language wherever $t$ occurs under the same conditions. This phenomenon has caused, through its regularity, endless speculation; for it is strange that, if a father can pronounce $t$, the son or grandson, or later descendants, should find difficulty in pronouncing the same sound in the same circumstances. Some scholars have postulated an organic change in the mouth, making it impossible to pronounce a $t$. But, needless to say, there is as yet no anthropological or biological evidence which even pretends to substantiate such a contention. There are, further, endless examples of sound-shifts which took place only in certain positions of a word, initially, medially, or finally, thereby precluding an organic mutation of the vocal system. These scholars, further, forget that a few generations later other changes may take place, as in Germanic, toward those very categories which shortly before were presumably unpronounceable. Moreover, later generations of these supposedly mouth-twisted races, when mixed together in America, all seem in course of time to pronounce with equal ease what is perhaps the most complicated phonetic system ever evolved.

Other scholars have maintained that children's mispronunciation affects their own, if not also their parents', language. But who ever knew a growing child not eager to be rid of his baby-talk, or a parent not eager to help him? And why should the children of Lithuania have found the Indo-European consonants less difficult to pronounce than the children of the Celts or Germans?

Yet other scholars hold that this change is caused by either an acceleration or by a sudden phlegmatism in speaking or, perhaps, in thinking. Though there is undoubtedly some truth in this unproved assertion, - a rapid speaker noticeably skips sounds, even words, yet when it is considered that each nation has its quota of quick tongues and slow tongues, and that a person at home in both English and German, for example, would be at a loss to tell which language was more rapidly spoken, it is hardly plausible to assume that the Ger- 
manic sound-shifts were due entirely and exclusively to an altering speed of enunciation.

Again, there are other scholars who insist that sudden, unaccountable, unrecorded changes in climate or soil have been the cause. But they have always failed to make clear just what a tenuis climate or an aspirate soil would be!

Finally, another theory is that man is constantly making his speech easier and simpler. That is also, perhaps, to a certain extent true, despite many notable examples to the contrary. Yet, how many syllables would "simplified" French need to express that cumbrous Latin phrase ueni, uidi, uici, and how many sounds!

Indeed, all these factors - change in environment, change in linguistic tempo, structural change in the mouth, change in baby-talk, a tendency toward simplification - would undoubtedly influence the actual form of the language, if only on the general principle that a winking of the eye will shake the physical universe. But is it not possible that one of the causes of a phonetic change lies in the structure of the language itself?

(I5) Viewing the host of consonants in a language as so many different phonetic sounds, we perceive at once that some are more difficult to pronounce than others. Let us take the dentals as an example: $d h$ is both more difficult to pronounce and more audible than $d$, because it has all that $d$ contains, plus the increment of aspiration. So too the media $d$ is more difficult to pronounce and more conspicuous or audible than the tenuis $t$, since it has both the dental position and explosiveness of $t$, plus the increment of voice. For similar reasons the aspirate th or the affricate $t s$, are both more conspicuous and more audible than the $t$. But how about the spirant $b$ ? It seems to be least conspicuous of all, for it has only the interdental position, without the increment of aspiration, the increment of voice, or the increment of explosiveness. Yet be it well noted, that what the spirant $p$ may lose in explosiveness, voice, and aspiration, it may gain in duration ( $b, p b, b p p$, etc.), a thing almost entirely denied to the other sounds which we have been considering.

As with the dentals, so too with the labials and gutturals. We can almost generalize, saying that the mediae aspiratae are phonetically and acoustically more conspicuous than the mediae; the mediae more 
so than the tenues; the affricates more so than the tenues, and perhaps even more so than the mediae. The spirants may or may not be more conspicuous, depending solely upon their duration. ${ }^{1}$ In fact, we might go on to say that each consonant is made up of a certain number of units of phonetic difficulty or acoustic audibility. That is, it is thinkable that with the help of more highly advanced sciences of phonetics and acoustics, we might compare consonants with physical and mathematical exactitude, not only different consonants in the same language, but the same consonants in different languages.

(I6) When we consider I.-Eu. ${ }^{*} d{ }_{0}{ }_{o} n t s$ "tooth" (cf. Latin dens, older *dents) and the English tooth, older tō $p$, older *ton $p$, from the Germanic *tanp; and understand that the English is another and linguistically later form of the I.-Eu. word, we must, in the light of these facts, say that $d$ of the stem ${ }^{*} d^{e} /{ }_{o} n t$ - weakened into $t$, and that $t$ of $* d^{e}{ }_{o} n t$ - weakened into $b$. So too, the $d$ of $d u \bar{o}$ weakened into the $t$ of $t w o$. And when we regard the High German zwei, we must say that the $t$ of a pro-ethnic Germanic form hardened again, this time into the affricate $t s$, written $z$. In this fashion we might continue through all the languages. What is the cause of this?

(I7) In Part I we noticed from many clear examples that the accent seems to pass from a syllable, when that syllable becomes too frequent, and likewise from a word. Can we, perhaps, say that the "accent" or conspicuousness left $d$ and $t$ of ${ }^{*} d^{e}{ }_{o} n t$-, because in the stream of spoken language they were becoming too frequent? Such a thing is not so absurd as it at first sounds, for many are the examples where the speaker does not permit two like sounds to follow one another too closely. When two mediae aspiratae occurred in the same stem in Sanskrit, the one lost its aspirate quality, for example, Sanskrit dahati, "it burns," for older *dhaghati, from the root *dhagh-, "to burn" (Gothic dags, O. E. dog, O. H. G. tac, "day"). Further examples of this reluctance to permit two similar sounds to follow each other too closely are offered by the Sanskrit consonantal laws of verbal reduplication.

1 Unfortunately, the phoneticians have not hitherto been able to discover exactly how much energy it takes to produce a given consonant, nor how much energy a given consonant conveys to the hearer's brain. Investigations in this field, notably in the laboratory of the Bell Telephone Company, will undoubtedly shed greater light on this important phase of phonetics, and possibly at a not too distant date. 
Originally the reduplicated consonant must have been the same as the initial of the stem. Yet in classical times we find that the aspirate is reduplicated by means of the corresponding non-aspirate:

\begin{tabular}{ll}
\multicolumn{1}{c}{ Root } & \multicolumn{1}{c}{ Reduplication } \\
chid, "cut away" & cichid (perfect stem) \\
$d h \bar{a}$, "set" & dadha (present stem) \\
$b h \bar{i}$, "fear" & bibhi (present stem)
\end{tabular}

Similarly, in Greek the aspiration of a tenuis aspirata, and also the spiritus asper, are lost if in the first or second following syllable there is an aspirate:

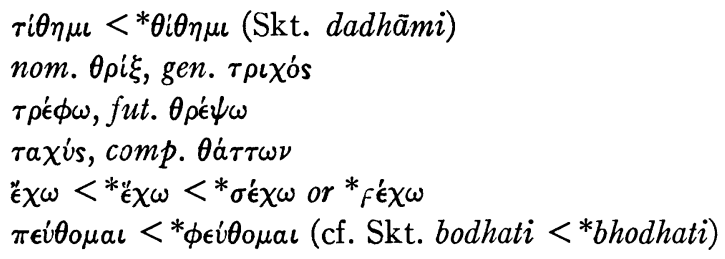

To these examples from Sanskrit and Greek we might further add the concept of haplology, where one of two similar and adjacent syllables

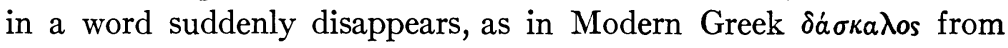

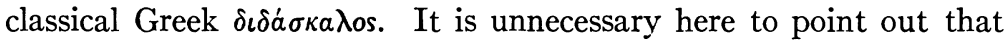
haplology has influenced to a greater or less extent all spoken languages notably German and Modern Greek.

Now, from this it is clear that two similar sounds cannot always follow one another too closely. But in the cases given above there is something even more striking. The sounds so dissimilated are without exception what we must term the heavier or more conspicuous sounds: aspiratae, or even an entire syllable. Lighter or less conspicuous consonants must, therefore, be able to endure closer proximity to one another than the heavier or more conspicuous. Nor is that strange.

(I8) Let us, for example, suppose that in some language every spoken word began with $d$. What would happen? Undoubtedly this $d$ would cease to be a characteristic part of the word; the speaker, from laziness, would tend to neglect it (Trägheitsgesetz); the hearer, being accustomed to it would not insist upon clear pronunciation of it. 
The result would be that the initial sound $d$ would weaken to a more easily pronounceable dental, if it did not entirely disappear. The same weakening of $d$ would take place if, instead of being everywhere initial, it were everywhere medial or final. Surely, no one will dispute this point.

But would it be necessary, in the stream of spoken language, that every spoken word had $d$ initially, or medially, or finally, as the case might be, before it began to seem superfluous? Indeed, $d$ in such circumstances would weaken if merely a large portion of the words had it.

But let us go further and assume that one half, or three fourths, or some other large fraction of the consonants in use were $d$ 's, scattered, as you will, initially, medially, and finally. By this I do not mean one half or three fourths of the consonants of words in the dictionary, in which each word is counted but once, but one half or three fourths of the consonants of the words in a speech or long conversation taken stenographically; or, in other words, suppose that the one hundred most frequently used words contained $d-$ for this entire thesis is concerned with language only as it occurs in the stream of spoken language.

Now, if there were as many $d$ 's as one half or three fourths, they would doubtless tend to weaken. Hence, there must be some percentage in spoken language above which the $d$ tends to weaken. What this upper threshold is, we do not know; but that it exists is at least quite probable. And if the Germanic $d$ had passed such a proportion of frequency, that would be an excellent reason for its having weakened into the tenuis $t$.

Turning now to the next weakest dental, $t$, we find that this sound, being both less difficult to pronounce and less conspicuous to the ear, should, accordingly, be able to appear in spoken language much more frequently than $d$, without becoming so conspicuous in its repetition that it would cease to be a characteristic part of the word. But should it exceed its allotted percentage, it too ought to weaken. And if one were able to show the superfluity of $t$ in Germanic, that would be an excellent reason for its having weakened into $b$. As we have argued about $t$ and $d$, so we might continue, and show that each sound must have an upper threshold of frequency which it cannot pass without becoming weak. 
But to reverse the argument. Let us suppose that there are only a few $t$ 's appearing in spoken language, so few in fact that they are scarcely ever used. These would then become a distinctive and very characteristic part of the word, pronounced carefully by the speaker, heard distinctly by the hearer. Indeed, the inner accent (or Hauptgestalt) of the word would cluster about that $t$. It is, therefore, thinkable that the speaker in taking care to pronounce it distinctly would unconsciously add a following aspiration, or spirant, or some other increment of conspicuousness. For any $t s$, or $t h$, which has arisen from $t$, clearly shows that the speaker had accented his $t$ rather strongly. In other words, there is not only an upper threshold of frequency for, say, a $t$, but likewise a lower limen, below which the $t$ will tend to take on a more conspicuous form. In such a manner an affricate or an aspirate may arise; or rather, in this manner a sound may assume a more conspicuous form. Now, if we can show that, in the Old High German dialect of Tatian for example, $t$ had for some reason become infrequent, that would be an excellent reason for its having changed to the affricate $t s$, written $z .^{1}$

(ig) We can measure the frequency-percentages of $t, d, p, b, k$, and $g$ in modern languages. If the tenues tend to be constantly more frequent in the stream of spoken language, we cannot demand a better proof of our theory.

But, before proceeding, let us remember one thing: the change of a tenuis, for example $p$, to its media, $b$, does not always mean that $p$ has become infrequent. For a tenuis between two voiced sounds is obviously more difficult to pronounce, and, by way of contrast, more audible to the ear than a media; to produce it, the speaker must stop vibrating his vocal cords, pronounce the tenuis, then continue vibrating his vocal cords - an action more difficult than vibrating his vocal cords all the way through. Let us take as an example the Latin ripa, which fulfills this condition, and which later in Old Provençal became

1 Incidentally, we may note that a good example of the overpronunciation of an unusual sound is offered by a person learning to speak a foreign tongue which has unaccustomed sounds. How the Germans caress an English th, and the Americans the German $c h$ ! As we have argued about $t$, so we may argue about all other consonants: each must have its upper and lower thresholds of frequency. Though this statement may sound exceedingly incredible, I shall none the less endeavor to demonstrate its truth. 
$r i b a$. In the intervocalic position the $b$, which differs from $p$ only in respect of voice, was obviously easier to pronounce. We must say that the $p$ weakened into $b$, not because of the rareness of $p$, but because of the frequency of $p$. If the $p$ had been a rarely occurring sound, it would have been so contributory to the Gestalt of the word, that the people of Old Provence would have pronounced it as $p$ despite its being intervocalic. To word our theory so that it shall be true for such special conditions, we may say that any assimilation points to the weakening of the assimilated sound, and this weakening is due to frequency.

If, on the other hand, $t$, initially or not, in the neighborhood of voiced sounds took on voice and became $d$, where such voicing made it at once more difficult to pronounce and more audible to the ear, we must look upon this as a strengthening of the sound. Now, since our theory asserts that a strengthening of a sound is due to its comparative rareness, we must expect to find the sound so strengthened comparatively rare in occurrence. But the important point to remember is that each sound has both an upper and lower threshold. As it approaches the upper threshold, ex hypothesi it becomes "lenior"; as it approaches the lower, "fortior." Hence, should we find the media in some instances more frequent than the tenuis, we must first of all look for a weakening of the media toward a less conspicuous form. But we must not forget that a "lenissima" media may be less conspicuous than a "fortissima" tenuis, and therefore be more frequent. We may say that a media is more conspicuous than its tenuis, only when the media does not lose so much in intensity as to offset its increment of voice, or the tenuis does not gain so much in intensity as to compensate for its lack of voice.

(20) To get exact results in such an investigation, one should have only phonetic examinations of the spoken dialogue of uneducated people speaking a language uninfluenced by literary tradition. For obviously spelling often misrepresents the spoken word; written language differs vastly in style from the spoken; educated people confessedly strive to maintain their speech free from popular expressions and pronunciations which, if my theory is true, are at once the cause and result of Lautverschiebungen; and, finally, the literary language is so conservative that it may continue, like Sanskrit, so impervious to popular changes as, in the course of time, to appear a foreign tongue. 
Among the ten modern languages the relative frequencies of whose consonants are given below, none have fulfilled these requirements. The French, English, Hungarian, and Swedish percentages are fairly exact phonetic measurements of the written language; in Bulgarian, a Volkssprache, the figures represent the frequency of printed letters; so too in Czech and German. The others have had only their written languages examined by a foreigner.

This, however, is not the only handicap. In working out the percentages of frequency I was obliged to treat all vowels, consonants, and diphthongs, not as varying amounts of abstract units of phonetic difficulty or acoustic conspicuousness, but as equal units; yet by definition a long vowel is more conspicuous than a short, and some consonants more so than others. But since the residue of sounds in a language remains constant for both the tenues and the mediae of a language, in the comparative frequency of which alone we are at present interested, I have added all the vowels, consonants, and diphthongs together as so many equal sounds, and have then taken the percentages of the mediae and tenues of the resultant totals. For the benefit of other students I shall, however, include the relative frequencies of these other sounds (that is, other than the tenues and mediae) as given by the authorities quoted, using as far as possible their own sound-symbols.

(2I) For French I have used F. Dujardin aîné, Journal des Connaissances Usuelles (I834), whose results are quoted on page 327 of Karl Faulmann, Historische Grammatik der Stenographie (Vienna: Bermann und Altmann, I887), a copy of which is available in the Preussische Staatsbibliothek, Berlin. ${ }^{1}$

1 I was prevented from using the statistics of B. Bourdon, Des Émotions et des Tendences dans le Langage (Paris, $\mathrm{x} 892$ ), because of the highly literary nature of the language he examined, ranging from Comte's Système de politique positive to Hugo's Ballades. Moreover, Bourdon was mainly interested in determining "des émotions et des tendences dans le langage," whereas Dujardin was intent solely upon determining for a system of stenography the actual frequency of sounds in French, for the ultimate purpose of saving money for French business men. Consequently, Dujardin examined a greater quantity of matter. If I use Bourdon's analyses of other languages, it is because of their completeness, since he elsewhere pursued a much less subjective method. In such instances I have included the results of others as a partial control. 
Consonants

\begin{tabular}{lrc}
$\mathrm{t}$ & 634 & $6.28 \%$ \\
$\mathrm{~d}$ & 356 & 3.55 \\
$\mathrm{k}$ & 485 & $4.8 \mathrm{I}$ \\
$\mathrm{g}$ & 76 & .76 \\
$\mathrm{p}$ & 357 & 3.54 \\
$\mathrm{~b}$ & $\mathrm{I} 40$ & $\mathrm{I} .39$ \\
$\mathrm{l}$ & 380 & 3.77 \\
$\mathrm{r}$ & 254 & 2.52 \\
$\mathrm{~m}$ & 258 & 2.56 \\
$\mathrm{n}$ & 322 & $3 . \mathrm{I} 9$ \\
$\mathrm{gn}$ & $\mathrm{I} 5$ &. $\mathrm{I} 5$ \\
$\mathrm{~s}$ & 646 & 6.40 \\
$\mathrm{z}$ & 237 & 2.35 \\
$\mathrm{f}$ & $\mathrm{I} 45$ & $\mathrm{I} .44$ \\
$\mathrm{v}$ & 222 & 2.20 \\
$\mathrm{ll}$ & 74 & .74 \\
$\mathrm{ch}$ & 39 & .39 \\
$\mathrm{j}$ & 99 & .99 \\
$\mathrm{~h}$ & $\mathrm{I} 9$ &. $\mathrm{I} 9$ \\
$\mathrm{x}$ & $\mathrm{IO}$ &. $\mathrm{IO}$ \\
$\mathrm{gs}$ & $\mathrm{I} 3$ & .13 \\
\cline { 2 - 3 } & $\mathbf{4} 38 \mathrm{I}$ & $47.45 \%$ \\
& $4,78 \mathrm{I}$
\end{tabular}

Nasalized Vowels

\begin{tabular}{lrl} 
an & 387 & $3.84 \%$ \\
ein & I IO & I.09 \\
on & 303 & 3.00 \\
un & 27 & .27 \\
oin & I2 &. I2 \\
\cline { 2 - 3 } & 839 &
\end{tabular}

Vowels and Diphthongs

\begin{tabular}{lrr} 
e & 900 & 8.92 \\
é & 507 & 5.02 \\
è & 664 & 6.58 \\
i & 690 & 6.84 \\
o & 382 & 3.79 \\
ou & $24 \mathrm{I}$ & 2.39 \\
u & 274 & 2.72 \\
eu & 97 & .97 \\
a & 674 & 6.68 \\
oi & 68 & .68 \\
\cline { 2 - 3 } & 4,497 & $44.59 \%$
\end{tabular}

Total Io,II7 I00.36\% ${ }^{1}$

Thus, that which we have assumed $a$ priori, we actually find in the French language: the tenues are all more frequent than their corresponding mediae. ${ }^{2}$

${ }^{1}$ I have carried these percentages, as all others, to the second decimal place (though well aware that by such rough analyses mere hundredths are without significance) solely to avoid the necessity of interpolation.

${ }^{2}$ As a partial control of these figures I here quote from the bibliography on page 39 of F. W. Kaeding's Häufigkeitswörterbuch der deutschen Sprache (Steglitz bei Berlin, I898):

"Thierry-Mieg, J. J. de Mulhouse: Phonography à pente unique, Nouveau Système d' écriture abrégêe (Paris, Librairie de Firmin Didot frères, I853).

"Unter anderem giebt Verfasser folgende Häufigkeitsreihe der Konsonanten 
(22) For Russian (as well as for Spanish and Italian) I have used the results of B. Bourdon, Des Émotions et des Tendences dans le Langage (Alcan: Paris, I892), pp. $80 \mathrm{ff}$; the percentages for Russian are:

\section{Consonants}

\begin{tabular}{|c|c|c|c|c|c|}
\hline $\mathrm{t}$ & 298 & $7.49 \%$ & c & 129 & 3.25 \\
\hline d & I36 & 3.42 & $\mathrm{j}$ & 44 & $\mathrm{I.12}$ \\
\hline $\mathrm{k}$ & & & $\mathrm{q}(\mathrm{x})$ guttural spira & nt $4 \mathrm{I}$ & $\mathrm{I} .03$ \\
\hline $\mathrm{g}$ & $\begin{array}{r}139 \\
44\end{array}$ & $\begin{array}{l}3.49 \\
\text { I. } 10\end{array}$ & i (i-cons.) & 255 & 6.42 \\
\hline $\mathrm{p}$ & 87 & 2.IO & & 2,398 & $60.38 \%$ \\
\hline b & 70 & $\mathrm{I} .76$ & \multirow{2}{*}{\multicolumn{3}{|c|}{ Vowels }} \\
\hline 1 & I65 & $4 . \mathrm{I} 5$ & & & \\
\hline $\mathrm{r}$ & I 88 & $4 \cdot 75$ & $\mathrm{y}$ & $5^{8}$ & I. $46 \%$ \\
\hline $\mathrm{m}$ & I 24 & 3.12 & $\mathrm{u}$ & I 57 & 3.94 \\
\hline $\mathrm{n}$ & 204 & $5 \cdot \mathrm{I} 3$ & o & I92 & 4.83 \\
\hline $\mathrm{h}$ and $\tilde{\mathrm{n}}$ & 7 & .I 7 & $\mathrm{i}$ & $25^{\mathrm{I}}$ & $6.3 \mathrm{I}$ \\
\hline $\mathrm{s}$ & 239 & $6.0 I$ & e & 273 & 6.86 \\
\hline$z$ & 63 & I. $5^{8}$ & $\mathrm{a}$ & $65^{\circ}$ & I6.30 \\
\hline f & I 7 & & & $\mathrm{I}, 5^{8 \mathrm{I}}$ & $39.70 \%$ \\
\hline $\mathrm{v}$ & $\mathrm{I} 48$ & 4.20 & & & \\
\hline $\mathrm{f}$ and $\mathrm{v}$ & I65 & & Total & 3,979 & $100.08 \%$ \\
\hline
\end{tabular}

der stenographischen Schrift: $r$ 350; $s$ 298; $t$ 295; $m$ 224; $k$ 190; $d$ I85; $l$ I7I; $n$ I63; $v 1_{5} 8 ; p \mathrm{I}_{5} ; ; j$ 120; $f$ 106; $z 77 ; c h 47 ; b 45 ; g$ I6; $g n_{14} ; l l$ Iо; $p r$ 54; $\operatorname{tr} 50 ; d r$ 18; $k r$ 17; br 16; fr II; $v r ~ 9 ; g r ~ 2 ; p l ~ 24 ; b l ~ 17 ; g l ~ 9 ; k l ~ 8 ; f l 6$.

"Diese Reihenfolge ist gewonnen worden aus einer Zergliederung der ersten 3232 Worte des Werks: Essai sur la vie et les travaux de Marie-Joseph, baron de Gerando, par Mlle. Octavie Morel, also aus einem sehr kleinen Zählstoff.

"Professor Dr. Michaelis bespricht das Werk in seiner Zeitschrift für Stenographie und Orthographie, 1859, Seite 18r: 'Das Verfahren welches dabei befolgt ist, scheint uns keineswegs eine solche Zuverlässigkeit zu bieten, dass wir darauf näher einzugehen uns veranlasst sehen könnten. Wie ungenau auch diese Zahlen sein mögen, so geht doch aus ihnen hervor, worauf es für die Stenographie der französischen Sprache besonders ankommt, deutlich das bedeutende Überwiegen der starken oder harten Laute $p, t, k$, über die weichen $b, d, g$ indem jene im Durchschnitt beinahe dreimal so häufig sind als diese. Ferner erkennen wir aus diesen Zahlen, dass der Häufigkeit nach, wie dies im allgemeinen in fast allen Sprachen der Fall ist, die Laute nach den Organen in der Ordnung: linguale, labiale, gutturale sich folgen." " 
That which we postulated $a$ priori we actually find again in Russian: the tenues are all more frequent than the mediae. ${ }^{1}$

(23) For Czech I used the results of Professor Dr. Jos. Sedláček, in Těsnopisné Rozhledy (Prague, I924), pp. 65-66, which represent "die Verhältnisse der Worte und deren Teile in der Tcheckischen Sprache, ermittelt durch die Analyse von I8,000 Worten." The numbers following the letters give the number of letters per Ioo words.

\begin{tabular}{|c|c|c|c|c|c|}
\hline \multicolumn{6}{|c|}{ Consonants } \\
\hline $\mathrm{t}$ & 27 & $5.60 \%$ & \multirow{3}{*}{$\begin{array}{l}\mathrm{j} \\
\mathrm{c}(\mathrm{ts}) \\
\mathrm{ch}\end{array}$} & \multirow{2}{*}{$\begin{array}{r}\text { II } \\
6\end{array}$} & \multirow{2}{*}{$\begin{array}{l}2.28 \\
\mathrm{I} .24\end{array}$} \\
\hline $\mathrm{d}$ & I8 & $3 \cdot 73$ & & & \\
\hline k & I9 & 3.93 & & 5 & I.O3 \\
\hline g & .7 & $\begin{array}{r}3.93 \\
.15\end{array}$ & $\mathrm{~h}$ & 7 & \multirow{2}{*}{$\begin{array}{l}\text { I. } 45 \\
2.69\end{array}$} \\
\hline \multirow{2}{*}{$\begin{array}{l}\mathrm{p} \\
\mathrm{b}\end{array}$} & & & \multirow{2}{*}{$\mathrm{y}$} & I3 & \\
\hline & 9 & $\begin{array}{l}3.3^{2} \\
1.86\end{array}$ & & $\overline{295}$ & $\overline{61.22 \%}$ \\
\hline 1 & 22 & $4 \cdot 5^{6}$ & \multirow{2}{*}{\multicolumn{3}{|c|}{ Vowels }} \\
\hline $\mathbf{r}$ & I 5 & $3 . I I$ & & & \\
\hline $\mathrm{m}$ & I7 & $3 \cdot 5^{2}$ & \multirow[t]{2}{*}{$\mathrm{e}$} & 46 & $9.52 \%$ \\
\hline $\mathrm{n}$ & 31 & 6.42 & & 45 & $9 \cdot 3^{2}$ \\
\hline $\mathbf{S}$ & 24 & 4.97 & \multirow{2}{*}{$\begin{array}{l}0 \\
\mathrm{i}\end{array}$} & 35 & $\begin{array}{l}9 \cdot 3^{2} \\
7.25\end{array}$ \\
\hline \multirow{2}{*}{$\begin{array}{l}z \\
f\end{array}$} & 9 & I. 86 & & 35 & \multirow{2}{*}{$\begin{array}{l}7.25 \\
3 \cdot 3 \mathrm{I}\end{array}$} \\
\hline & I & .20 & \multirow{2}{*}{$\begin{array}{l}\mathrm{u} \\
\text { è (pal.) }\end{array}$} & I6 & \\
\hline $\begin{array}{l}f \\
v\end{array}$ & $2 \mathrm{I}$ & $4 \cdot 35$ & & 8 & I. 66 \\
\hline š (pal.) & 6 & I. 24 & \multirow[t]{3}{*}{ ou } & 3 & .62 \\
\hline$\check{\mathbf{z}}$ (pal.) & 6 & I. 24 & & \multirow[t]{2}{*}{$\mathrm{I} 88$} & \multirow[t]{2}{*}{$38.93 \%$} \\
\hline č (pal.) & 5 & 1.03 & & & \\
\hline г̆ (pal.) & 6 & I. 24 & Total & 483 & IOO.I $5 \%$ \\
\hline \multicolumn{6}{|c|}{ 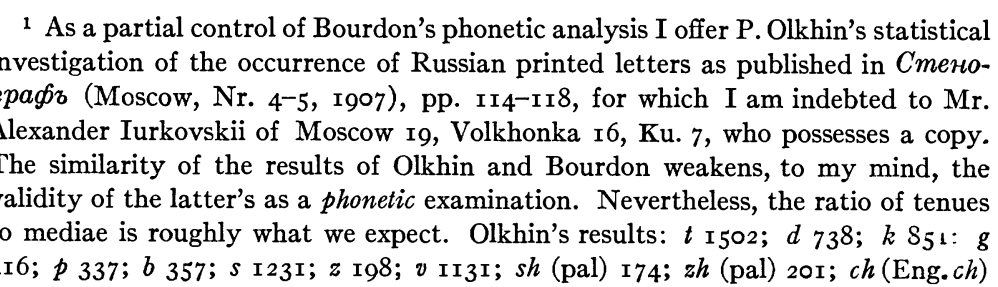 } \\
\hline
\end{tabular}


Again in Czech we find the tenues more frequent than the mediae. There is, to the best of my knowledge, no other examination of Czech sounds with which to check these figures.

(24) For Bulgarian I used the results in Обща Българска Знакова Мргжа на Пишещитт Машини, No.2 (Sofia, I9o8), p. 8, an analysis of the printed letters of Io,000 words. I am indebted to the kindness of Privat-Dozent Dr. Th. Goluboff, Ul. Schejnovo 27, Sofia, the author of this article, for my copy. ${ }^{1}$

\begin{tabular}{|c|c|c|c|c|c|}
\hline & Consonants & & sht (pal.) & $35 \mathrm{I}$ & .70 \\
\hline$t$ & 3,760 & $7.54 \%$ & & $20 I$ & .40 \\
\hline $\mathrm{d}$ & I,773 & $3 \cdot 55$ & \multicolumn{2}{|c|}{ kh (Germ.ch) 200} & .40 \\
\hline $\mathrm{k}$ & 1,485 & 2.98 & \multicolumn{2}{|r|}{25,975} & $52.07 \%$ \\
\hline g & 727 & I.46 & \multicolumn{3}{|c|}{ Vowels } \\
\hline $\mathrm{p}$ & $\mathrm{I}, 4 \circ 9$ & 2.82 & a & & I. $68 \%$ \\
\hline$b$ & $65^{6}$ & I. 32 & $\begin{array}{l}\mathrm{a} \\
\mathrm{o}\end{array}$ & $\begin{array}{l}3,79^{2} \\
4,970\end{array}$ & $\begin{array}{l}1.00 \% \\
0.06\end{array}$ \\
\hline 1 & I,444 & 2.90 & $\mathrm{i}$ & $4,2 \mathrm{I} 6$ & 8.45 \\
\hline $\mathrm{r}$ & $2, \mathrm{I} 26$ & 4.26 & $\mathrm{e}$ & 3,559 & 7.13 \\
\hline $\mathrm{m}$ & $\mathrm{I}, \mathrm{IO} 4$ & 2.22 & $\mathbf{b}$ & 2,234 & 4.48 \\
\hline $\mathrm{n}$ & $3,49^{2}$ & 7.00 & $\breve{\mathrm{e}}$ & $\mathrm{I}, 377$ & 2.76 \\
\hline f & 48 & & ia & $65^{\circ}$ & I.3O \\
\hline \multirow[t]{2}{*}{$\mathrm{v}$} & 2,387 & & $\mathrm{u}$ & $5^{82}$ & I.I 7 \\
\hline & 2,435 & 4.88 & $\check{\mathrm{u}}$ & $2 \mathrm{I} 3$ & .42 \\
\hline S & 2,435 & 4.88 & $\breve{1}$ & I95 & .39 \\
\hline \multirow{4}{*}{$\begin{array}{l}\text { sh (pal.) } \\
\text { zh (pal.) } \\
\text { ch (pal.) }\end{array}$} & 997 & 2.00 & $\mathbf{b}$ & I 29 & .25 \\
\hline & 325 & .65 & iu & 33 & .06 \\
\hline & 475 & $\begin{array}{l}.05 \\
.95\end{array}$ & & 23,950 & $48.05 \%$ \\
\hline & 580 & I.I 6 & Total & 49,925 & IOO.I $2 \%$ \\
\hline
\end{tabular}

$o$ 2460; $i$ I710; $a$ 1660; $u$ 646; ia 5 16; $y$ 419; $i$ 229; $i u$ I78. It is regrettable that in so important a language we must content ourselves with statistics of such palpable inexactitude. The Russian letters are here transliterated according to the rule of the Library of Congress (Washington, D.C.).

1 The Bulgarian letters are here transliterated according to the rule of the Library of Congress (Washington, D.C.). 
If we can trust these figures, as I believe we can to a great extent, since Bulgarian is a Volkssprache, and, as I understand, the present alphabet corresponds phonetically in an unusual degree to the spoken sounds, these figures are exceedingly interesting. For the tenues show the startling ratio of exactly 2 to $\mathrm{I}$ to the mediae in each category. It is a great pity that there is no phonetic examination which might serve to control these figures. Yet even so, with so great a count as 49,925, these averages are significant, especially since the Bulgarian alphabet, possibly inexact elsewhere, is quite precise in the representation of its tenues and mediae.

(25) For Hungarian I used the results, as yet unpublished, of Herr Ludwig von Jakab (Budapest IX, Mesta-utca 37. II. I), who with great kindness supplied me with a transcript of his statistics which he promises to publish soon.

\section{Consonants}

$\begin{array}{lrllrr}\mathrm{t} & \mathrm{I}, 795 & 7 . \mathrm{I} 8 \% & \mathrm{~s} & 5 \mathrm{I} 8 & 2 . \mathrm{IO} \\ \mathrm{d} & 5 \mathrm{IO} & & \mathrm{z} & 627 & 2.56 \\ \mathrm{dj} & 3 \mathrm{I} 8 & & \mathrm{f} & 243 & .97 \\ & 828 & 3.30 & \mathrm{v} & 5 \mathrm{I} 4 & 2.05 \\ & & & \text { s (pal.) } & \mathrm{I}, 039 & 4 . \mathrm{I} 6 \\ \mathrm{k} & \mathrm{I}, 429 & 5.72 & \mathrm{z} \text { (pal.) } & 24 & . \mathrm{IO} \\ \mathrm{g} & 6 \mathrm{I} 2 & 2.45 & \mathrm{c} \text { (pal.) } & \mathrm{II} 4 & .43 \\ \mathrm{p} & 259 & \mathrm{I} .04 & \mathrm{ts} & 55 & .2 \mathrm{I} \\ \mathrm{b} & 428 & 1.7 \mathrm{I} & \mathrm{h} & 394 & \mathrm{I} .59 \\ \mathrm{l} & \mathrm{I}, 627 & 6.50 & \mathrm{y} & 2 & \\ \mathrm{r} & \mathrm{I}, 037 & 4 . \mathrm{II} & & \mathrm{I} 3 & .05 \\ \mathrm{~m} & 836 & 3.35 & & & \\ \mathrm{n} & \mathrm{I}, 438 & 5.74 & & & \\ \mathrm{nj} & 204 & .82 & & & \end{array}$


Vowels

\begin{tabular}{|c|c|c|c|c|c|}
\hline \multirow{2}{*}{$\begin{array}{l}a \\
a \text { (short) }\end{array}$} & $2,29 \mathrm{I}$ & $9.16 \%$ & \multirow{2}{*}{$\begin{array}{l}\text { u (short) } \\
\text { u (long) }\end{array}$} & $26 \mathrm{I}$ & I.O4 \\
\hline & 932 & $3 \cdot 72$ & & 75 & .29 \\
\hline \multirow{5}{*}{$\begin{array}{l}\text { e (back) } \\
\text { e (short) } \\
\text { e (long) }\end{array}$} & 3,223 & I 2.88 & & $33^{6}$ & I. 33 \\
\hline & I,969 & 7.86 & $\ddot{o}$ (short) & 326 & 1.30 \\
\hline & 906 & 3.62 & ö (long) & 255 & 1.02 \\
\hline & I,O48 & 4.18 & $\ddot{\mathrm{u}}$ (short) & I96 & .78 \\
\hline & 3,923 & I5.66 & ü (long) & 34 & .14 \\
\hline \multirow{3}{*}{$\begin{array}{l}\text { i (short) } \\
\text { i (long) }\end{array}$} & $\mathrm{I}, 09^{2}$ & $4 \cdot 37$ & & Iо, 682 & $42.66 \%$ \\
\hline & I09 & .43 & & & \\
\hline & $\mathrm{I}, 20 \mathrm{I}$ & 4.80 & Total & 25, OI 8 & $100.00 \%$ \\
\hline \multirow{3}{*}{$\begin{array}{l}\text { o (short) } \\
\text { o (long) }\end{array}$} & 965 & 3.86 & & & \\
\hline & 223 & .89 & & & \\
\hline & $\mathrm{I}, \mathrm{I} 88$ & 4.75 & & & \\
\hline
\end{tabular}

Here again, save for the labials, which will be discussed later, the tenues are more frequent than the mediae. This fact is for our theory especially important, since Hungarian is not an Indo-European language. ${ }^{1}$ I hope the phonetic transcription, especially of the vowels, both here and elsewhere, will not unduly confuse the reader. My intent is simply to show the approximate categories of the remaining sounds; for their exact phonetic value, which is extraneous to this chapter on consonants, I refer the reader to phoneticists specializing in the particular languages concerned.

(26) For Swedish sounds I have selected the investigations, as yet unpublished, of Oberst a. D. Olof Melin, Arild (Skåne), Sweden,

1 As a control of the excellent statistics of von Jakab, I offer the analysis of B. Bourdon in his Des Émotions $\epsilon t$ des Tendences dans le Langage of which he says (pp. 85 ff.): "Cette analyse a été fait sous le contrôle immediat d'une personne parlant le hongrois de naissance, et par conséquent doit être considerée comme une des plus exactes de celles qui sont rapportées dans ce chapitre. Pour simplifier cependant, je ne distingue pas dans le résumé, qui suit, les voyelles ouvertes des fermées." $t 34 \mathrm{I} ; d$ 164; $k$ I94; $g$ I 23; $p$ 30; $b$ 76; $s 77 ; z$ 109; $f 54 ; v 89 ; s$ (pal.) I54; $z$ (pal.) I; $l$ 328; $m$ 216; $n$ 218; $r$ 167; $i$ (i-cons.) 133; $\tilde{n}$ (pal.) $36 ; h 7 \mathrm{I}$; $\ddot{u} 31$; $u 45 ;$ e 76 ; $i$ I63; o $274 ; a$ 550; ê 673; Total 4,393 . 
to whose kindness I am indebted for them. They are a phonetic analysis of the language of parliamentary and business Swedish, for which reason, though excellent for Colonel Melin's contemplated system of stenography, they hardly approach the popular Swedish vernacular with such closeness as to make them of final validity for this thesis. None the less their ratios of tenues to mediae are significant.

\section{Consonants}

\begin{tabular}{|c|c|c|c|c|}
\hline 68,068 & $7.64 \%$ & $\mathrm{a}$ & 98,997 & I $1.10 \%$ \\
\hline 48,887 & 5.48 & $\mathrm{e}$ & 86,023 & 9.66 \\
\hline 31,386 & $3 \cdot 5^{2}$ & ĕ (short) & I 3,778 & I. 54 \\
\hline 22,240 & 2.50 & $\bar{a}$ (long) & $23,28 \mathrm{I}$ & $2.6 \mathrm{I}$ \\
\hline 10,732 & & i & $5^{I, 642}$ & 5.80 \\
\hline I I, $73^{2}$ & 1.20 & o & I 5,077 & I.69 \\
\hline $11,73^{2}$ & $1.3^{2}$ & ŏ (short) & I8,340 & 2.06 \\
\hline 37,792 & 4.24 & å & I9,387 & 2.18 \\
\hline $7 \mathrm{I}, 703$ & 8.05 & $\mathrm{u}$ & I 5,153 & I. 70 \\
\hline 29,301 & 3.28 & $\mathrm{y}$ & 4,338 & .48 \\
\hline $65,2 \mathrm{I} 8$ & $7 \cdot 32$ & $\bar{o}$ (long) & I6,I60 & $\mathrm{I} .8 \mathrm{I}$ \\
\hline 6,874 & .77 & & 362,176 & $40.63 \%$ \\
\hline 50,426 & 5.66 & & & \\
\hline I9,723 & $2.2 \mathrm{I}$ & Total & 890,892 & $99.94 \%$ \\
\hline 27,379 & 3.07 & & & \\
\hline 2,908 & $\cdot 32$ & & & \\
\hline $\mathrm{I}, 307$ &. $\mathrm{I} 4$ & & & \\
\hline I 2 , I I9 & I. 36 & & & \\
\hline Io,92 I & I. 23 & & & \\
\hline $5^{28,7}$ I 6 & $59 \cdot 3 \mathrm{I} \%$ & & & \\
\hline
\end{tabular}

Once more, except for the labials, about which more is to be said later, we find the tenues distinctly more frequent than the mediae. ${ }^{1}$

1 As a partial control of the Melin investigation, I offer the examination of Dr. Julius Braun of the consonants of $\mathrm{I}, 000$ syllables of Swedish from an article on protective tariff in his Entrourf und Begründung eines neuen Schulkurzschriftsystems und Schnellschrift (Hamburg: Kommissionsverlag der Verlagsanstalt und Druckerei A. G., vormals J. F. Richter, I888), pp. 84 ff. (a copy of this book is in the 
(27) For Italian sounds I have taken the results of B. Bourdon in his Des Émotions et des Tendences dans le Langage, pp. $80 \mathrm{ff}$.

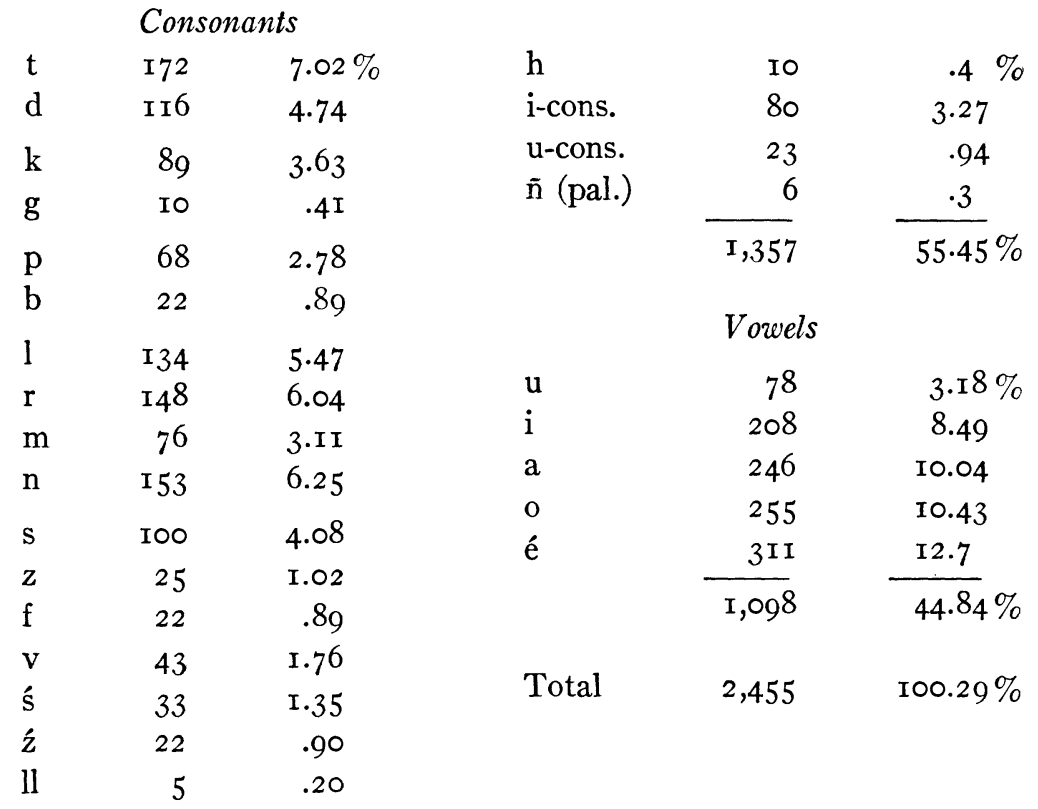

Though it may be doubtful whether Bourdon's ${ }^{1}$ examination is extensive enough to make his averages significant, yet, even as it is,

Preussische Staatsbibliothek, Berlin): $r$ 201; $n$ I82; $t$ I59; $l$ II $; s$ 108; $d 94 ; m$ $79 ; w(v)$ and $6 h v 70 ; k$ and $4 c h 69 ; f 55 ; g$ 53; $n d 32 ; h$ and $6 h v 32 ; j$ (and $\mathrm{I} 3$ $g$ and $3 h j$ ) 29; ng 27; p 24; st 22; b 21; sk 19; nt 7; sch (ske) 6; mp 3; ' (pal.) 2; $n k 2 ; x 2 ; t j \mathrm{I} ; \dot{z}$ (pal.) I; these, when the double consonants are resolved, show the same general trend as the Melin figures.

1 As a control I offer the statistics on Italian sounds by Dr. Julius Braun in his Entwurf und Begründung eines neuen Schulkurzschriftsystems und Schnellschrift (Hamburg, I888), p. 85: $t 88 ; d 59 ; k 55 ; g 5 ; p 49 ; b$ I4; $l$ I $22 ; r$ I 2 I; $m 43 ; s 87$; v 49; $\dot{c}$ (pal.) 29; $f 27 ; z 23 ; \dot{z} 2 \mathrm{I} ; n t 20 ; n d$ II; st $9 ; q u$ 8; mp 7; $s 6 ; l j(g l) 5$; $s k_{4} ; n j 3 ; s p 2 ; h 2$; $i$-cons. 2 ; $n k \mathrm{I} ; n$ 108; these are sufficiently in accord with Bourdon to permit our believing that the tenues are more frequent than their mediae. 
the Italian tenues seem much more frequent than their corresponding mediae. ${ }^{1}$

(28) For Spanish I have adopted the examination of Bourdon: ${ }^{2}$

Consonants

\begin{tabular}{|c|c|c|c|c|c|}
\hline $\mathrm{t}$ & I23 & $4.27 \%$ & $\delta$ & 7 & $.24 \%$ \\
\hline d & I 44 & 5.02 & $\mathrm{q}$ (ch dur ou & & \\
\hline $\mathrm{k}$ & I IO & 3.82 & guttural) & I8 & .625 \\
\hline g & I9 & .07 & ś (pal.) & 9 & $\cdot 3 \mathrm{I} 3$ \\
\hline $\mathrm{p}$ & 76 & & $\tilde{\mathrm{n}}$ (pal.) & 7 & $\cdot 34$ \\
\hline b & 59 & $\begin{array}{l}2.04 \\
2.05\end{array}$ & $\mathrm{~h}$ & I & .03 \\
\hline 1 & I 86 & 6,46 & & $\mathrm{I}, 607$ & $55.32 \%$ \\
\hline $\mathbf{r}$ & I94 & 6.74 & & Vorvels & \\
\hline $\mathrm{m}$ & 66 & 2.29 & & owero & \\
\hline $\mathrm{n}$ & I 75 & 6.08 & u & $5^{2}$ & I.8I \\
\hline s & 224 & 7.78 & o & $\begin{array}{l}141 \\
252\end{array}$ & $\begin{array}{l}4.90 \\
8.75\end{array}$ \\
\hline f & I4 & .48 & é & 371 & $\begin{array}{r}0.75 \\
12.90\end{array}$ \\
\hline $\mathrm{v}$ & 23 & .8 & a & $45^{6}$ & $\mathrm{I} 5.80$ \\
\hline i-cons. & 104 & $3.6 \mathrm{I}$ & & $\mathrm{I}, 272$ & $44.16 \%$ \\
\hline $\begin{array}{l}\text { u-cons. } \\
\text { b }\end{array}$ & $\begin{array}{l}\text { I5 } \\
33\end{array}$ & $\begin{array}{r}\cdot 52 \\
\text { I. } 15\end{array}$ & Total & 2,879 & $99.48 \%$ \\
\hline
\end{tabular}

Again in Spanish, save for the dentals, which will be later considered along with the Swedish and Hungarian labials, which likewise seem at first to refute the principle of frequency, the Spanish tenues are more frequent than the mediae. ${ }^{3}$

${ }^{1}$ Sr. Cav. Uff. Professor Dr. Guiseppe Aliprandi, Presidente della Accademia Italiana di Stenografia, Padua Ir, Via Galilei 1 7, published an article "Ricerche sulle Frequenze," in the Bollettino della Accademia Italiana di Stenografia for 1928. Though his research was exhaustive, yet it was unfortunately restricted to Italian letters instead of sounds. Notwithstanding, his ratios of tenues to mediae are in favourable accord with Bourdon.

${ }^{2}$ Op. cit., pp. 80 ff. But see p. 64 , infra.

${ }^{3}$ To control the Bourdon investigation, I here offer Dr. Julius Braun's analysis of $\mathrm{I}, 000$ syllables of Spanish, as found in his Entwurf und Begründung eines newen Schulkurzschriftsystems und Schnellschrift on p. $85: s$ 190; $r$ 139; $n$ I25; $l$ II5; $d$ 96; $k(c) 87 ; m$ 68; $t 44 ; z(c e) 44 ; p 34 ; b 3 \mathrm{I} ; n t ~ 27 ; s t ~ 21 ; n d ~ 20 ; f$ 19; $v$ 19;

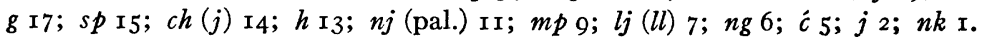


(29) For English I have used the excellent phonetic analysis of I00,000 words made by Godfrey Dewey in his Relativ Frequency of English Speech Sounds. ${ }^{1}$ Since this book is easily accessible to others, I restrict myself to giving the consonants, together with their percentage of all the 372,729 sounds:

\section{Consonants}

\begin{tabular}{|c|c|c|c|c|c|}
\hline $\mathrm{t}$ & $26,55^{\circ}$ & $7.13 \%$ & $\dot{z}$ (pal.) & I 70 & $.05 \%$ \\
\hline d & I6,050 & $4 \cdot 3 \mathrm{I}$ & ć (pal.) & I,930 & $.5^{2}$ \\
\hline $\mathrm{k}$ & IO,IOO & $2.7 \mathrm{I}$ & j (pal.) & I,630 & .44 \\
\hline g & 2,760 & .74 & $\mathrm{f}$ & 6,860 & I. 84 \\
\hline $\mathrm{p}$ & 7,620 & 2.04 & V & 8,490 & 2.28 \\
\hline b & $6,75^{\circ}$ & I. $8 \mathrm{I}$ & $b$ & $\mathrm{I}, 380$ & .37 \\
\hline 1 & I3,930 & 3.74 & $\mathrm{w}$ & $\begin{array}{r}\text { I } 2,780 \\
7,760\end{array}$ & 3.43 \\
\hline $\mathbf{r}$ & 25,620 & 6.88 & $\mathrm{y}$ & 2,230 & .60 \\
\hline m & Io,360 & 2.78 & h & 6,755 & $\mathrm{I} .8 \mathrm{I}$ \\
\hline $\mathrm{n}$ & 26,980 & 7.24 & Consonants & 231,387 & $62.10 \%$ \\
\hline ng & 3,590 & .96 & Vowels & I3I,7 I9 & $35 \cdot 3^{2}$ \\
\hline $\mathbf{S}$ & 16,970 & 4.55 & Diphthongs & 9,623 & $2.5^{8}$ \\
\hline $\begin{array}{l}z \\
\text { ś (pal.) }\end{array}$ & $\begin{array}{r}\text { II }, 070 \\
3,052\end{array}$ & $\begin{array}{r}2.97 \\
.82\end{array}$ & Total & 372,729 & $0.00 \%$ \\
\hline
\end{tabular}

Again in English we find the tenues decidedly more frequent than the mediae. It would, indeed, be unkind to think of a possible control for these figures, which are so extensive in scope and so accurate in analysis. Yet even these cannot be said to represent any actually spoken language; nor was that the author's intent. Both the terms "English" and "Modern American" designate artificial languages which exist rather in spite of phonetic laws than because of them. Let us repeat again, that the present law of frequency can only be exactly demonstrated in an actually spoken dialect.

(30) For Modern German I was for some time at a loss. Though many analyses had been made of German letter-frequency, none had ever been seriously undertaken for German sounds. To be sure,

1 Harvard University Press, Cambridge, I923, p. I 25. 
Bourdon and others had made attempts in that direction, but their results were always vitiated by their counting the written media as the spoken media, a thing in German far from being the case: take, for instance, the actual pronunciation of words like Tod, Herbst, Kind, $Z u g$. At last $I$ resolved to undertake an analysis and redistribution of the frequency of German letters as determined by F. W. Kaeding in his Häufigkeitswörterbuch der deutschen Sprache (Steglitz bei Berlin, I 898), striving to include, as far as possible, in the totals for the tenues, also such tenues as might be written mediae. Taking then the table on page 646 , I considered all initial mediae in the Vorsilben, Haupt(Stamm-)silben, and Nachsilben, as mediae both written and spoken. All mediae appearing finally in the Vorsilben and Nachsilben I considered as tenues in pronunciation ( $a b$-finden, a $b$-geben, notwendig, and so on), though written as mediae. There remained, therefore, only the final mediae in the Haupt-(Stamm-) silben, which may or may not be pronounced as tenues, according as they are or are not in absolute Auslaut, and, if not, varying with the nature of the sound that follows. Indeed, some final mediae under Kaeding's Haupt- (Stamm-) silben are always pronounced as tenues because of the nature of surrounding stem-sounds: Herbst, selbst, and the like.

Further, on page 34, Kaeding divides words into their syllables thus:

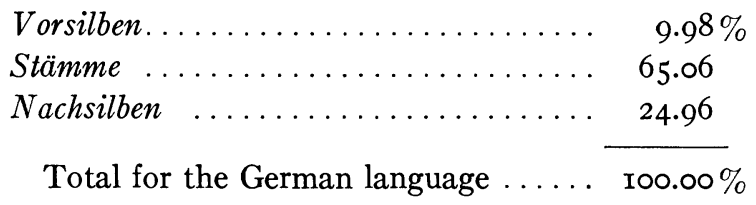

In short, 24.96/65.06 or 38.5 per cent of the Hauptsilben are followed by some sort of Nachsilben. Therefore - after we have deducted those mediae which, owing to surrounding sounds, are always spoken as tenues regardless of a Nachsilbe - of those remaining, written mediae, according to the law of probability, 38.5 per cent will be followed by Nachsilben, while the remaining 6r.5 per cent will stand absolutely final, and accordingly be pronounced as tenues. Therefore, if we can segregate those mediae which are always pronounced as tenues, and of the remaining take 6 r.5 per cent as standing absolutely final, we 
can roughly reapportion the letter-frequencies so as to correspond approximately to the actual sound-frequencies. Such approximation will, of course, be very rough, since in many instances the mediae are also pronounced as tenues even before Nachsilben: Mädchen (d), vorzüglich $(g)$, strebsam (b), and so on. But this error, such as it is, is weighted against my theory, since it adds actual tenues to the category of mediae. Hence, we may proceed convinced that whatever the results are, they are not unfairly favoring the principle of frequency.

Now, on pages 611-630 of Kaeding are given the Auslaut Konsonanten der Hauptsilben with their surrounding sounds. Examining these, I segregated, on the principle outlined above, the tenues from the mediae according to the neighboring sounds. For illustration I shall give my analysis of the letter $b$. Whenever I was in the slightest doubt, I placed the letters $b, d$, and $g$ in the category of the mediae.

\begin{tabular}{|c|c|c|c|c|c|}
\hline \multicolumn{2}{|c|}{$\begin{array}{l}\text { Written } b \text { and always } \\
\text { pronounced as } b\end{array}$} & \multicolumn{2}{|c|}{$\begin{array}{l}\text { Written } b \text { and always } \\
\text { pronounced as } p\end{array}$} & \multicolumn{2}{|c|}{$\begin{array}{l}\text { Written } b \text {, but vary- } \\
\text { ing in pronunciation }\end{array}$} \\
\hline $\mathrm{bb}$ & $85^{\circ}$ & $\mathrm{bs}, \mathrm{b}(\mathrm{s})$ & $\mathrm{I}, 630$ & $\mathrm{~b}$ & $337,6 \mathrm{I} 6$ \\
\hline bbl & I & bsch, b (sch) & 797 & & 31,261 \\
\hline $\mathrm{bc}$ & 2 & bst, b (st) & 2,46 I & rbl, rbn & $\mathrm{I} 4$ \\
\hline bd & 9 & $\mathrm{bs}(\mathrm{t}), \mathrm{b}(\mathrm{sts})$ & 4 & & 368,801 \\
\hline bg & 2 & $\mathrm{bt}, \mathrm{b}(\mathrm{t})$ & 28,435 & & \\
\hline bj, bl, b (l) & $2,80 \mathrm{I}$ & $\mathrm{b}(\mathrm{ts})$ & 208 & & \\
\hline $\mathrm{bn}, \mathrm{b}(\mathrm{n}), \mathrm{b}(\mathrm{ns})$ & 223 & $\mathrm{~kb}$ & 12 & & \\
\hline $\mathrm{br}, \mathrm{b}(\mathrm{r})$ & 7,527 & $\mathrm{lb}$ & 40,160 & & \\
\hline $\mathrm{lbr}, \mathrm{lb}(\mathrm{r})$ & 75 & $\mathrm{lb}(\mathrm{s})$ & I9 & & \\
\hline $\mathrm{mbr}, \mathrm{mbs}$ & 90 & lbst (l) (s) & 20,578 & & \\
\hline $\mathrm{nb}, \mathrm{nbl}$ & IO & $\mathrm{lb}(\mathrm{t})$ & I47 & & \\
\hline & II, 590 & $\mathrm{mb}$ & 596 & & \\
\hline & טע, 11 & $\mathrm{mbl}$ & 26 & & \\
\hline & & rbs, rb (s) & 420 & & \\
\hline & & rbst, rb (st) & 538 & & \\
\hline & & $\mathrm{rb}(\mathrm{t})$ & 940 & & \\
\hline & & $\mathrm{sb}$ & 32 & & \\
\hline & & & 97,003 & & \\
\hline
\end{tabular}


Check (sounds): Always $b \ldots \ldots \ldots \ldots \ldots \ldots \ldots$ II, 590

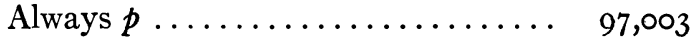

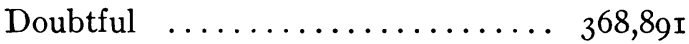

Error.................... $6_{5}$

Total printed $b$ in Auslaut $\ldots \overline{477,549}$

Check (letters), Kaeding p. 646, Column 9:

$\begin{array}{rrr}\text { Auslaut } b \text { Hauptstammsilbe } \ldots & 476,698 \\ \text { Auslaut } b b \text { Hauptstammsilbe } \ldots & 85 \mathrm{I} \\ \text { Total printed } b \text { in Auslaut } \ldots & 477,549\end{array}$

The 368,89 i doubtful cases of $b$ represent German words whose Stammhauptsilbe ends in $b$; concerning what follows the stem in these cases we know nothing. According to the law of probability 38.5 per cent have some sort of Nachsilbe which, we shall assume, always causes the $b$ to be pronounced $b$, though, strictly speaking, that is far from being true; while the remaining 6r.5 per cent, having no Nachsilbe, are invariably pronounced as $p$. Or, in figures:

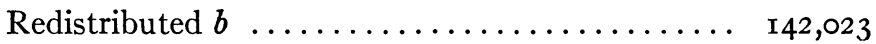

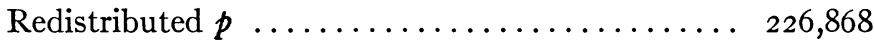

Doubtful (total) ................ $\overline{368,89 \mathrm{I}}$

Let us now add together the $b$ 's and $p$ 's from all sources:

$b$ Anlaut Vorsilbe .................. 235,772

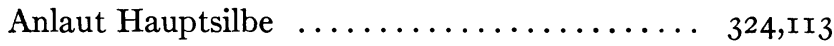

Anlaut Nachsilbe .................. I5,2 18

Hauptstammauslaut: always $\ldots \ldots \ldots \ldots \ldots$ II, 590

Hauptstammauslaut: redistributed $\ldots \ldots \ldots \ldots$ I42,023

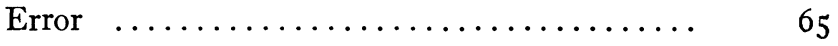

Total $b$-sounds in German .......... 
$p$ All written $p \ldots \ldots \ldots \ldots \ldots \ldots \ldots \ldots \ldots . \ldots \ldots, \ldots \ldots 3,293$

All written $p p \ldots \ldots \ldots \ldots \ldots \ldots \ldots \ldots \ldots \ldots \ldots \ldots \ldots \ldots \ldots \ldots \ldots \ldots \ldots, 1 \mathrm{II}, \mathrm{I} 3$

All written $s p \ldots \ldots \ldots \ldots \ldots \ldots \ldots \ldots \ldots, 66,028$

$b$, Vorsilbenauslaut ................ 91,420

$b$, Nachsilbenauslaut $\ldots \ldots \ldots \ldots \ldots \ldots \ldots . \quad 5,480$

Redistributed $p \ldots \ldots \ldots \ldots \ldots \ldots \ldots \ldots \ldots .226,868$

Written $b$, always pronounced as $p \quad \ldots \ldots \ldots . \quad 97,003$

All written $m p \quad \ldots \ldots \ldots \ldots \ldots \ldots \ldots \ldots . \ldots \ldots$ 13,689

Total $p$-sounds in German ............ 705,494

The same procedure I followed with regard to $g$ and $d$. By splitting up those double letters given by Kaeding on page 646, which actually represent two different sounds (as $n d, s p$, st, and so on), and by adding the individual sounds together, plus $21,023,877$, the number of vowels and diphthongs given on page 643.3.a, and getting 54,322,44I as the sum total of all German sounds, I then took the percentages as given below. I need not point out that such an analysis is exceedingly crude; yet such error as it contains is in every detail weighted against my thesis. Even so, while acknowledging that every tenuis I counted is pronounced as a tenuis, though despite my redistribution many sounds still counted as mediae are actually pronounced as tenues, the reader may wonder why $I$ include such crude evidence at all. To this I answer simply, that I would rather include this interpolated evidence, inexact and weighted against my theory as it is, than by neglecting mention of so important a language as German, run the risk of overlooking a possible disproof of my thesis. For all said and done, the rough redistribution does show the general relationship of tenues to their mediae, which it is here our purpose to demonstrate. The actual percentages, however, are additionally untrustworthy, ${ }^{1}$ because the total of supposed German sounds include many which are merely orthographic.

${ }^{1}$ For a brief yet fair criticism of Kaeding's Häufigkeitswörterbuch, see B. Q. Morgan: German Frequency Word Book based on Kaeding's Häufigkeitswörterbuch. der deutschen Sprache, Publications of the American and Canadian Committees on Modern Language, X (New York: Macmillan, I928), vii ff. 


\section{Consonants}

\begin{tabular}{|c|c|c|c|c|c|}
\hline t & $3,484,437$ & $6.42 \%$ & $\begin{array}{l}\mathrm{ch} \\
\mathrm{pf}\end{array}$ & $\begin{array}{r}\mathrm{I}, 347,4 \mathrm{I} 7 \\
43, \mathrm{II} 3\end{array}$ & $\begin{array}{r}2.48 \\
.08\end{array}$ \\
\hline $\mathrm{k}$ & I, 2 I 8,057 & 2.24 & & $\overline{33,298,564}$ & $61.24 \%$ \\
\hline g & 996,592 & I. 84 & & Vowels & \\
\hline p & 705,494 & I. 30 & e & $9,260,044$ & $17.6 \%$ \\
\hline b & $728,78 \mathrm{I}$ & I. 34 & i & $3,378,88$ I & 6.22 \\
\hline s & $2,595,706$ & 4.78 & $\mathrm{a}$ & $2,659,78 \mathrm{I}$ & 4.90 \\
\hline $\mathrm{f}$ & $\mathrm{I}, 432,028$ & 2.64 & $\mathrm{u}$ & I $, 694,672$ & 3.12 \\
\hline $\mathrm{v}$ & $1,062,833$ & I.95 & o & I, $276, \circ 77$ & 2.35 \\
\hline ś & I,I 49,687 & $2 . \mathrm{I} 2$ & ei & & \\
\hline 1 & I $, 85 \mathrm{I}, 3$ I 5 & $3.4 \mathrm{I}$ & ai $\}$ & $\mathrm{I}, 2 \mathrm{I} 5, \mathrm{O} 4 \mathrm{I}$ & 2.24 \\
\hline$r$ & $4,899,656$ & 9.02 & $\mathrm{au}$ & 449,083 & .83 \\
\hline $\mathrm{m}$ & $\mathrm{I}, 433, \mathrm{I} 6 \mathrm{I}$ & 2.64 & $\ddot{\mathrm{u}}$ & & \\
\hline $\mathrm{n}$ & $5,679,663$ & 10.40 & y j & $429,95^{6}$ & .79 \\
\hline $\mathrm{j}$ & I I8,6I9 & .20 & ä & 324,469 & .60 \\
\hline $\begin{array}{l}h \\
n g\end{array}$ & I, 277,970 & $\begin{array}{r}2.35 \\
.83\end{array}$ & $\ddot{0}$ & I 83,448 & .34 \\
\hline $\begin{array}{l}\text { ng } \\
q u\end{array}$ & $\begin{array}{r}45 \mathrm{I}, 676 \\
\text { I0,22 I }\end{array}$ & $\begin{array}{l}.83 \\
.02\end{array}$ & $\left.\begin{array}{l}\mathrm{eu} \\
\mathrm{a} u\end{array}\right\}$ & I 52,2 I 5 & .28 \\
\hline $\mathrm{x}$ & 9,337 & .02 & ey & & \\
\hline $\mathrm{y}$ & 76 & & ay $\}$ & $2 \mathrm{IO}$ & - \\
\hline $\mathrm{tz}(\mathrm{z}, \mathrm{c})$ & 765, OI 3 & I.4I & & $21,023,877$ & $39.27 \%$ \\
\hline & & & Total & $54,322,44 \mathrm{I}$ & $100.51 \%$ \\
\hline
\end{tabular}

Save for the labials, which will be discussed later when we come to consider those ratios which are not in accord with our theory, the tenues are again more frequent than the mediae.

(3I) In addition to these ten modern languages I thought it prudent to add examinations of Rigvedic Sanskrit, Platonic Greek, and Ciceronian Latin.

For the Rigveda I shall use W. D. Whitney's percentages for Io,০o० sounds, as published in his article "On the Comparative Frequency of Occurrence of the Alphabetic Elements in Sanskrit."1

1 American Oriental Society Journal, X (I880), Proceedings at New York (October, 1877$), \mathrm{cl}$ ff. 


\begin{tabular}{|c|c|c|c|}
\hline $\mathrm{t}$ & $6.65 \%$ & $\mathrm{~m}$ & $4 \cdot 34 \%$ \\
\hline $\mathrm{d}$ & 2.85 & $\mathrm{r}$ & $5 . \circ 5$ \\
\hline $\mathrm{dh}$ & .83 & 1 & .69 \\
\hline th & $\cdot 5^{8}$ & s (dent.) & $3 \cdot 56$ \\
\hline $\mathrm{k}$ & I.99 & ś (pal.) & I. 57 \\
\hline g & .82 & $\mathbf{s}$ (cerebral) & I. 45 \\
\hline gh & .15 & h (visarga) & I. $3 \mathrm{I}$ \\
\hline $\mathrm{kh}$ &. $\mathrm{I} 3$ & $\mathrm{~h}$ & I.07 \\
\hline $\mathrm{p}$ & 2.46 & $\mathrm{v}$ & 4.99 \\
\hline $\mathrm{b}$ & .46 & $\mathrm{y}$ & 4.25 \\
\hline $\mathrm{bh}$ & I. 27 & & $\overline{56.48} \%$ \\
\hline ph & .03 & \multirow{2}{*}{\multicolumn{2}{|c|}{ Vowels }} \\
\hline $\mathrm{t}$ & .26 & & \\
\hline d & $.2 \mathrm{I}$ & $\mathrm{a}$ & $\mathrm{I} 9.78 \%$ \\
\hline dih & .03 & a (long) & 8.19 \\
\hline thh & .06 & $\mathrm{i}$ & 4.85 \\
\hline c & $\mathrm{I} .26$ & i (long) & I.I9 \\
\hline j & .94 & $\begin{array}{l}\mathrm{u} \\
\mathrm{u} \text { (long) }\end{array}$ & $\begin{array}{r}2.6 \mathrm{I} \\
.73\end{array}$ \\
\hline $\mathrm{jh}$ & $.0 \mathrm{I}$ & $r$ & $\begin{array}{l}\cdot 73 \\
.74\end{array}$ \\
\hline $\operatorname{ch}$ & .17 & ṛ (long) & $.0 \mathrm{I}$ \\
\hline n (dent.) & $4.8 \mathrm{I}$ & 1 & $.0 \mathrm{I}$ \\
\hline $\bar{n}$ (anusvara) & .63 & $\mathrm{e}$ & 2.84 \\
\hline ṇ (cerebral) & 1.03 & ai & $.5 \mathrm{I}$ \\
\hline$\tilde{\mathbf{n}}$ (pal.) & .35 & o & I. 88 \\
\hline ń (gut.) & .22 & $\mathrm{au}$ &. $\mathrm{I} 8$ \\
\hline & $7.04 \%$ & & 43.52 \\
\hline
\end{tabular}

These figures are particularly interesting because, except for the one sound $b$, they show clearly that the mediae aspiratae, as first postulated (see above, $\$ \S$ I $_{5}, \mathrm{I}_{7}$ ), are less frequent than the mediae, the mediae less frequent than the tenues, and the tenues aspiratae less frequent than the tenues. ${ }^{1}$

1 I here call attention to E. Förstemann's "Numeralische Lautbeziehungen des Griechischen, Lateinischen, und Deutschen zum Sanskrit," Zeitschrift für Vergleichende Sprachforschung, II (I853), 36 ff. Since Förstemann specifies neither what 
(32) From this point on, for the want of sufficiently exact investigations of others in sound or letter frequency, I am obliged to offer statistical analyses made by myself. I have taken as a sample of Attic Greek certain parts of the Platonic dialogues which seemed both to me and to others especially suitable for analysis because of their popular style. My count, which covers Io,000 Greek letters (that is, diphthongs considered as one letter, geminatae as two) divides itself as follows: (a) the first 3,000 letters of direct discourse of Plato's Phaedrus ${ }^{1}$ and (b) 7,000 letters from Crito. ${ }^{2}$

Of the ro,ooo letters, 4,783 or 47.83 per cent were vowels and diphthongs which I did not count individually, since the present thesis will in no way use the Greek vowels. For convenience in reckoning I considered $\xi, \psi$, and $\zeta$ as single sounds, since their percentages are so small as to be negligible.

\section{Consonants}

\begin{tabular}{|c|c|c|c|c|c|}
\hline$\tau$ & 758 & $7.58 \%$ & $\xi$ & $5^{I}$ & $.5 \mathrm{I}$ \\
\hline$\delta$ & 287 & 2.87 & $\psi$ & 9 & .09 \\
\hline$\theta$ & I 36 & I.36 & $\zeta$ & $2 \mathrm{I}$ & $.2 \mathrm{I}$ \\
\hline & & & $\sigma$ & 649 & 6.49 \\
\hline$\kappa$ & 407 & 4.07 & $\nu(\gamma)$ & 10 & .10 \\
\hline$\gamma$ & 174 & I.74 & $\mathrm{h}$ (asper) & 254 & 2.54 \\
\hline$\chi$ & 77 & $\cdot 77$ & & & \\
\hline$\pi$ & 338 & $3 \cdot 38$ & \multicolumn{3}{|c|}{ Geminatae } \\
\hline$\beta$ & 49 & .49 & $\lambda \lambda$ & 87 & $.87 \%$ \\
\hline$\phi$ & 75 & $\cdot 75$ & $\mu \mu$ & 4 & .04 \\
\hline$\lambda$ & 197 & I.97 & $\nu \nu$ & 3 & .03 \\
\hline$\rho$ & $35^{I}$ & $3 \cdot 5^{I}$ & $\sigma \sigma$ & 2 & .02 \\
\hline$\mu$ & 3 I 9 & 3.19 & $\tau \tau$ & 4 & .04 \\
\hline$\nu$ & 855 & 8.55 & & 217 & $52.17 \%$ \\
\hline
\end{tabular}

Sanskrit texts, Vedic or Classic, he examined, nor how extensive a count his percentages represent, I do not see how his results may be used as a control of Whitney's study, even though, these factors considered, they do not vary widely.

${ }^{1}$ Chapters I, II, III, and the first line of chapter IV through 'A $A \lambda{ }^{\prime} \epsilon i, \kappa \tau \lambda$. (Platonis Convivium - Phaedrus, ed. by C. Fr. Hermann, Leipzig: Teubner, 1925).

${ }^{2}$ Chapters I, II, III, IV, VI beginning with Crito: $\kappa a \lambda \omega \hat{\omega} \kappa \tau \lambda$. to the end of

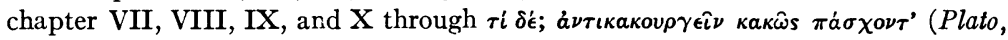
A pologia, Crito, ed. by C. Fr. Hermann and M. Wohlrab, Teubner). 
Here, as elsewhere, we find the tenues distinctly more frequent than the mediae; and, as we assumed previously, the tenues, with no exception, are more frequent than the tenues aspiratae. ${ }^{1}$

(33) For Ciceronian Latin, I counted Io,ooo letters, considering, as in Greek, the diphthongs as single, the geminatae as double sounds. Taking Ciceronis Epistulae II, Epistulae ad Atticum, Pars Prior, Libri I-VIII (Oxford: Clarendon Press, I903), I selected at random Book I, Letters 16,3 , and lines I-3, through Nunc vero sentio. . . . of Letter 4. Of the 10,000 letters 5,277, or 52.77 per cent, were consonants, 4,723 , or 47.23 per cent, vowels. Not here being concerned with the vowels, I did not count them singly.

\section{Consonants}

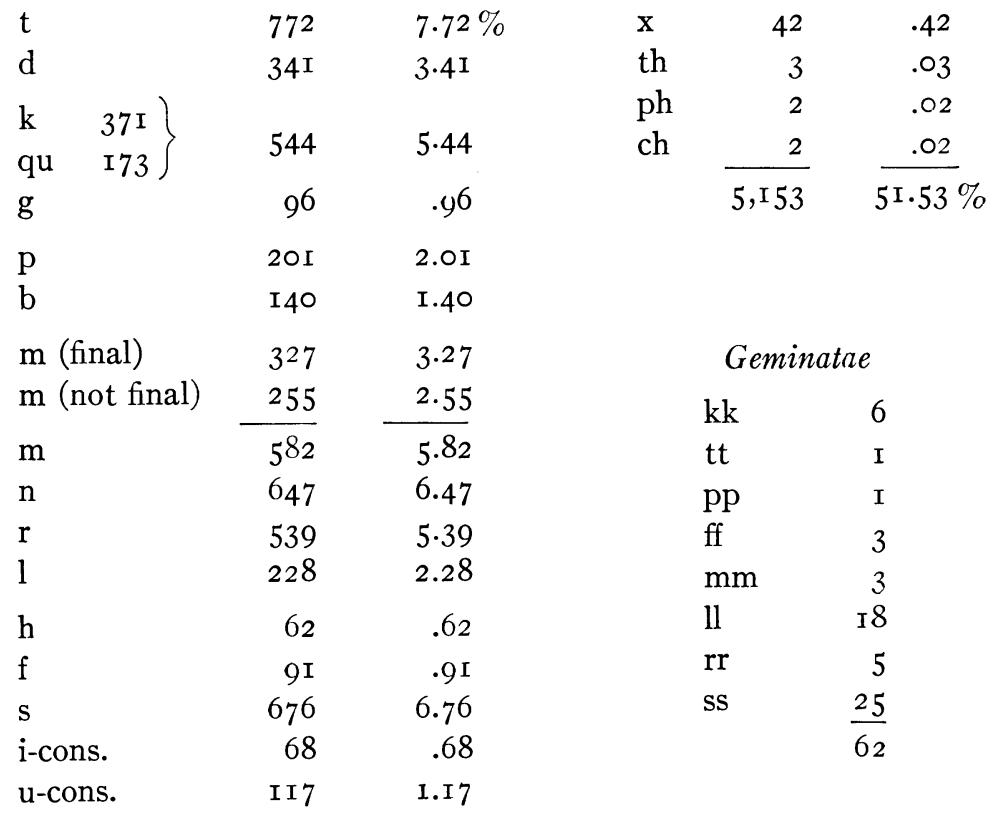

1 E. Förstemann likewise determined the frequency of letters in the Attic dialect without naming the author examined or the amount counted. His percentages, which do not vary considerably from mine, may be used as a partial control (Kuhns Zeitschr., I (1852), 163 ff.). 
Here as elsewhere, we discover that the tenues tend to be more frequent than the mediae. ${ }^{1}$

(34) To make the ratios given above more convenient for examination, a tabulation of the tenues with their respective mediae would be useful. The four instances which we have noted, where the individual media seems to be more frequent than its corresponding tenuis, I will italicize for convenience in subsequent reference.

\begin{tabular}{|c|c|c|c|c|c|c|}
\hline & $t$ & d & $\mathrm{k}$ & $\mathrm{g}$ & $p$ & b \\
\hline 3ulgarian & $7 \cdot 54 \%$ & $3.55 \%$ & $2.98 \%$ & I. $46 \%$ & $2.82 \%$ & I. $32 \%$ \\
\hline nglish . & $7 \cdot 13$ & $4 \cdot 3 \mathrm{I}$ & $2.7 \mathrm{I}$ & .74 & 2.04 & I.8I \\
\hline$\ldots \ldots$ & $7 \cdot 49$ & $3 \cdot 42$ & 3.49 & I.IO & 2.19 & I. 76 \\
\hline talian . & 7.02 & $4 \cdot 74$ & 3.63 & $.4 \mathrm{I}$ & 2.78 & .89 \\
\hline wedi & 7.64 & 5.48 & $3 \cdot 5^{2}$ & $2.5^{\circ}$ & 1.20 & 1.32 \\
\hline Iungarian & $7 \cdot 18$ & $3 \cdot 30$ & $5 \cdot 72$ & 2.45 & 1.04 & $I .7 I$ \\
\hline rerman & 6.42 & $3 \cdot 75$ & 2.24 & I. 84 & $I \cdot 30$ & 1.34 \\
\hline rench & 6.28 & 3.55 & $4.8 \mathrm{I}$ & .76 & $3 \cdot 54$ & I. 39 \\
\hline zech & 5.60 & $3 \cdot 73$ & 3.93 & .15 & $3 \cdot 5^{2}$ & I. 86 \\
\hline panis & 4.27 & 5.20 & 3.82 & .07 & 2.64 & 2.05 \\
\hline nskrit & 6.65 & 2.85 & I.99 & .82 & 2.46 & .46 \\
\hline eek $\ldots \ldots \ldots$ & $7 \cdot 5^{8}$ & 2.87 & 4.07 & I. 74 & $3 \cdot 38$ & .49 \\
\hline & $7 \cdot 72$ & $3.4 \mathrm{I}$ & $3.7 \mathrm{I}$ & .96 & 2.01 & $\mathrm{I} .40$ \\
\hline iage & $6.8 \mathrm{I} \%$ & $3.84 \%$ & $3.58 \%$ & I.I $5 \%$ & $2.38 \%$ & I. 37 \\
\hline
\end{tabular}

This result is indeed startling. Despite the roughness of the examination, we see that $t$, for example, tends to hover about 7 per cent of the language; $d$ around 3.5 per cent; $k$ around 3.5 per cent; and so forth. Bulgarian, as has been said, shows the very startling ratio of 2 to I. From the actual Bulgarian percentages the English percentages vary but slightly. Surely it is clear that the tenues tend to be more frequent than the mediae.

But what is most amazing is that this ratio persists in languages most widely separated from one another by time and space, many

1 E. Förstemann likewise determined the frequency of letters in Latin, without naming the author examined, or the amount counted. His percentages, which vary but slightly from mine, may be used as a partial control; cf. Kuhns Zeitschr., I ( 1852$),$ I63 ff. 
of which have undergone devastating sound-shifts. Latin $t$ and French $t$, roughly speaking, go back to Indo-European $t$; English $t$ goes back roughly to Indo-European $d$; whereas German $t$ is made up largely from Indo-European $d h$ with a substantial addition from $d$ and $t$. Yet in all these languages the superior frequency of the $t$ is apparent. If the absolute percentages vary somewhat, that is what we expect, first, from the varying number of different consonants at the disposal of different languages; second, from the differing positions of articulation of the sounds; and finally, from our upper and lower thresholds of conspicuousness. Some of these $d$ 's are fortes, others are lenes; and it is certainly safe to say that more exact phonetic measurements of purely colloquial dialogue would give us correlations even more startling than these. Nor can we here fail to observe that Hungarian, a non-Indo-European language, seems to follow the same law, thus indicating that our principle of frequency obtains not only for Indo-European tongues, but for post-primitive speech in general.

Of the thirty-nine groups of tenues and mediae in the thirteen languages examined, four alone, or roughly ro per cent, show a preponderance of mediae over tenues: I refer to the Hungarian, Swedish, and German labials, and the Spanish dentals. Since we see that 90 per cent of the cases obey the principle of frequency, let us now turn to the remaining ro per cent.

(35) Concentrating our attention on the labials, we observe at once that it is not $b$ which is over-frequent, but $p$ that is over-rare. For by comparison with the other languages we see that $b$ tends to hover roughly about I.4 per cent, from which the Hungarian with I.7I, the Swedish with I.32, and the German with I.34 per cent differ too slightly by such inexact statistics to warrant further consideration. It may be suggested by the reader that since $b$ was undoubtedly very rare in pro-ethnic-Indo-European, $p$ should accordingly be rare in Germanic. That, to be sure, might, by a great stretch of the argument, explain Swedish. But it cannot explain German, since Old High German shifted into affricates, and later double spirants the Germanic $p$ 's derived from the Indo-European $b$ 's. Consequently, one might search modern German with a lantern without finding even a few examples of $p$ from Indo-European $b$. Hungarian likewise refutes such a supposition, for, not being an Indo-European tongue at all, its consonants 
could not have been greatly influenced by the Indo-European order of things.

Hence, there remain only two other possible solutions (see $\S$ I9): either $(a)$ that the $p$ 's through their frequency have been assimilated to adjacent sonants (for example, Latin ripa, Old Provençal riba); or $(b)$ that the upper threshold of a $b$ may be less intense or conspicuous than the lower threshold of a $p$; that is to say, a fortis $p$ may be more difficult to pronounce and more audible to the ear than the lenis $b .^{1}$

Since we have no marked law in modern German for the assimilation of $p$ 's to voiced sounds, it follows that the first alternative cannot be the cause of their paucity. Then, if our theory be true, the German $p$ must be fortis, the German $b$ lenis. That such is the fact is very well known. A German in pronouncing a $p$ often adds an accompanying aspiration; whereas, for example, in pronouncing the English phrase "bad boy," he invariably utters what an Englishman hears as "pat poy." Hence the superior frequency of German $b$ to $p$, far from vitiating our theory, adds another proof.

Similar is the explanation of the phenomenon observable in Leipzig, where $p$ and $b$ have fallen together into a labial sound which, strictly speaking, is neither. The same phenomenon happened there with the other mediae and tenues (begleiden may mean begleiten or bekleiden); for, as we observed, if all written mediae were truly pronounced as mediae, they would be vastly more frequent than the tenues. ${ }^{2}$ In some parts of Germany the speakers unvoiced the mediae in the most convenient positions - namely, the beginning (Notker's Anlautgeset $^{3}$ ) and the end of words. In the neighborhood of Leipzig the two

1 Of course, both of these conditions may, at least theoretically, have operated simultaneously.

${ }^{2}$ See F. W. Kaeding, Häufigkeitswörterbuch der deutschen Sprache (Steglitz bei Berlin, I897), p. 647 , column 21 .

${ }^{3}$ Wilhelm Braune: Althochdeutsche Grammatik (Halle: Niemeyer, I923), pp. 86 ff., § r 3. "Bei N[otker] wechseln die anlaute $p-b, k-g, t-d$ derartig, dass $p, k, t$ steht: I. am anfange eines satzes (oder satzteils); 2. im satze, wenn das vorhergehende wort auf einen stimmlosen laut endigt." That this Anlautgesetz is an individual dialectal peculiarity, and not a general linguistic tendency, as some scholars assume, is clearly shown by the following Sanskrit law of Sandhi covering precisely similar conditions with opposite results: "In external combination ... an initial 
sounds fell together. Thus we have a possible explanation of the labials of modern German. I leave an explanation of the Swedish and Hungarian labials to someone who has a better opportunity than I for studying objectively the actual phonetic intensities. Yet I hazard the guess, which inquiry seems to substantiate, that the same condition of lenis-fortis obtains there also.

(36) Let us now turn to the case of the Spanish dentals, which with $t$ at 4.27 and $d$ at 5.02 per cent seem to offer a disproof of our theory, though in reality they add another support. For if 5.02 per cent represents the frequency of $d$ in Spanish, we may with certainty assume that it has crossed the upper threshold, especially since it is almost 25 per cent more frequent than the Spanish $t$. We should, accordingly, expect that in Spanish the $d$ would lose one of its increments of conspicuousness, either its voice, or explosive quality, or both. This is actually the case. According to T. Navarro Tomás, Manual de Pronunciación Española (Madrid, I9I8), pp. 75 ff., only in the absolutely initial position, or when preceded by $n$ or $l$, is the written Spanish $d$ pronounced as a media, and then only lenis. Elsewhere it has taken on a spirantic quality, losing the increment of explosiveness as postulated above. In many cases, ${ }^{1}$ the spirant is so weak as to be neglected entirely in the vulgar pronunciation current in the greater part of Spain. Examples of this phenomenon may be had by consulting the work cited above. $b$ likewise, with 2.05 per cent, the highest percentage in the entire list, always has a spirantic quality.

(37) Before leaving these thirteen languages let us consider their liquids and nasals:

sonant of whatever class . . requires the conversion of a final surd to a sonant" (Whitney, op. cit., p. 54, $\S I_{57}$ c). Take the dentals as an example: O. H. G. ist daz appears in Notker as ist taz; but Sanskrit āsit dāsah, 'there was a slave,' becomes $\bar{a} \operatorname{si} d d \bar{a} s a h$.

1 Tomás, op. cit., pp. 77-79. 


\begin{tabular}{|c|c|c|c|c|}
\hline & $\mathrm{m}$ & $\mathrm{n}$ & 1 & $\mathrm{r}$ \\
\hline French $\ldots \ldots \ldots$ & $2.56 \%$ & $3.19 \%$ & $3.77 \%$ & $2.52 \%$ \\
\hline Russian ....... & 3.12 & 5.13 & $4 \cdot I 5$ & $4 \cdot 75$ \\
\hline Czech ......... & $3 \cdot 5^{2}$ & 6.42 & $4 \cdot 5^{6}$ & $3 . \mathrm{II}$ \\
\hline Bulgarian ....... & 2.22 & 7.00 & 2.90 & 4.26 \\
\hline Hungarian ...... & $3 \cdot 35$ & $5 \cdot 74$ & 6.50 & 4.II \\
\hline Swedish........ & 3.28 & $7 \cdot 32$ & 4.24 & 8.05 \\
\hline Italian .... & $3 . I I$ & 6.25 & $5 \cdot 47$ & 6.04 \\
\hline Spanish ....... & 2.29 & 6.08 & 6.46 & 6.74 \\
\hline English . . . . . . . & 2.78 & 7.24 & $3 \cdot 74$ & 6.88 \\
\hline German........ & 2.64 & 10.40 & $3.4 \mathrm{I}$ & 9.02 \\
\hline Sanskrit $\ldots . .$. & $4 \cdot 34$ & 7.04 (all) & .69 & 5.05 \\
\hline Greek $\ldots \ldots \ldots$ & 3.19 & 8.55 & I. 97 & $3 \cdot 5^{\mathrm{I}}$ \\
\hline Latin ......... & 5.82 & 6.47 & 2.28 & $5 \cdot 39$ \\
\hline
\end{tabular}

That $r$ should in no way agree among the languages is at once clear when we consider that in some cases $r$ is uvular, in some trilled, in some vocalic, or now pronounced distinctly, now again so lightly that it is almost unnoticeable. Since each variety has its varying degree of conspicuousness and difficulty of pronunciation, we cannot apply our theory here. Too great a frequency would undoubtedly cause a weakening, even to the vanishing point, as is the case perhaps in certain positions in English. But, owing to this very difference in the nature of the sounds, we cannot use them for purposes of comparison. So, too, $l$ has various manners of pronunciation. Perhaps ultimately the tendency in Indo-Iranian of $l$ and $r$ to fall together in one category or the other was due directly to the frequency or infrequency of one or both. But this fact is not demonstrable from existing data.

On the other hand the $n$ is by definition ${ }^{1}$ dental, and the $m$ labial. Though the exact position of articulation may vary from language to language, and likewise their intensity, yet the nasals do not admit so widely varied pronunciations as the liquids. Accordingly, in the table above, we find with few exceptions that $m$ hovers around 2.75 per

1 Because of the confused orthography of many languages in this very point, the column of dentals given above in some cases includes palatal and guttural nasals. But their percentage is so slight that in such rough statistics they are virtually imperceptible. 
cent and $n$ around 6.5 per cent. To this statement the French and German $n$ and the Sanskrit and Latin $m$ offer exceptions.

(38) Why now should the French $n$ be so infrequent? The French nasalized vowels (an, ein, on, un, oin, and the rest) constitute, according to Dujardin, whose results are given above, 8.3I per cent of all spoken French sounds. Since these nasalized vowels in virtually all cases developed from dental nasals, we may assume that before the historic French nasalization these dental nasals which were later nasalized would alone constitute roughly 8.3I per cent of French sounds. ${ }^{1}$ In addition to these, there were dental nasals roughly to the amount of 3.I9 per cent, which for one reason or another have maintained themselves until present times. Now the sum total of these two categories, II.5O per cent, representing roughly the percentage of dental nasals before the nasalization, is almost 50 per cent more than in most of the other languages. In other words, before the French nasalization, roughly every ninth sound was an $n$. Hence, it is not over-bold to say that, owing to this very frequency, the French dental in many places weakened, losing its individual form to merge with the adjacent vowel. And if at one time nasals weakened, having passed the upper threshold, so now, after having receded below the lower, they compensate in the other direction, becoming more distinctly and intensely articulated to compensate for their loss in frequency. As they are rarer in occurrence than the English $n$, so too, as is most apparent to anyone hearing French, they are more intensely pronounced.

German offers a similar state of affairs. With $n$ at 10.4 per cent, it is not at all surprising that dialectally the $-n$ is beginning to vanish, as in "Sie ham gesunge" for "Sie haben gesungen," or "Ich fahre mit de achte" for "Ich fahre mit der achten (Strassenbahn)." One may say that such dropping of $-n$ occurs only in popular speech. True, but it is in popular speech that sound-changes first manifest themselves; though in regard to the dropping of $-n, \mathrm{I}$ have heard many a sedate German consistently though unconciously do it.

1 It is not necessary to point out that by adding these nasals in the nasalized vowels as extra sounds one increases the sum total of French sounds, thereby reducing all individual percentages. Consequently, the percentage of nasals which later become nasalized vowels, would be a smaller part of the whole language at that early time, than the present resulting nasalized vowels of present French. This qualification is to be understood, here as elsewhere, by the word "approximately." 
Latin, with its superior number of $m$ 's offers a convincing explanation of the mutation of final Indo-European $m$. Without troubling the reader's patience with a complete enumeration of all the languages where the final $m$ became $n$ or was lost, I do point out that it was consistently preserved in Latin: Latin equum, "horse," goes back to Indo-European *eknom. The question now arises, which is the more difficult to pronounce and which more conspicuous to the ear, $n$ or $m$ ? If we might for the nonce assume the principle of frequency, we could at once say that the $n$ is less conspicuous because it is more frequent. But even without assuming the principle of frequency we can demonstrate the same truth. To make the question more concrete, when the Greek accusative singular * $i \pi \pi o \mu$ became $i \pi \pi o \nu$, did the $-\mu$ weaken into $-\nu$ or strengthen into $-\nu$ ? It must have weakened into $-\nu$, since the Greek Auslautgesetze (loss of final consonants) show a thorough-going tendency toward weakening and not strengthening. Similarly, did Germanic *quom weaken into Gothic wan or strengthen? Patently it must have weakened, for the weakening continued right through until the nasal was completely lost: Germanic accusative singular *stainam $>{ }^{*}$ stainan $>$ Runic staina, Gothic stain. It would be quite absurd to maintain that this change was not a consistent and continuous weakening until the ending was completely gone. As in these two cases, so elsewhere. ${ }^{1}$

When we observe that in practically all the Indo-European dialects final $m$ tended to weaken, we must assume that even in pro-ethnic Indo-European times $-m$ had begun to cross its upper threshold. After the break-up into dialects, this tendency so far continued that in most languages it actually did cross the threshold, and, according to our principle of frequency, weakened. Now Latin, maintaining its $-m$ down to historical times, shows a percentage not only definitely greater than in other ancient languages, ${ }^{2}$ but likewise greater than is to be found in the ten modern languages examined, including the Hungarian. But at last it too obeyed the principle of frequency, and weakening in the

1 For example, in Middle English, as has been ably shown by Prof. Samuel Moore, "Earliest Morphological Changes in Middle English," Language, IV (I928), $240 \mathrm{ff}$.

2 It is to be remembered that the maintenance of final $m$ was largely merely orthographic. 
Auslaut finally vanished. By consulting paragraph 33 above, we find that 327 of the $582 \mathrm{~m}$ 's in 10,000 letters of Ciceronian Latin stood absolutely final. When these disappeared, as they had begun to do before the time of Plautus, the percentage fell from 5.82 to 2.55 , bringing it within the thresholds between which it could maintain itself. So too in Sanskrit, the $m$ had crossed the upper threshold, and accordingly tended to weaken, passing into anusvara before a following sibilant.

From these examples it seems to be very clear that the nasals too obey the principle of frequency. For it cannot be by chance that $n$, which is less conspicuous and more easily pronounceable than $m$, is in thirteen different languages likewise more frequent. Nor can it be by chance that, whenever $m$ or $n$ does vary roughly from the mean percentage, a weakening has either just taken place, or is about to set in. Perhaps the reader will retort: "Of course final $m$ weakened, but that was due to a general weakening of inflectional endings." Indeed, so it might well be argued about many instances, with apparent reason. But let us not forget that the Greek accusative singular $i \pi \pi o \nu$ is still as inflected as before; the change from ${ }^{*} i \pi \pi o \mu$ to $i \pi \pi o \nu$ did not make the word less inflected, though it did make the ending less conspicuous. So, too, with the Runic accusative singular staina.

(39) Though the cause of many other sound-changes is apparent from these data, such as the instability of Indo-European $s$, which, doubtless because of its frequency in inflectional endings and suffixes, must have crossed its upper threshold in late Indo-European times and, accordingly, in Sanskrit, Greek, Latin, Germanic, had either disappeared in part, or showed a decided tendency toward assimilation, still I prefer to restrict myself for the present to those soundchanges which were thorough and far-sweeping, and which have in particular caused endless speculation on the whole subject of linguistic mutation.

Let us then turn to the first great sound-shift in Germanic, formulated in Grimm's Law.

(40) According to Grimm's Law the Indo-European tenues and tenues aspiratae shifted in all but a few positions to their corresponding spirants:

$$
\begin{aligned}
& t, t h>p \\
& p, p h>f \\
& k, k h>\chi
\end{aligned}
$$


The mediae shifted in all positions to their respective tenues:

$$
\begin{aligned}
& d>t \\
& b>p \\
& g>k
\end{aligned}
$$

The mediae aspiratae shifted, depending upon their position, either to their mediae or to their voiced spirants:

$$
\begin{aligned}
& d h>d, d \\
& b h>b, b \\
& g h>g, 3
\end{aligned}
$$

Though this is a rough statement of Grimm's Law, yet it is adequate for our present purpose.

Why did these changes take place? The causes suggested by theories hitherto advanced range from malformation of the mouths of Germanic children to climatic conditions as on the plateaus of Armenia, including possibilities of Sprachmischung and the like. But the present thesis maintains that the changes enumerated under Grimm's Law, like other sound-changes, were due to conditions within the language itself. For, if we look at the three changes that took place, we are at once struck by their similarity: in all cases the consonants became less conspicuous. The tenues lost their increment of explosion, the mediae their increment of voice, the mediae aspiratae either their increment of aspiration, or else both aspiration and explosion. In fact, the IndoEuropean explosives were made less conspicuous in Germanic. This point cannot be disputed.

But if the principle of frequency be true, it follows that all the explosives in Germanic had become too frequent; that is, that the explosives as a whole occurred so often that there was no longer the need of pronouncing them as conspicuously as heretofore. It is perhaps fitting to point out further that the whole shift could and did take place without leading to any confusion of words and their meanings, because of its complete substitution of new sounds for the old. But since this change took place before the writing of Germanic dialects, it is unfortunately impossible for us to examine the frequency of the explosives either before, during, or immediately after the sound-shifts. What, then, can we examine? 
The first pieces of prose literature of any extent even remotely approaching popular speech are separated by almost a thousand years from the period when the changes described by Grimm's Law took place. During those ten centuries new and obliterating changes occurred: many consonants were either changed (Verner's Law) or completely lost; the Romanized or Christianized peoples were using a vocabulary vastly different from that of the heathen Germans. In the face of such obstacles any examination of the cause of Grimm's Law in the light of our principle of frequency seems at first sight like quixotic temerity.

Yet let us approach the problem as follows. We can now argue from the principle of frequency that, if a given sound-change had not taken place, the sound, all other things remaining equal, would be found above the upper or below the lower threshold of frequency, as the case might be. So too with Germanic. If we can show that, in some Germanic language, $b$ 's for example, in addition to such $t$ 's as remained unshifted in Germanic (e.g., st), greatly surpass in their frequency the upper threshold of $t$ as demarcated by the thirteen languages already examined, we may safely assume that the Indo-European $t$ tended to cross the upper threshold in primitive Germanic times. This is especially true since $b$ has subsequently passed, in certain instances, notably under Verner's Law, into an entirely different category.

No Germanic dialect preserved its consonants so well as Old English, and few possess such old monuments. Yet here again we meet the old problem of just what is sufficiently popular in style to justify examination. We cannot take poetry, for that is obviously artificial; we cannot take the chronicle, or other historical or descriptive pieces, for these, written largely in the preterite, would, through the action of Verner's Law, give an unduly false picture. After discussion with friends I decided upon King Alfred's translation of Boethius, selecting those passages which were in direct discourse. When one considers the artificial and philosophical nature of the De Consolatione, and the fact that it is a translation of a much older, and of a foreign work but imperfectly transmitted to us, one must admit at the outset that our chances of demonstrating our principle are but slight. Yet here as elsewhere things may not turn out so badly as we fear, for, if the Germanic sound-shift was really due to frequency, unmistakable traces 
of the law of frequency must be still discernible, even a thousand years later.

Taking Mr. Walter John Sedgefield's King Alfred's Old English Version of Boethius de Consolatione Philosophiae, ${ }^{1}$ I selected portions of direct discourse scattered throughout the book in passages long enough to avoid the appearance of making a prejudiced selection, yet numerous enough for variety of language. They are pages $\mathrm{I}_{3}, 59,87$, 88, 106, 107, 137, 138, and page 1o through beréafap, ponne he in line 7 . The variations in percentages from page to page were only slight.

By considering diphthongs as individual units as in Greek and Latin, but counting geminatae (except as specified below) as double sounds, since they originally represented two distinct sounds in proethnic Germanic, I counted a total of $\mathrm{I}, 000$ sounds; in reckoning the number of individual explosives, however, I counted the geminatae as one sound, since the gemination undoubtedly occurred much later than the sound-shift described by Grimm's Law, as is attested by its absence from Old Norse and Gothic. For example, I counted $d d$ as two sounds for the total, since it almost invariably goes back to two pro-ethnic Germanic sounds; but I counted $d d$ as one sound in the $d$-column, since only one of these sounds was an original $d h$. To be explicit, gemination frequently arose from a following $i$-consonant. Thus we set any possiblity of error against our thesis. Moreover, in making my percentages I included the tenues of $s k$, st, and $s p$ among their respective spirants, $h, b$, and $f$, since their presence added to the frequency of the tenues before the change, even if the $k, t$, and $p$ when combined with $s$, and $t$ when preceded by $k$ or $p$, did not themselves shift. Naturally the percentages do not represent the frequency of individual sounds in Boethius, but rather their calculated frequency, as far as we can detemine it, if they had remained unshifted. The sign $t$ represents baet; 7 is and. As I make no use of the vowels in this part of my paper, I omit their differentiation, which in Old English would be especially speculative.

1 Oxford: Clarendon Press, 1899. 


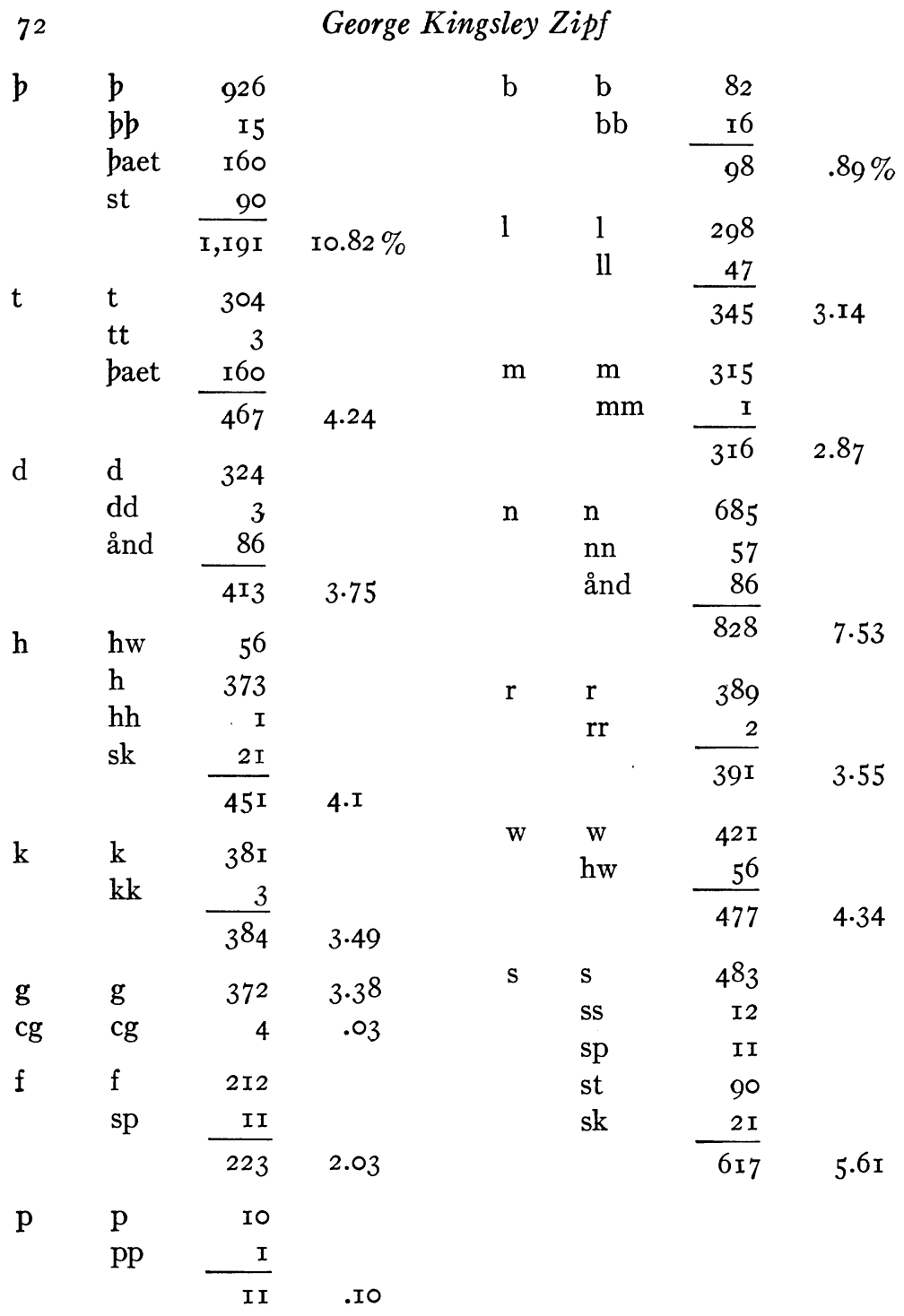




\section{Geminatae}

\begin{tabular}{|c|c|c|c|c|}
\hline ss & 12 & pp & I & \\
\hline rr & 2 & cg & 4 & \\
\hline $\mathrm{nn}$ & 57 & $\mathrm{kk}$ & 3 & \\
\hline $\mathrm{mm}$ & $\mathbf{I}$ & $\mathrm{hh}$ & I & \\
\hline 11 & 47 & & $\overline{I 65}$ & I. $49 \%$ \\
\hline dd & $\begin{array}{l}3 \\
3\end{array}$ & Total & 6,753 & 6 r. $36 \%$ \\
\hline $\mathrm{bb}$ & $\begin{array}{r}3 \\
15\end{array}$ & Vowels & 4,247 & 38.60 \\
\hline $\mathrm{bb}$ & r6 & Total Sounds & II, 000 & $99.96 \%$ \\
\hline
\end{tabular}

Using the thresholds of frequency as approximately deduced in the table of $\S 34$ as standards for comparison, let us now examine the Old English frequencies sound by sound. $b$, with a frequency of 10.82 per cent, had it remained in toto an unshifted $t$, would have been almost $5 \circ$ per cent above the upper threshold of $t$. The fact that it has crept into the first person plural present of the verbs subsequent to the sound-shift is at least partially offset by the action of Verner's Law, even considerably later than the operation of the sound-shift, which converted not a few occurrences of the new Germanic $b$ into a voiced spirant. With this sound at least there can be no doubt that in early Germanic times it was very near to the upper threshold. If it had not shifted then, it never could have continued as $t$ with the unparalleled frequency of II per cent.

$t$, at 4.24 per cent, is colorless. It is too low for a $t$, and yet almost too frequent for a $d$. If this at all represents the early Germanic condition of things, we must say that the Indo-European $d$ at 4.24 per cent had approached the upper threshold so closely that it must have been spoken very lenis.

$d$ at 3.75 per cent is just right for $d$, and consequently too frequent for $d h$ from which it became less conspicuous, were it not that a certain part of these $d$ 's arose under the shift described by Verner's Law.

$h$ at 4 .I per cent, had it remained an unshifted $k$, would certainly be at the upper threshold and ready to become less conspicuous. For we must remember that the frequency of this sound was diminished by the operation of well-known sound-shifts (Verner's and Siever's Laws). 
But what is more important is the unconcerned fashion in which the Anglo-Saxons even at that early date dropped their $h$ 's. Two sound-laws alone in Old English illustrate how many $h$ 's were lost before that date of the language at which we are examining it. A medial $h$, when preceded by $r$ or $l$ and followed by an inflectional vowel, was lost - as nom. mearh, gen. mēares, "horse." Further, every intervocalic $h$ disappears, as O. E. slēan, "strike," but Gothic slahan; O. E. èa, "water," Gothic ahsa; O. E. sēon, "see," Gothic saîhan; and many other exceedingly common words, evidence which seems to imply that 4.I per cent is a very conservative estimate for Germanic $k$. Hence, it is not overbold to assume, as in the case of $b$, that it too had crossed the upper threshold and become less conspicuous.

$k$ at 3.49 per cent would be well above the upper threshold had it remained $g$, for which the highest frequency is the modern Swedish 2.5 per cent. Therefore, we may safely say that Indo-European $g$ became Germanic $k$ because the $g$ had crossed the upper threshold.

$g$ at 3.38 per cent is much too frequent for $g$, not to mention $g h$, from which it developed. But here we may conclude nothing, first, because part of these g's may have arisen under Verner's Law, while some of them also represent consonantal $i$ written as $g$. Yet that the Germanic $g$ was already too frequent in Old English, and hence the Indo-European $g h$ too frequent in primitive Germanic, is attested by the tendency of Old English $g$ to shift into a spirant, if not totally to disappear: wagn, "wagon," became wān, for example. The $g$ in giefan, "give," Gothic giban, scholars are agreed was pronounced a spirant. Similar examples might be multiplied almost indefinitely.

$f$ at 2.03 per cent, even after we allow for the action of Verner's Law, was not frequent enough to justify its weakening. To say that Boethius did not write about friend, foe, fish, field, fee, fear, fight, fright, and so on, is after all no argument. This fact may be the explanation of its rareness, since these words undoubtedly made up a considerable part of the normal vocabulary of the early German. Yet the moment we begin postulating what the primitive Germans talked about, we are in a quandary.

$p$ at one tenth of one per cent is indeed well below the lower threshold for $b$, and certainly had no cause to shift. That the figure is more or less correct is attested by the rareness of the Indo-European $b$ from 
which it shifted. Germanic $p$, like $t$, which was at the lower threshold, must then have had a very fortis pronunciation - an important factor when we turn to the Old High German sound-shift.

$b$ at 89 per cent does not seem to have had good cause to change, though it must be borne in mind that I.-Eu. $b h$ is written in O. E. not only as $b$ but also as $f$, a fact which, instead of helping us, simply further vitiates the significance of the percentage for $f$ (from I.-Eu. $p$ ).

$m$ at 2.87 per cent and $n$ at 7.53 per cent offer startling correspondences to the nasals of modern languages, the more significant because to a large extent they are not cognate.

Now of our nine explosives, measured almost a thousand years after the historic sound-shift, $b, h, k$, and $g$ with all certainty, and perhaps $d$, appear to have crossed the upper threshold of frequency and accordingly were weakened. If the reader retorts that they have these high percentages simply because subsequent to the sound-shift many final vowels have dropped, thereby reducing the total number of sounds, I reply likewise that consonants dropped finally, as well as in the reduplicating syllable initially. Perhaps the very falling together of the Indo-European aspects into the Germanic preterite, which included what was originally the reduplicated perfect, together with the new dental preterites, was the ultimate cause of the sudden ascendency in frequency of the explosives.

But, to return to our main question, why did Indo-European $p, d$, $b$, and $b h$ shift to Germanic $f, t, p, b$ ? Were they simply dragged along with the dentals and gutturals, in a general phonetic drift, without really having any right to weaken their form? I believe that they were. When Indo-European $t$ and $k$ shifted because of their vast frequency, $p$, which was likewise a tenuis, followed analogically, since for the conspicuousness which it lost in explosion it could compensate in duration. This then left no large number of tenues. $g$ was very frequent and shifted; $d$, which was at the upper threshold, shifted presumably from a lenis media to a fortis tenuis; and $b$, again, by analogy followed suit. Both $g h$ and $d h$ were either too frequent, or else had so nearly approached the upper threshold, that they shifted, since after all no mediae now stood in their way.

But, the reader may reply, is not the shifting of $b$ and $d$ to $p$ and $t$ really a disproof of the theory, since, though they were infrequent, 
yet they became less conspicuous? No, this shifting rather proves the thesis, for these were the very sounds which later returned to greater conspicuousness in Old High German and brought about the Old High German sound-shift. It was because such a large part of Grimm's Law was due to the operation of analogy, together with new conditions resulting from the action of Verner's Law, that the various dialects tried to compensate for the unequal balance, and adopting different measures, split farther apart. Let us now concentrate our attention on Old High German.

(4I) In respect to the figures above we must assume, if our principle of frequency be correct, that both Germanic $p$ and $t$, which were shifted analogically despite their comparative infrequency, would tend in turn to become more conspicuous - other things being equal - after the influence of analogy was exhausted and the new sounds were no longer felt as weakenings of the old. To be sure, other things were not equal in Germanic, and least of all in Old English. The Indo-European tenues that followed spirants remained unshifted, thereby helping to strengthen the new tenues. Old English itself, for example, by weakening of endings, by syncope of vowels, by loss of nasals, and of $h, g$, w (in certain circumstances), must have so far diminished the number of vowels and other consonants, that the percentages of the tenues rose correspondingly. In this revision the gradual borrowings from Norman French undoubtedly helped. For, say what one will, the tenues of modern English are safely within their thresholds. And similar changes must have taken place in North Germanic. Old High German helped its $b$ by hardening the voiced labial spirants.

But in Old High German the endings did not weaken so early or so completely, and the rareness of $t$ and $p$, and the excessive frequency of $g$ and $d$ must have been perceptible. It would not be surprising, then, if $t$ and $p$ tended to strengthen, $d$ and $g$ to weaken. How great a change was to be made would depend here, as in pro-ethnic Germanic, partly upon analogy. Perhaps the strengthening of $t$ and $p$ to affricatae might in some places drag along $k$ by analogy, though such a change would not be so thorough and permanent as the others. Perhaps the weakening of $d$ and $g$ might again influence $b$, especially since it had been made more frequent by the hardening in many places of the voiced labial spirant. 
Hence, we may expect to find in German that which we do find regular shifting of some consonants over huge territories, and great confusion in analogous shifting of other consonants in narrower localities. At this point of the inquiry we are somewhat better placed than in discussing the Germanic sound-shift; for in East Franconian, the dialect of the Tatian translation, one of the sound-shifts characteristic of Old High German ( $b$ to $d$ ) was still in progress. This shift of $b$ to $d$ we might well now consider. Since the sound $b$ was taking on voice in all positions and also passing into the media (explosive), we must assume, according to the principle of frequency, that $b$ had lost greatly in frequency and was beginning to approach the upper threshold of $d$.

Taking Eduard Sievers's Tatian (Paderborn, I892), I counted the following: Tatian II (Luke i, 5-25), III (Luke i, 26-56), IV (Luke i, 57-80), V (Luke ii, I-7), VI (Luke ii, 8-20), VII (Luke ii, 2I-39), XII (Luke ii, 40-52), IX (Matt. ii, I3-I5), X (Matt. ii, I6, through thes after ther). For this count of ro,000 sounds, I treated each affricate and double spirant as single sounds, all other double consonants except $u u$ as two sounds. Without interpolating I took the letters in the form in which they occurred in the text, though without such an interpolation it is exceedingly difficult in the case of $h$ to say what percentage of $h$ goes back to Germanic, and what to Indo-European $k$.

\section{Dentals}

\begin{tabular}{|c|c|c|c|c|c|}
\hline $\mathrm{t}$ & $79^{2}$ & $7.92 \%$ & \multirow{2}{*}{$\begin{array}{l}\mathrm{k} \\
\mathrm{qu}\end{array}$} & \multirow{2}{*}{$\begin{array}{l}63 \\
49 \\
\end{array}$} & \multirow{2}{*}{$\begin{array}{l}.63 \% \\
.49 \\
\end{array}$} \\
\hline$z, z z$ & I75 & I. 75 & & & \\
\hline th & 330 & & & I 49 & I. 49 \\
\hline d & $I_{4} 6$ & & $\mathrm{~g}$ & $35^{2}$ & $3 \cdot 5^{2}$ \\
\hline$\gamma$ & 8 & & & & \\
\hline New d & 484 & 4.84 & & ials & \\
\hline & Gutt & & b & I 45 & I. $45 \%$ \\
\hline h & 302 & $3.02 \%$ & $\begin{array}{l}\text { pp } \\
\mathrm{bb}\end{array}$ & $\begin{array}{l}3 \\
2\end{array}$ & \\
\hline h & I 8 & . 18 & & $\frac{0}{6}$ & \\
\hline & I9 & .I9 & & 6 & .06 \\
\hline
\end{tabular}




\begin{tabular}{|c|c|c|c|c|c|}
\hline 78 & \multicolumn{4}{|c|}{ George Kingsley Zipf } & \multirow[b]{2}{*}{$\begin{array}{l}.35 \% \\
.28\end{array}$} \\
\hline f & I72 & I. $72 \%$ & $\begin{array}{l}\mathrm{nn} \\
\mathrm{n} \text { (gutt.) }\end{array}$ & $\begin{array}{l}35 \\
28\end{array}$ & \\
\hline $\mathrm{ff}$ & 3 & .03 & r & $5^{69}$ & 5.69 \\
\hline \multirow{4}{*}{$\begin{array}{l}\mathrm{v} \\
\mathrm{ph}\end{array}$} & I3 &. $\mathrm{I} 3$ & \multirow[t]{2}{*}{$\mathrm{rr}$} & \multirow[t]{2}{*}{4} & \multirow[t]{2}{*}{.04} \\
\hline & 9 & .09 & & & \\
\hline & \multirow{2}{*}{25} & \multirow{2}{*}{.25} & $\mathrm{~s}$ & $5^{22}$ & 5.22 \\
\hline & & & SS & 9 & .09 \\
\hline \multirow[t]{2}{*}{$\mathrm{p}$} & 20 & \multirow[t]{2}{*}{.20} & $\mathrm{w}$ & 210 & 2.10 \\
\hline & \multirow{2}{*}{208} & & $\mathrm{j}$ & 26 & .26 \\
\hline 1 & & 2.08 & $\mathrm{u}$ & 9 & .09 \\
\hline $\begin{array}{l}11 \\
\mathrm{~m}\end{array}$ & $\begin{array}{r}29 \\
289\end{array}$ & $\begin{array}{r}.29 \\
2.89\end{array}$ & $\operatorname{sch}$ & 2 & .02 \\
\hline $\mathrm{mm}$ & 4 & .04 & \multirow{2}{*}{\multicolumn{2}{|c|}{ Total consonants 5,639}} & \multirow[t]{2}{*}{$56.39 \%$} \\
\hline $\mathrm{n}$ & I, O73 & 10.73 & & & \\
\hline
\end{tabular}

Because of the varying and inexact orthography of Tatian, this table is not so helpful as we could wish. But the dentals, none the less, give a definite clue to the nature of things, and may be considered one of the decisive proofs of our theory. The Germanic $b$ in East Franconian had dropped from roughly to per cent to 4.84 , which is certainly below the lower threshold of frequency. Hence, there was every good reason for its taking on voice and becoming more conspicuous. If 5.02 per cent, which is the percentage of modern Spanish $d$, at all represents the threshold where $d$ becomes a voiced spirant, it is not surprising that the Germanic $b$, at 4.84 per cent, having crossed this threshold, slowly grew more conspicuous until it became $d$. Incidentally, the $b$ in Modern English has become much less frequent, and has in most positions taken on voice. If Godfrey Dewey's percentage of 3.4 per cent for English th may be taken roughly to represent American colloquial speech, that fact would account for the occasional, vulgar pronunciation "dese," "dose," "wid," for these, those, with. $t$ in East Franconian at 7.92 per cent is another definite proof of our theory. For we must here flatly assume that, if Germanic $d$ had not weakened in East Franconian, it would have had this frequency of 7.92 per cent, which is certainly well above the upper threshold of that sound. To be sure, some of these were actual Germanic $t$ 's protected by a spirant from shifting earlier to the affricate. But even so they were not so 
numerous as to prevent us from saying that the Germanic $d$ in Old High German, at such a percentage, had become too frequent. ${ }^{1}$

The affricates $z$ and $z z$, with only I.75 per cent, are a further proof. Here $t$, without any question, must have crossed the lower threshold, since in none of the thirteen languages examined do we find anywhere nearly so few $t$ 's, even should we add to $\mathrm{I} .75$ per cent a considerable sum representing the $t$ protected by a spirant which accordingly remained unshifted. In this change, moreover, we have a happy parallel in Greek. Greek $\theta$ at 1.36 per cent later shifted to the affricate $t b$, then to $b p$, and finally to $b$ (as in modern Greek), illustrating a similar strengthening of sound under diminishing frequency. So too, incidentally, the other two Greek aspirates shifted in a corresponding fashion and from the same cause.

Why the Franconian dentals became partly so rare, partly so frequent, it is not difficult to discover. First of all, the Germanic $t$ being rare, had every reason to shift to the affricate. And that East Franconian had more $d$ 's and decidedly less frequent $b$ 's than Old English is explicable at once from their differing verbal systems, which go back to two different Indo-European categories.

O. E. strong verbs, with few exceptions, fell together in the stemaccented class of thematic verbs (Sanskrit tudati), and hence show $b$ wherever the ending originally contained a $t$. But Old High German adopted the general class of root-accented thematic verbs (Sanskrit bhâvati), and consequently, according to Verner's Law, had in similar positions the voiced spirant which, long before the Old High German sound-shift, had hardened to $d$. By this simple difference, which affected the third singular and plural, and the second plural, the most frequently occurring forms, Old High German gained as heavily in $d$ as it lost in $b$.

All the labials are uncertain because of the orthography. $b$, with I.45 per cent, which had been attained by shifting the corresponding voiced spirant to the media, had undoubtedly crept back within the threshold. Perhaps there is some connection of cause and effect here.

1 The fact that some Germanic d's appear orthographically unshifted in Tatian (for example, dohter), only strengthens our contention, since in counting them as $d$ instead of $t$ we make the Germanic $b$ appear seemingly more frequent, the Germanic $d$ less frequent, a condition which is exactly contrary to our thesis. 
$p$, despite the confusion of its several orthographic forms, undoubtedly strengthened into its affricate because of rareness, just as we forecasted. $g$, at $3.5^{2}$ per cent, on the other hand, was well above its upper threshold. At any rate it is not at all surprising that in some High German dialects this over-frequent $g$ actually weakened into a $k$ (Tatian's geban, Bavarian kepan).

$k$ and its affricate, despite the uncertain orthography, seem from their percentages to have been too rare. Germanic $k$ was near enough at least to the lower threshold to have been in part shifted to the affricate, after the analogy of the excessively rare $t$ and $p$.

Reviewing these statements, we may, therefore, say just what we postulated before beginning the actual examination: $t$ and $p$, being rare, were shifted in all positions to affricates; $k$ followed analogically, at least in part, though not so completely as the other two tenues. The same view is applicable to Bavarian and Alemannic, mutatis mutandis. Alemannic, for example, also shifted its $p$ and $t$, and $k$ followed by analogy. It, further, shifted its $d$; but here $b$ and $g$, which were already near the upper threshold, followed by analogy. Where Tatian has geban, the other two dialects had keban and kepan. Though this later change was not so complete as the change of $d$ to $t$, yet, even after the new $k$ and $p$ slowly returned to the voiced mediae in most positions, they must have had the lenis pronunciation of a sound near the upper threshold to explain the peculiarities of Notker's Anlautgesetz. In this, the new $d$, arising from Germanic $b$, often shared, as the modern word tausend (English thousand) clearly shows. And, as pointed out above $(\$ 35)$, the over-frequency of the mediae caused such a lenis pronunciation that in some parts of modern Germany the inhabitants cannot and do not distinguish them from the tenues.

Despite the comparative inexactitude of our measurements of Old English and East Franconian, we cannot fail to see that the many sound-changes which have occurred and are still occurring in the Germanic dialects are not arbitrary and irrational shifts. So often does a change in conspicuousness concur with a change in frequency, that a functional correlation cannot be denied. One might, of course, make counts of all the various High German dialects. But to what end? The results would show only that which we have already induced from the Tatian statistics. 
(42) In conclusion, we may examine our present problem both $a$ priori and $a$ posteriori. The moment one admits $a$ priori that, if every word should begin with a $d$, the $d$ would weaken, that moment one admits the entire thesis. For, if the $d$ should weaken in those circumstances, since it is known, on the other hand, that some words in a language can and do begin with a $d$, it follows that there is at some point a threshold where the $d$ will not weaken. If it is said that the $d$ would possibly weaken into a $t$, one admits thereby that $t$ possesses a higher threshold of frequency than $d$. So also $a$ priori, with regard to the lower threshold, one must admit a similar state of affairs. And as we argue of the $d$, so we may argue about every other spoken sound.

$A$ posteriori the case is just as strong. The statistics are approximate only, though not altogether false; they are not perfect; yet they do show one thing which cannot be disputed - a preponderant frequency of the tenues over the mediae in languages spoken by hundreds of millions of people, yet in languages separated from each other often by thousands of miles and years. To say that this high frequency comes about by chance is a thoughtless assertion. According to the laws of probability, we should expect one sound to be roughly as frequent as another, since language is but a permutation of the same, helped out by conventions of accent and syntax. To say that sounds occur at a random frequency is to say what is contrary to fact. For the constant ratio of tenues to mediae is nothing less than astounding; none of us has ever dreamed that such a law was the basis of phonetic change. The tendency of given consonants to hover about a mean which remains constant in each language may, therefore, be regarded as one of the striking phenomena of human behavior in language.

To be sure, one may say that there are a few cases in which this ratio is not true. But these few cases are, indeed, very few, and serve to illustrate further the efficacy of our law, since a compensatory weakening is actually taking place in these very instances. What is more natural than to find among ten modern languages a few which are preparing to undergo changes?

The truly regrettable thing is that a principle which is a priori so seductive must depend upon somewhat imperfect statistics for demonstration. Nowhere do we have entirely satisfactory conditions. In East Franconian, perhaps the most untrustworthy analysis of all, 
not only are we hampered by varying orthography imperfectly transmitted, but the text itself is a translation of a translation. This we must use instead of an accurate phonetic examination of colloquial speech. Surely, the principle of frequency is valid, if by means of it, in face of such difficulties, we can demonstrate anything at all.

The great and undeniable proof of our theory is this - that after leaving the Indo-European parent thousands of years ago, and after having spent those thousands of years in changing and obliterating the old consonants, nine descendants of that language have still kept this ratio of tenues to mediae, even though by now their tenues and mediae go back historically to the most various and dissimilar sources. As man, developing culturally and changing in environment, uses one series of concepts more frequently than others, and consequently some words more frequently than the rest, slowly but steadily changing here as elsewhere his old methods of life, still he remains lazy, and even in his speech will not pronounce a single sound more forcibly than is necessary to make his hearer understand him. And nothing so obviates the necessity for clear, careful, and exact pronunciation of a sound as the comparative frequency of that sound; and nothing so compels a clear and careful articulation of a sound as the tendency of that sound to become rare.

\section{B. Vowels}

(43) Vowel-changes fall roughly into two great categories: the independent and the dependent. The dependent changes in turn can be again divided into two categories: the environmental and the accentual. By independent vowel-changes are meant changes in the color or quantity of a vowel, which take place without in any way being influenced by the position of the accent or the character of the surrounding sounds. Every spoken language offers in its history many such examples: Old English hüs becoming house, Old High German min becoming mein, Old Latin douco becoming düco. We might continue these examples indefinitely.

Dependent vowel-changes, on the other hand, are such shifts as are occasioned directly by the position of the accent, or by the character of surrounding sounds. Where a change is due to the influence of neighboring sounds, the change may be called environmental; where due to the position of the accent, accentual. Nasalization, umlaut, 
"compensatory" lengthening, are all environmental vowel-changes. Moreover, such a change as early Latin *suesor to soror, where the $u$ rounded the following $e$ to $o$, belongs to this category. Such dependent changes of vowels, however, as are brought about by conditions of accent, as for example ${ }^{*}$ còn + fácio $>{ }^{*}$ cónfacio $>$ cónficio $>$ confício, differ enough from the environmental to merit consideration as a separate category.

(44) We need not delay long over a consideration of vowel-shifts dependent upon the position of accent. Any reduction or syncope of a vowel, which is caused directly by the position of the accent, has as its ultimate cause that force which determines the location of its accent. From Part I of this paper we have seen that the position of the accent of a word is directly dependent upon the relative frequency of that word and its component parts in the stream of spoken language. Therefore, the reduction or syncope of any vowel effected by a shift of accent is due directly to the comparative frequency with which the word, its stem, or its various prefixes, formative suffixes, and endings occur in the stream of speech. Examples are: English master-mister (cf. page 3); Latin *oónfacio, confício (cf. § 10); Sanskrit dvéșmi, dvișmas $\left(\S_{4}\right)$. If the reader accepts the results of Part I, he must perforce accept the present deductions from it.

It may not be amiss to point out here that such a theory as the present is extremely far-reaching in Indo-European philology, for nothing is more characteristic of the Indo-European language than ablaut, which all Indo-European vowels exhibit without exception. If it be true, as no one can seriously doubt, that ablaut was the result of the system of Indo-European accentuation, we have now pushed the investigation of the problem one step further. The phenomenon of ablaut was detected long ago; its extent and its dependence on accent have been thoroughly investigated in recent years. The present thesis strives to make accent, which is the determinant of ablaut, itself a function of relative frequency. If this be true, there then remains for us to deduce from the Indo-European accent the actual frequency of occurence of various concepts in their relationship to one another in Indo-European times; and hence the relative intensity of the concepts, ${ }^{1}$ which, if we are able to determine it, should throw light on the

1 I hope, in a future paper, to investigate the problem of relative frequency and intensity in concepts. 
condition of Indo-European culture and the degree of its civilization shortly before the break-up into dialects. For, if this argument be valid, the character of the pro-ethnic civilization ultimately determined the frequency of use of its concepts, the frequency of use of the concepts determined the actual accent of the words and their component parts, which in turn is finally reflected in the accentual vowel-changes known to us as ablaut.

But the problem of dependent accentual vowel-changes is not so easily despatched. The question still remains why some unaccented vowels are not reduced. An example is the $\bar{a}$ in Latin in the originally unaccented syllable of exāctus. ${ }^{1}$ Why was not this $\bar{a}$ reduced? Is it ever possible for an $\bar{a}$ to be reduced when unaccented? Of course it is, for unaccented $\bar{a}$ in Indo-European was invariably reduced, becoming $\partial$ (schwa). There is nothing in the nature of $\bar{a}$ which, when it is unaccented, precludes reduction.

If the Latin $\bar{a}$ had been reduced, would it have developed homonyms that might have led to confusion? Obviously not. If it had become short $\breve{a}$, or schwa, either of which would be a logical step, there would still have been no other short $\breve{a}$ or schwa in an unaccented syllable with which it might have been confused. For there is no proof of the existence of schwa in Latin at all after Indo-European schwa had become short $\breve{a}$; and an original short $\breve{a}$ in an unaccented syllable in Latin had become $i, e, u$ or had been syncopated. Here then is a definite disproof of the Trägheitsgesetz as the sole cause of phonetic change. A short vowel is, by the very nature of things, easier to pronounce than the corresponding long vowel; $\bar{a}$, as is shown by other languages, is capable of reduction in an unaccented syllable; unaccented $\bar{a}$ might have been shortened in every single instance in Latin without leading to the slightest confusion. If the Trägheitsgesetz, as stated, were the sole determinant of phonetic change, there is absolutely no excuse for its having failed to operate here.

There remains, in light of this argument, only one explanation. The sound $\bar{a}$ in Latin, even in the unaccented syllable, must have been so contributory to the inner Gestalt of the word and always felt as such

1 The fact that $\bar{a}$ appears in exäctus under special conditions ( $\breve{a g o:} \bar{a} c t u s$ ) does not affect the question; cf., for example, other long vowels originally unaccented and yet also unreduced, dèlätus, confëci, impürus, and many more. 
a distinguishing feature of each word in which it occurred, that, despite the reduction of other vowels under like conditions, it maintained itself unchanged. If a consonant had so behaved, we should say in light of the results obtained in Part II, that it had been too conspicuous, and that the cause of its conspicuousness was its being near the lower threshold of frequency. So, too, we must argue of a vowel.

For vowels likewise have thresholds. If every word contained no other vowel than $a$, the $a$ as such would surely not serve to distinguish one word from another, but would exist merely as a glide between consonants or as an appended element. Only the consonants would be distinguishing marks. From this we can easily establish an upper threshold of frequency below which the vowel begins, with increasing rareness, to become more conspicuous and to constitute a distinguishing feature of every word in which it occurs. So too, conversely, if a vowel appeared but rarely. Let us suppose that a fairly rare word consisted of a single vowel which occurred nowhere else. Here the vowel, which alone constituted the word, would be pronounced very carefully and distinctly, - so distinctly in fact that it would undoubtedly be provided with an on-glide and off-glide to separate it from surrounding sounds, - and would itself be increased in duration until the hearer was sure of its identity. In such a way a short vowel might become long, if not actually diphthongal. From this we see that each vowel has likewise a lower threshold below which it gains in conspicuousness.

With these vowel-thresholds in mind, we can now easily see why $\bar{a}$, though unaccented, remained in such Latin words as exāctus. If the Indo-European vowels without exception underwent reduction in unaccented syllables, this means that all the vowels, as an entire category, had become so frequent as to cross the upper threshold, and consequently weakened wherever opportunity offered. A similar condition of things was postulated above for the Germanic consonants. In regard to accentual vowel-changes then, we must say that, though the accent of a syllable depends upon its relative frequency, the behavior of the vowel in that syllable, which has lost accent, depends upon the position of that vowel in respect to its own frequency-thresholds.

(45) Turning now to environmental sound-changes which are similar to the preceding in their dependence upon conditions in the remainder 
of the word, we are at once faced by a similar problem. We are told that the $u$ of *suesor rounded the following $e$ in Early Latin to soror. This is undoubtedly true. Similarly, Germanic *kueman became Old Norse koma, Early Old High German (Hl.) wëla became later wola. Yet that such a rounding is not universal, automatic, and invariable when $u$ precedes $e$ is shown by modern English sweat, which fulfils the same conditions as * suesor without undergoing the same changes. Since similar things under similar conditions should remain similar, there can be no complete explanation of any sound-change, which does not consider and explain all instances in which, under similar conditions, the results are different. Let us approach the problem by an examination of more obvious changes.

A simple example of environmental vowel-change is the historic French nasalization already treated in $\S 38$. There the change from simple to nasalized vowel was due to the following nasal, which, because of its excessive frequency, had weakened so far as to disappear, imparting its color to the preceding vowel. The phenomenon of "compensatory" lengthening is similar. The disappearing sound imparts, not its color, but its time or duration, to the neighboring vowel. The "compensated" sound disappears, presumably because of excessive frequency. Hence, we may say that some environmental vowel-changes are due to the weakening of a neighboring sound; that this weakening results from excessive frequency; and that the sound-change is in reality an assimilation of some attribute of the vanishing sound to the vowel.

But in *suesor $>$ soror it is the vowel that is really assimilated to the labial, as is clearly shown by Old Latin duenos $>$ duonos $>$ bonos, where the labial quality, far from being lost, is preserved to this day. Similar to this are all cases of umlaut in which the assimilation takes place at a distance, despite intervening and stable sounds, as proethnic Germanic *mati, *domian, *dohtri becoming Old English mete, $d \bar{a} m a n, d œ h t e r$. The reason for this change is undoubtedly the anticipation of the position of the following $i$ during the pronunciation of the preceding vowel - in other words, assimilation. But that such an anticipation is not invariable in human speech is illustrated by Modern English hotly, fondly, moody, German Honig, sonnig, where with apparently similar conditions there is no tendency toward umlaut. 
Here again we must view the assimilation as a weakening of the assimilated sound, and its weakening as resulting from excessive frequency. Any environmental sound-change in which the vowel is assimilated to another sound in the word is an example of this. Cases of vowel-contraction are corollary to the above, since the fusion is nothing but assimilation. That vowel which renounces its color for the sake of the other must be less intense, even if the color of the assimilated vowel by nature is less conspicuous than its neighbor's, unless the assimilated vowel is likewise at its upper threshold of frequency. Too many languages maintain successive vowels without contraction for us to assume that vowel-contraction depends on nothing but vowelcontiguity. In short, before any assimilation can take place, the assimilated element must first be weak, the assimilating element intense; and the weakness or intensity of a vowel, as of any other sound, depends solely upon its relative frequency in the stream of spoken language.

(46) Turning to the independent vowel-changes which take place per se regardless of their environment, we find not only a disproof of the Trägheitsgesetz as the sole determinant of vowel-change, - since here again vowels frequently become more conspicuous to the ear and more difficult to pronounce, - but likewise a disproof of any other theory, either of climatic influence or of organic changes in the mouth. If, to be concrete, gales in England, or a possible recession of the English jaw-bone shifted Anglo-Saxon $\bar{i}$ to $a i$, and $\bar{o}$ to $\bar{u}$, as in O. E. rizdan into ride (raidd) and $\mathrm{s} \bar{o} \bar{\delta}$ to sooth $(s \bar{u} p)$, because of their incompatibility with the new order of things, why then, after having in large measure successfully rid the language of $\bar{i}$ and $\bar{o}$, did speakers of English in turn select these very tabooed sounds as the goal for new shifts? Why did O. E. $r \bar{a} p$ become rope $\left(r o^{a} p\right)$, and etan become eat (it), if mouths or climate or temperamentality of babyhood, or linguistic substrata, or Sprachmischung had only a few generations before seen fit to delete $\bar{o}$ and $\bar{i}$ from the language? Perhaps here again the cause of change in a language lies in the language itself.

We have seen in the preceding paragraph that vowels, like consonants, must have thresholds. To be sure, we cannot demonstrate this fact, as in the case of consonants, first, because no exact investigation of the frequency of vowels in any spoken dialect has ever been made, and second, because vowels vary so greatly from dialect to dialect, 
as a result of the constant flux of language, that even if we did have percentages for all dialects, the dissimilarity of the vowels would prevent comparison. Consonants vary less and are more stable. Or again, we may say that a long vowel is more conspicuous than its corresponding short vowel; and indeed by glancing at the vowels given in the tables in Part II (for example, for Sanskrit), we find that the long vowels tend to be accordingly less frequent. The diphthongs, which are even more conspicuous, are even less frequent. This is a partial proof of the existence of thresholds among vowels of the same color. Though not in detail demonstrable, the case must be that vowels of the same quantity but different color differ among themselves in point of conspicuousness; for example, $e$ from $o$ and $u$. And for each vowel that is felt as a distinct sound, there must be an upper and a lower threshold of frequency, whose absolute percentages, however, will depend upon the total number of sounds at the disposal of the language.

Now, if any vowel crosses its lower threshold, it should become more intense, and surrounding sounds might well be assimilated to it. But in ridan > ride (raid) no assimilation can take place; and in dozens of other words the $\bar{i}$, if it must become more conspicuous, will have to add an increment of conspicuousness to itself without any consideration for the nature of surrounding sounds. Correspondingly, if a vowel should cross the upper threshold of frequency, it would lose conspicuousness and weaken. In such cases where it can be assimilated to other sounds, it will no doubt undergo that assimilation. But in the many instances where, by the nature of things, no assimilation is possible, the vowel will become less conspicuous by sacrificing some of its color or duration. This, I hold, is the cause of the independent vowelchange. O. E. $\bar{u}$, having become too rare, strengthened to au; Latin $o u$, having become too frequent, weakened into $\bar{u}$. Since vowels can shift by easy and imperceptible stages, changing greatly in conspicuousness by slight changes in color, intensity, or duration, it is not surprising that they are especially sensitive to any shift in frequency of use.

(47) Observing the speech of many hundreds of millions of people, we have demonstrated, in part actually, in part by induction, that the conspicuousness or intensity of any element of language is 
inversely proportionate to its frequency. Using $\mathrm{X}$ for frequency, and $\mathrm{Y}$ for conspicuousness we can express our thesis thus:

$$
\mathrm{Y}=\frac{n}{\mathrm{X}} \text { or } \mathrm{XY}=n \text {, }
$$

where $n$ is some constant, the actual size or value of which need not be our immediate concern now. Let us for the sake of clarity plot the curve of this formula, which is a hyperbola, using the $\mathrm{X}$-axis for fre-

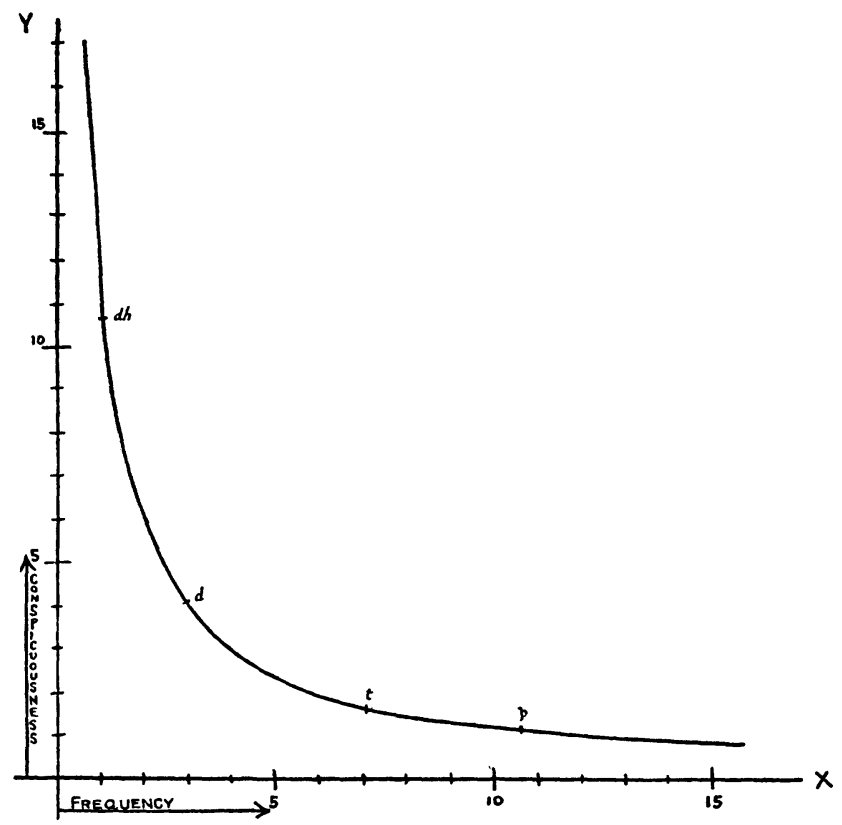

quency, the $\mathrm{Y}$-axis for conspicuousness, and taking a convenient number for $n$. Let us, further, place upon the curve some of the dentals as they approximately occur in a few of the several languages examined. Even though this curve of dentals does not actually exist in any language, the interrelationship will be interesting.

In the light of this curve the process is quite clear. As any given sound becomes more frequent, it tends to pass down the curve of the hyperbola, and vice versa; $d h$ is in conspicuousness what $b$ is in frequency. 
The number of consonants in a language is limited by the powerful Weber-Fechner Law, ${ }^{1}$ which states that actual differences in intensity must surpass a certain relative proportion before the difference is perceptible to the mind. This law prevents the number of sounds from becoming too great, and accounts for the fact that a tenuis is not only more frequent than its corresponding media, which we expected to find $a$ priori, but that the actual frequency varies but little from language to language. Hence, we may explain sound-changes, the mention of which I have reserved until now, and also gain light on the explanation offered above of the cause of the Germanic changes under Grimm's Law. For the sake of clarity I shall approach my argument by a consideration of the vowels.

A short $o$, in shifting to $\ddot{o}$ ( $i$-umlaut), becomes a sound quite distinct from a short $e$. We perceive the difference at once. But let us suppose that for some reason the new $\ddot{o}$ becomes more frequent in the language, and consequently, according to the Principle of Frequency, loses some of its conspicuousness. If this waning of conspicuousness continues, there will at last come a time when the difference between $\ddot{o}$ and $e$ (or some other vowel), though still physically actual and phonetically recordable, will cease to be perceptible. The $\ddot{o}$ and $e$ will still differ physically, yet to both hearer and speaker this difference will be subliminal. It is not surprising, then, that the coming generation, perceiving no difference, and having little concern for etymology, will make no difference in pronunciation. Hence $\ddot{o}$ and $e$ will fall together also on the recording apparatus.

The results of this collapse will be twofold. First, the $e$, which now includes the old $\ddot{o}$, will instantly become too frequent to justify a continuation of its previous intensity. Therefore, it must weaken, either by shifting to a new and less conspicuous sound (that is, we shall have independent vowel-change), or must be assimilated to neighboring sounds (that is, a dependent, environmental vowel-change). In the latter case it is possible for two or more sounds to fall together into one, only to separate (that is, Brechung) again into two or more - not to restore the original condition, but to establish a new condition. The

1 For a careful, illuminating, and complete discussion of the Weber-Fechner Law, see Edward Bradford Titchener: Experimental Psychology (New York: Macmillan, 1905) II'1, 25 ff., $\$ \S$ I3, 14 . 
sounds fell together because their differences were subliminal; the new sound "breaks" because of the excessive, new frequency. Germanic $i$ and $e$ fell together in Gothic because $e$, or $i$, or both had become so weakened by their frequency that the difference in conspicuousness was no longer perceptible. This new $i$ in turn broke back to $e$ before $r, h$, $h w$ because it was so weak in the neighborhood of these sounds as to be assimilated to them. As it happened, this assimilation resulted in $e$ (ai); as it happened, it restored some of the old $e$ 's; but only by chance, and not as a restoration. For we know that the $e$ in Gothic wair, Old English wer, was originally an $i$, as in Latin uir. After the assimilation had gone so far as to reduce the frequency of $i$ to such a point that it again corresponded to its intensity, the assimilation of the weak $i$ to surrounding sounds ceased, and the new $e$ took on a new intensity befitting its frequency. The phenomenon is so frequent in linguistics, and its explanation, in light of the present Principle of of Frequency, so patent, that it deserves at this time no further illustration.

But as with vowels, so too with consonants. Consonants may be so weakened that their differences are no longer perceptible. Then they will fall together just as the vowels. Obviously, the less conspicuous consonants undergo such changes more readily, but the more conspicuous are not excluded. For example, the dental spirant and the labial spirant, $f$ and $b$, may each become so inconspicuous that their actual difference ceases to be liminal. Hence, perceiving no difference, the speaker makes no difference, and a $b$ may become $f$, or an $f$ become $b$. To be sure, this falling together will first take place in soundcombinations which favor the assimilatory change. ${ }^{1}$ Thus a dental may become a labial, or a labial a guttural.

This explanation answers a possible objection to my exposition of the sound-changes under Grimm's Law. The reader perhaps stopped at

1 Though the influence of sound-groups on the conspicuousness of a component sound is exceedingly important, and had to be considered to some extent in my treatment of the vowels, yet a full treatment of this phase of the Principle of Frequency demands more space than is at my present disposal. However, I feel that the reader will see that the action of the consonantal or sound-group does not vitiate the Principle of Frequency; for it is clear that any weakening or strengthening necessitated by frequency will first take place in groups which especially favor the change. 
that time to pronounce $p, \chi, f, t, k$, and $p$, and was at a loss to perceive a difference in conspicuousness, forgetting that conspicuousness may also be a matter of duration. That the pro-ethnic Germanic spirants were weaker than the spirants in modern Germanic languages is proved by Germanic $p$, as is in Gothic pliugan, appearing in Old English as $f$ in fleoon; and Germanic $f$, as in German Neffe, appearing as $c h$ in Dutch nicht. These changes are explicable only in the light of the WeberFechner Law, and the Weber-Fechner Law means excessively low conspicuousness in this instance rather than excessively high. For it is almost impossible to pronounce the $b$ and $f$ in normal speech with such gigantic intensity when followed by $l$ as to make their distinction imperceptible. ${ }^{1}$

This statement holds not only for vowels and consonants, but also for liquids and nasals. From the point of view of acoustics, $r$ and $l$ must have a certain intensity before their difference is perceptible. The reader, by pronouncing weakly to another person two nonsensewords containing $r$ and $l$, can demonstrate this fact to himself. For it has always been clear to phoneticists that a certain relative intensity of articulation in speech is necessary to distinctness - a word may be pronounced neither too softly, nor too rapidly, nor too loudly, without leading to obfuscation. Changes within these thresholds are due to relative frequency.

Hence it is possible that the $r: l$ variations in Indo-European and Indo-Iranian, whether one considers them as a falling together or as

1 In reading our statistics of Old English Boethius ( $\$ 40$ ), we were obliged to assume the working of analogy to account for the weakening under such comparatively low frequency of $p$ to $f$, saying that, though it changed to a spirant, its increased duration compensated for its unwarranted loss of the increment of explosion. As shown by the Old High German of Tatian, analogy can be a factor in a sound-change. But Gothic bliugan opposed to O. E. flẽon directly proves that $f$ was so weak that, in certain combinations which favored a dental, its difference of conspicuousness either in point of duration or in position of articulation was subliminal. But from our statistics we know that $b$, which had vastly overstepped the upper threshold of $t$, was but a faint spirant, hence $f$ must also have been a faint spirant. The statistics, therefore, contradict the facts. In this case, we must say either that the Principle of Frequency is entirely wrong, which with increasing evidence in its favor is very difficult, or that the language of O. E. Boethius does not entirely reflect the language of Primitive Germanic $x, 000$ years before. The reader can take his choice. 
a "breaking" apart, may ultimately be caused by this, namely, that their differences in conspicuousness had become sublimimal, the result of excessive frequency. The current explanation that $r$ and $l$ are so similar in place and manner of articulation as to be difficult of distinction is but begging the question, since we distinguish very carefully between $l a p$ and $r a p$. Philologists must be constantly aware of what phoneticists are constantly emphasizing: a given sound has not only a given place and manner of articulation, but also a lower threshold of intensity. Though some positions of articulation will be more conspicuous than others, because of the motor aspect of phonetics (the labial position being more difficult to pronounce than the dental, and so on), and though we have constantly pointed out that conspicuousness is both phonetic and acoustic, yet we must also remember, in light of O. E. flèon, that a sufficient decrease in acoustic conspicuousness may at last make the difference in phonetic conspicuousness subliminal.

The reason that a change in conspicuousness is generally a change in manner is solely that the changes in frequency which occasion it are at a subliminal speed (that is, imperceptible at any time), and hence the changes in conspicuousness must be subliminal. Now the changes in manner of articulation can be, as they generally are, subliminal. But a sound must first be very weak before it can shift in position of articulation without that shift being perceptible.

In other words, a speaker is never conscious of the sound-changes which his words are undergoing; if he were conscious of them, he would check them, as he indeed of ten does whenever, rightly or wrongly etymologizing, he perceives that changes have taken place which make his language appear inconsistent to him. But this is only after a change has advanced already so far that he can make comparisons. Frequency demands that a change must happen; the nature of man demands that the change must happen imperceptibly. Hence, a phonetic change must take place in that component element of the conspicuousness of a sound, which, according to the Weber-Fechner Law, is capable of a subliminal change; and what element is capable of subliminal change depends upon the conspicuousness of the sound about to be altered. 
Therefore, the need of language for many different sounds, that their permutations may be of sufficient number to express the wealth of concepts in the language, is checked by the Weber-Fechner Law, which says that the time will come, in increasing the number of sounds, as arranged hyperbolically according to frequency and conspicuousness, when the sounds will differ among themselves only subliminally and fall together. It is because our sounds are not unlimited and our concepts vast, that we must also depend upon the help of accent, pitch, and order (syntax).

For this reason the hyperbolic relationship expressed in two dimensions is far from accurate, for we cannot place the labials on the graph of the dentals, since only under highly special conditions does $b$ become $d(b>p>f>b>\forall>d)$. And even by swinging the hyperbola around in space on one of its axes and trying to plot the hyperbolas of dentals, linguals, palatals, gutturals, labials, nasals, vowels, and the rest on converging planes, we do not escape the difficulty. For, wherever we put the planes, some historical sound-change will demand a different position. The cause of this is clear: conspicuousness alone is at least three-dimensional, and we still have to plot the speed of pulsation of each sound, in other words its frequency, in the stream of speech.

Even after we so qualify our formula $\mathrm{XY}=n$, there are those who, if they ever read these lines, will be astonished at the casual manner with which I designate $n$ a constant. For it will seem to them that $n$, which determines the position of the hyperbola on the graph, is a far greater and more significant function than XY. For $n$ must designate something in actuality. It is very likely the coefficient of Sprachtempo, of which we are all conscious, but which has eluded our detection because it appears in terms of a function. For, though sounds stand in this hyperbolic relationship, and though this hyperbolic relationship alone accounts for phonetic change, yet we must not forget that the Weber-Fechner Law acts logarithmically. If, instead of solving our equation for $\mathrm{Y}$ (conspicuousness), we might fill in $\mathrm{X}$ and $\mathrm{Y}$ with their actual values and solve the equation for $n$, we should undoubtedly find in $n$ a number varying infinitesimally from person to person, slightly from dialect to dialect, distinctly from culture to cul- 
ture, and vastly between the languages of primitive and civilized man. In fact, I believe that an understanding of $n$ will ultimately lead to an understanding of that stuff called Life. Unfortunately, life is observable only in its expression; hence the great responsibility of philologists, who are working in that one field of expression which will perhaps lend itself to measurement more readily than any other. 